\title{
ECONOMETRIC MODELLING OF
}

HETEROGENEITY AND STRUCTURAL CHANGES IN DUTCH HORTICULTURE

Evert Jan Los

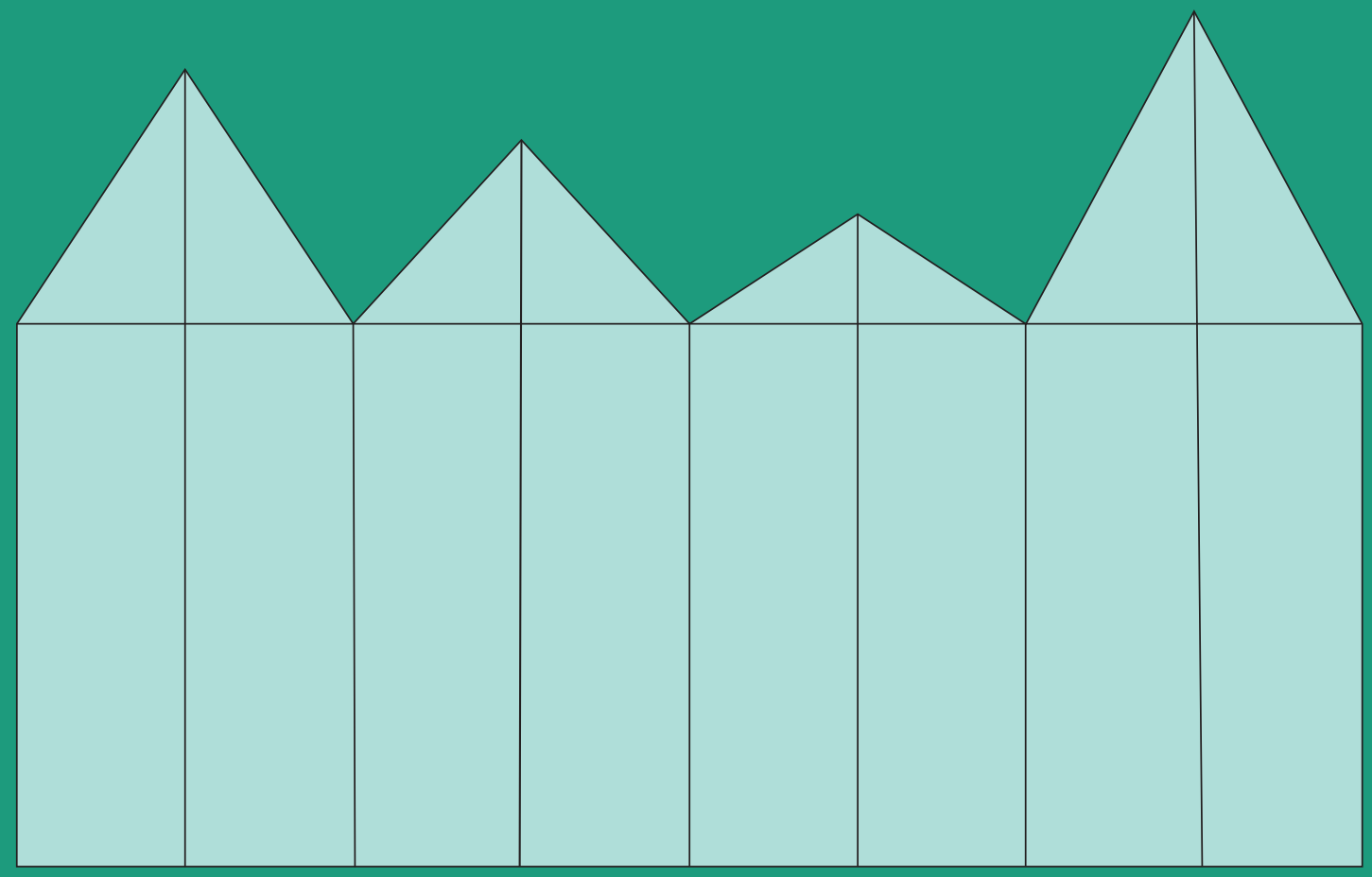





\section{Propositions}

1. Economies of scale in Dutch glasshouse horticulture do not reside in lower average production costs, but rather in more stable and better output prices. (this thesis)

2. Non-linearities are an often neglected, but important aspect in assessing the relation between a firm's debt structure and their efficiency.

(this thesis)

3. The lack of harmonisation in citation styles shows that vested interests are more important in shaping the scientific domain than striving for efficiency.

4. The focus on individual performance in scientific institutes threatens knowledge sharing.

5. Since most personality traits are normally distributed within a population, personality tests to divide respondents into personality types based on dichotomies should not be used by scientific institutes.

6. Social media should rather be called self-media given its emphasis on "the self" for starting any form of communication.

7. The increased focus on the malleability of life is primarily a negation of its main characteristic: her fragility.

Propositions belonging to the thesis, entitled:

Econometric modelling of heterogeneity and structural changes in Dutch horticulture

Evert Jan Los

Wageningen, 10 March 2021 
Econometric modelling of heterogeneity and structural changes in Dutch horticulture

Evert Jan Los 


\section{Thesis committee}

\section{Promotors}

Dr C. Gardebroek

Associate professor, Agricultural Economics and Rural Policy Group Wageningen University and Research

Prof. Dr R.B.M. Huirne

Special Professor Cooperative Entrepreneurship

Wageningen University and Research

\section{Other members}

Prof. Dr M.P.M. Meuwissen, Wageningen University and Research

Prof. Dr O. van Kooten, Inholland University of Applied Sciences, Delft

Prof. Dr R. Finger, ETH Zürich, Switzerland

Dr J. Bremmer, Wageningen University and Research

This research was conducted under the auspices of the Wageningen School of Social Science (WASS). 


\title{
Econometric modelling of heterogeneity and structural changes in Dutch horticulture
}

\author{
Evert Jan Los
}

\section{Thesis}

submitted in fulfilment of the requirements for the degree of doctor at Wageningen University

by the authority of the Rector Magnificus,

Prof. Dr A.P.J. Mol,

in the presence of the

Thesis Committee appointed by the Academic Board

to be defended in public

on Wednesday 10 March 2021

at 4 p.m. in the Aula 
Evert Jan Los

Econometric modelling of heterogeneity and structural changes in Dutch horticulture 152 pages.

PhD thesis, Wageningen University, Wageningen, the Netherlands (2021)

With references, with summary in English

ISBN: 978-94-6395-603-1

DOI: https://doi.org/10.18174/533881 
Veur mien va en moe, waar dan ook 


\section{TABLE OF CONTENTS}

1. INTRODUCTION 11

$\begin{array}{llr}1.1 & \text { BACKGROUND } & 12\end{array}$

1.1.1 MODERN AGRICULTURAL MARKETS

1.1.2 DUTCH HORTICULTURE AND MODERN AGRICULTURAL MARKETS 13

$\begin{array}{lll}1.2 & \text { PROBLEM STATEMENT } & 15\end{array}$

$\begin{array}{lll}1.3 & \text { OBJECTIVES OF THE THESIS } & 18\end{array}$

$\begin{array}{lll}1.4 & \text { METHODOLOGICAL APPROACH } & 18\end{array}$

$\begin{array}{ll}1.5 & \text { OUTLINE OF THE THESIS }\end{array}$

2. DATA AND STUDY AREA

2.1 DATA IN AGRICULTURAL PRODUCTION RESEARCH

$\begin{array}{lll}2.2 & \text { DATA AND THE STUDY AREA } & 23\end{array}$

$\begin{array}{lll}2.3 & \text { CONCLUSION } & 27\end{array}$

3. EXPLAINING RECENT FIRM GROWTH IN DUTCH HORTICULTURE 29

$\begin{array}{lll}3.1 & \text { INTRODUCTION } & 31\end{array}$

3.2 FIRM SIZE GROWTH IN DUTCH HORTICULTURE 31

3.3 THE EFFECT OF FIRM SIZE ON COST STRUCTURE 32

3.4 THE EFFECT OF FIRM SIZE ON OUTPUT PRICES 33

3.5 A SYNTHESIS: OPERATIONAL COSTS, PRODUCT REVENUE AND FIRM SIZE 35

3.6 CONCLUSION 36

4. EXPLAINING OUTPUT PRICE HETEROgENEITY IN DUTCH HORTICULTURE 37

$\begin{array}{lll}4.1 & \text { INTRODUCTION } & 39\end{array}$

$\begin{array}{lll}4.2 & \text { THEORETICAL BACKGROUND } & 40\end{array}$

4.2.1 PRODUCT HETEROGENEITY AND QUALITY ASPECTS 41

4.2.2 FIRM HETEROGENEITY AND SCALE EFFECTS 41

4.2.3 CONTEXT HETEROGENEITY: UNEVEN COMPETITION IN TIME AND SPACE 42

4.3 PRICE DISPERSION IN THE DUTCH HORTICULTURAL SECTOR 43

4.3.1 DEVELOPMENTS IN DUTCH HORTICULTURE 43

4.3.2 DATA SOURCE $\quad 43$

4.3.3 DESCRIPTIVE STATISTICS $\quad 44$

4.4 EMPIRICAL APPROACH 46

4.4.1 INDIVIDUAL OUTPUT PRICES OVER TIME: A MARKOV TRANSITION 46 ANALYSIS

4.4.2 MODELLING AND ESTIMATING PRICE HETEROGENEITY 48

4.4.3 HYBRID PANEL APPROACH 49

$\begin{array}{lll}4.5 & \text { RESULTS } & 51\end{array}$

4.5.1 RESULTS OF THE MARKOV TRANSITION ANALYSIS 51

4.5.2 RESULTS OF THE HYBRID PANEL APPROACH 53

$\begin{array}{lll}4.6 & \text { CONCLUSION AND DISCUSSION } & 57\end{array}$

5. FIRM-SPECIFIC RESPONSES TO ENERGY POLICIES IN DUTCH HORTICULTURE 61

$\begin{array}{lll}5.1 & \text { INTRODUCTION } & 63\end{array}$

5.2 ENERGY USAGE AND POLICY INTERVENTIONS IN DUTCH HORTICULTURE 65

5.2.1 ENERGY USAGE IN DUTCH HORTICULTURE 65 
5.2.2 CLIMATE-RELATED POLICY INTERVENTIONS IN DUTCH HORTICULTURE 65

$\begin{array}{lll}5.3 & \text { MODEL SPECIFICATION } & 66\end{array}$

$\begin{array}{lll}5.4 & \text { DATA AND DESCRIPTIVE STATISTICS } & 68\end{array}$

$\begin{array}{lll}5.5 & \text { EMPIRICAL PROCEDURE } & 70\end{array}$

5.5.1 SYSTEM ESTIMATION OF DEMAND EQUATIONS $\quad 70$

5.5.2 APPROACHES FOR ESTIMATING HETEROGENEOUS COEFFICIENTS $\quad 71$

5.5.3 BAYESIAN HIERARCHICAL RANDOM COEFFICIENT ESTIMATION 71

5.5.4 DEFINING PRIOR INFORMATION AND ESTIMATION PROCEDURE $\quad 72$

$\begin{array}{ll}\text { 5.5.5 EFFECTS ON ENERGY USAGE AND EXPENSES } & 74\end{array}$

$\begin{array}{lll}5.6 & \text { RESULTS } & 74\end{array}$

5.6.1 ESTIMATION RESULTS: COMPARISON OF MODEL SPECIFICATIONS AND 74 PRIOR VALUES

5.6.2 ESTIMATION RESULTS: POSTERIOR COEFFICIENT DISTRIBUTIONS 75

5.6.3 EFFECTS OF GAS PRICE INCREASES ON ENERGY USAGE AND EXPENSES 78

$\begin{array}{lll}5.7 & \text { CONCLUSIONS } & 80\end{array}$

6. IMPACT OF CREDIT CONSTRAINTS ON INVESTMENTS IN DUTCH HORTICULTURE 83

$\begin{array}{lll}6.1 & \text { INTRODUCTION } & 85\end{array}$

6.2 MOdELLING INVESTMENT DECISIONS 86

$\begin{array}{lll}6.3 & \text { DATA } & 91\end{array}$

$\begin{array}{lll}6.4 & \text { RESULTS } & 94\end{array}$

$\begin{array}{lll}6.5 & \text { CONCLUSION AND DISCUSSION } & 97\end{array}$

7. DEBT AND PRODUCTION EFFICIENCY IN CAPITAL INTENSIVE SECTORS: 101

AN APPLICATION TO DUTCH HORTICULTURE

$\begin{array}{lll}7.1 & \text { INTRODUCTION } & 103\end{array}$

$\begin{array}{lll}7.2 & \text { FINANCE, FARM PERFORMANCE AND EFFICIENCY } & 104\end{array}$

$\begin{array}{lll}7.3 & \text { FARM DEBT IN DUTCH HORTICULTURE } & 108\end{array}$

$\begin{array}{llr}7.4 & \text { METHODOLOGY } & 109\end{array}$

$\begin{array}{lll}7.5 & \text { DATA AND DESCRIPTIVE STATISTICS } & 111\end{array}$

$\begin{array}{lll}7.6 & \text { EMPIRICAL RESULTS } & 114\end{array}$

7.6.1 FIRST STAGE RESULTS: DEA EFFICIENCY SCORES 114

7.6.2 SECOND STAGE RESULTS: EFFICIENCY AND DEBT 116

$\begin{array}{lll}7.7 & \text { CONCLUSION } & 118\end{array}$

8. SYNTHESIS 121

$\begin{array}{lll}8.1 & \text { INTRODUCTION } & 122\end{array}$

$\begin{array}{lll}8.2 & \text { SYNTHESIS OF THE MAIN RESULTS } & 123\end{array}$

$\begin{array}{lll}8.3 & \text { POLICY IMPLICATIONS } & 127\end{array}$

8.4 MODERN AGRICULTURAL MARKETS AND MODERN DATA: NEW INSIGHTS 128 FROM DUTCH HORTICULTURE

8.5 CRITICAL REFLECTION AND SUGGESTIONS FOR FURTHER RESEARCH
130

$\begin{array}{lr}\text { REFERENCES } & 134\end{array}$

$\begin{array}{lr}\text { SUMMARY } & 146\end{array}$

$\begin{array}{lr}\text { BIOGRAPHY } & 148\end{array}$

$\begin{array}{lr}\text { ACKNOWLEDGEMENTS } & 149\end{array}$

$\begin{array}{ll}\text { TRAINING AND SUPERVISION PLAN } & 151\end{array}$ 



\section{Chapter 1}

\section{Introduction}




\subsection{Background}

\subsubsection{Modern agricultural markets}

For long, markets for agricultural products have been seen as prime examples of competitive markets (Bonanno et al., 2018a). This is largely based on the idea that all sellers and buyers in agricultural markets are price-takers, and are therefore unable to influence pricing (Sexton, 2013). Moreover, it is often assumed that agricultural products are homogeneous, supplied by anonymous and homogeneous firms (Levi et al., 2020). The modern reality of agricultural production however strongly contrasts this idea of homogeneous, competitive markets (Sexton, 2013; Bonanno et al., 2018a). Various studies therefore point at inconsistencies with these assumptions in the food supply chain, such as market power and concentration among retailers (e.g. Assefa et al., 2017; Saitone and Sexton, 2017). Sexton (2013) and Myers et al. (2010) in particular mention concentration in the food industry, a larger focus on product quality as well as increased usage of vertical coordination mechanisms as key trends in modern agricultural markets.

Underlying most of these transitions is the diminishing scarcity of food in Western societies combined with a higher purchasing power of most consumers (e.g. Koning et al., 2008; Hertel, 2011). The differentiated demand from consumers, but also the stronger pressure from society and policy-makers (such as the increased environmental regulations for agriculture production) have led to a shift in focus from production capacity to quality aspects and the external effects of production (Schneider et al., 2014). As a result of these shifts in underlying production constraints, agricultural producers constantly have to adapt (Herzfeld and Jongeneel, 2012). In modern agricultural markets, however, primary producers are not only subject to a changing environment, they also have the ability to adapt themselves, by e.g. specifically focusing on the quality of the product, or by applying more environmental-friendly production methods. Consequently, firms are able to apply different strategies, which increases heterogeneity among firms (Martinez-Cillero et al., 2019). Hence, also agricultural economists studying agri-food markets need to provide new tools and methods in order to study these changing markets (see e.g. Bonanno et al., 2018a) and trade in assumptions on homogenous products, prices and responses by allowing for more heterogeneity in studying the agricultural production and marketing process (Koutchade et al., 2018).

In addition, the Industrial Organization literature has increasingly paid attention to the embeddedness of primary producers in food supply chains (Sheldon, 2019; Barkley, 2019). The farm is therefore no longer seen as a separate, homogeneous entity operating on an anonymous market, but rather as an increasingly complex system, embedded in changing institutional environments and highly volatile markets. As a result of these developments, the farm itself also becomes more complex. This is reflected, among other things, in the growing number of farms operating under shared 
ownership, with separate management layers. Vice versa, a single farmer can also operate a farm in multiple locations. Such complex farm structures, with a broadening of commercial activities, are particularly found in the pig and poultry industry as well as in horticulture (Poppe and Vrolijk, 2019). The next section discusses the Dutch horticultural sector as example par excellence of a modern agricultural sector.

\subsubsection{Dutch horticulture and modern agricultural markets}

Glasshouse horticulture differs from other agricultural sectors in the Netherlands since the production of potted plants, flowers, fruits and vegetables takes place in (mostly heated) glasshouses. Moreover, these products are often grown in protected and soilless systems, using substrate such as rockwool in order to grow plants (Incrocci et al., 2006). Within the Netherlands, horticulture has been an economically important sector for decades, particularly in the southwest of the country (Berkers and Geels, 2011), although new horticultural clusters have emerged throughout the country (CLO, 2019). The latter contribute to the further development and expansion of glasshouse horticulture. Where the total production area of a number of crops has decreased over the years, the production of vegetable crops such as tomatoes, peppers and cucumbers is a stable factor in Dutch horticulture. For example, the total area of glasshouse vegetables has grown from 4200 hectares in 2000 to 5000 hectares in 2019 (Jukema, 2019). Despite the fact that the cultivation area in hectares is still rather small, the intensive production does contribute a clear share of the total Dutch economic production value and employment. For example, glasshouse horticulture employs more than 125000 workers at peak times in production, and the sector has a share of over $1 \%$ in both total Dutch added value and total Dutch employment (Jukema, 2019).

The sector is strongly oriented on exporting its products, which means operating in a very competitive environment without major support payments from the Common Agricultural Policy (CAP). More than $80 \%$ of the added value of the greenhouse horticulture complex is related to such exports (Wageningen Economic Research, 2019a). In addition, the sector makes intensive use of energy as the production of vegetables takes place in mostly heated glasshouses. As a result, nearly $9 \%$ of the total domestic usage of natural gas in the Netherlands is used by the glasshouse horticultural sector. Moreover, it accounts for $4.5 \%$ of the total $\mathrm{CO}_{2}$ emissions (Verreth et al., 2015). Since production takes place in an environment with mostly affluent consumers, it is not surprising that there is a strong demand for differentiated specialty products as well as environmental-friendly products (Erjavec and Lovec, 2017; Kirova et al., 2019). As a result, the constraints in which production takes place are subject to constant change (Herzfeld and Jongeneel, 2012). The most important developments are summarized below in order to point out why one can regard Dutch greenhouse horticulture firms as operating in a modern agricultural market. 


\section{Product differentiation}

The emergence of specialized products for niche markets such as cherry tomatoes, snack cucumbers and sweet pointed peppers ensures that, in addition to the classic orientation towards volume in production, there is also room for new and more differentiated products. This is particularly the case in tomato production, due to the active role of the breeding sector in developing new varieties (Dehnen-Schmutz et al., 2010). This has contributed to the heterogeneity of these products.

\section{Firm heterogeneity}

Despite the clear trend towards scale enlargement, traditional family farms are still central in Dutch glasshouse horticulture. However, they coexist with farms with distinct organizational structures (Poppe and Vrolijk, 2019) and more complex relations with retail partners. Some of the larger firms are able to ensure year-round delivery of fresh products to retail partners due to production at different locations (also in Southern Europe and Northern Africa). Furthermore, an increasing number of firms uses artificial growing light in order to deliver products off-season (Nichols, 2017). Such developments also result in more contractual relationships with retail partners in favour of simple coordination mechanisms such as spot markets (Crespi et al., 2012; Bonnano, 2018). These differences in firm strategy and structure also contribute to firm heterogeneity. This may also lead to heterogeneous responses to changes in policies or market conditions.

\section{Societal pressure and production methods}

Agricultural firms are facing strong societal pressure to take the environmental effects of production into account (Pons et al., 2013; Nishitana et al., 2014). This is particularly the case as new climate policies stress that urgent actions are required in order to reduce global warming (Falkner, 2016). Reducing greenhouse gas emissions in the coming decades is a main policy concern (Cuchiella et al., 2018) that will particularly affect horticultural production given its high energy intensity. Note that in the context of Dutch horticulture the societal pressure not only has its effect on energy usage, but also applies to the usage of external labour, as particularly the working and living conditions of migrant workers are a societal concern (Brinkmeier, 2011). Both these developments result in stronger pressure from society on the production process of horticultural firms.

\section{Primary production and (vertical) integration}

In order to finance further expansions, the dependence of horticultural firms on external credit is very high. This is particularly the case given the capital intensity of the sector, with e.g. the use of high-quality climate systems in order to control crop 
growth (Van der Meulen et al., 2007). Combined with some of the developments described above, such as contact with retail partners and the relation with breeding companies, these developments underline the interdependence among different partners in the supply chain.

\subsection{Problem statement}

The previous section discussed recent developments in Dutch horticulture and showed that Dutch horticultural firms operate in markets that can hardly be classified as perfectly competitive markets. Most notably this is the case given the lack of homogeneity in both products delivered as well as in firm structures. The latter also suggests that primary producers are likely to respond differently to price signals and changes in institutional environments (Finger and El Benni, 2020; Reidsma et al., 2010). Although a variety of studies pay attention to these developments, most empirical research in agricultural economics still assumes that firms respond homogeneously to external changes, as these effects are most often modelled as fixed slope coefficients, which are common to all firms (Koutchade et al., 2018). The main goal of this thesis is therefore to study these firm-specific developments, both in the ability of firms to differ in their market positioning as well as in how they respond to changes in the institutional and financial environment.

The research design is explained in figure 1.1, which provides an overview of the impact of changes in the outside environment on decisions and outcomes at firmlevel. It should be noted though that this figure does not aim to provide an exhaustive overview of all relationships among primary producers and other parties. Given the focus of this thesis, the three environments that are most relevant for the primary producer, namely the financial, institutional and market environment, are depicted. The lines between these external environments and the internal firm structure refer to the specific research objectives (RO) of this thesis, which are more clearly defined in section 1.3.

Most studies in agricultural production emphasize the weak position of primary producers in the relationship with their external environment. For example, it is often noted that the bargaining power of primary producers in relation to suppliers and buyers is very weak (Assefa et al., 2017). However, limited attention is paid to potential differences between primary producers. Figure 1.1 should therefore not only be seen as a force field in which the external environment only exerts its pressure on the primary producer, but also as an arena in which firm heterogeneity is central. This can either relate to heterogeneity in outcomes (for example by looking at structural differences in obtained output prices between firms), heterogeneity in responses (with regard to changing policies) as well as the heterogeneity in various conditions (e.g. by considering firm-specific conditions in order to obtain external credit). 


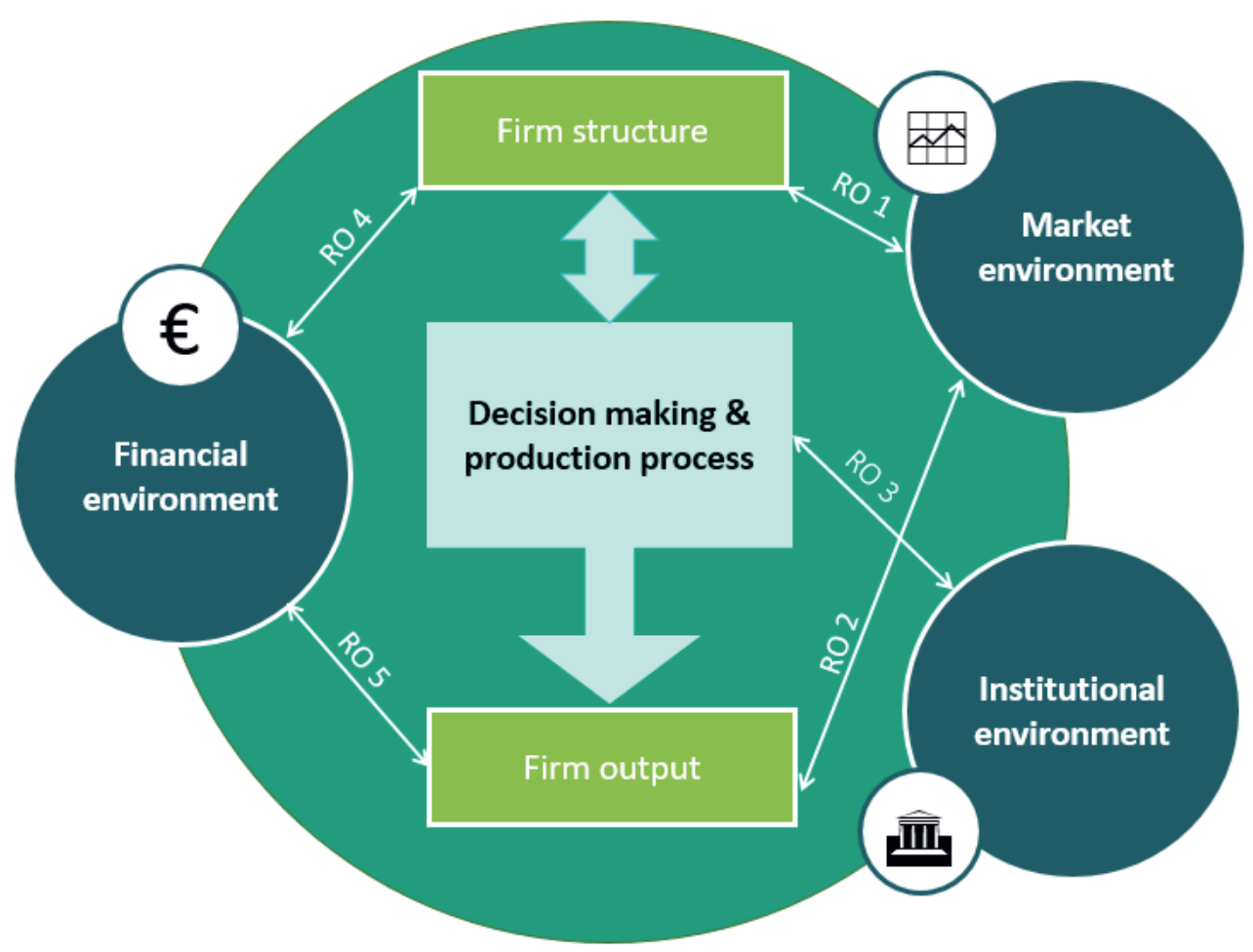

Figure 1.1: Approach for studying the relation between external environments and the internal firm environment in Dutch horticulture.

Starting with the linkage between the market environment and firm structure (RO1), it is important to emphasize that many horticultural firms have grown considerably in size in recent decades. Traditionally, firm growth is explained by assuming that firms want to benefit from economies of scale, given that the larger size of production lowers the fixed production costs (e.g. Kimura and Le Thi, 2013). It is however unclear whether the same dynamics also hold true for the recent growth of horticultural firms, as empirical studies in Dutch agriculture show that cost reductions due to scale economies often decline when firms grow even further. The largest average cost reductions are often found between small and medium-sized firms rather than between medium- and large-sized firms (Van der Meulen et al., 2011). Given the further integration of primary producers and other partners in the food chain, such as retailers, a possible explanation for these changes in firm structure might also be found in the advantages of large-scale production on the revenue side.

When considering the impact of the market environment on firm output ( $R O 2$ ), it should be noted that primary producers communicate with retail partners and input suppliers in the form of input and output prices. A wide variety of empirical research shows that primary producers are subject to price volatility in both input and output 
markets (e.g. Kirali and Power, 2013). Very few empirical studies however pay attention to the extent to which primary producers can deviate from these price developments and differentiate themselves in markets and obtain higher output prices. Doing so, allows for examining potential heterogeneity in market positioning and hence in firm-specific outcomes.

The heterogeneity in the relation between the institutional environment and the production process of producers (RO3) rather lies in the individual responses of firms to policy changes. In this light, the position of Dutch horticulture sector as a main consumer of energy forms an important aspect (Verreth et al., 2015). Given this position, stricter climate and energy policies will irrevocably affect the production structure of glasshouse horticulture. The policy proposals to raise taxes on nonrenewable energy sources (e.g. Dutch Climate Agreement, 2019), aim to impact relative energy input prices as there are particular incentives to reduce the usage of natural gas. This in turn is likely to lead to heterogeneous responses in energy input usage at firm-level, given the large differences in firm structure and production methods between firms.

With respect to the relation between the primary producer and the financial environment, the examined heterogeneity rather resides in the conditions needed for obtaining credits (RO4). This is in particular relevant given recent and forthcoming developments in the financial world (such as the Basel III and Basel IV agreements) which put additional emphasis on the liquidity and financial structure of the firm (e.g. Amorello, 2016). In contrast to traditional financing literature, which for long assumed unlimited access to capital (e.g. Modigliani and Miller, 1958), this causes firm-specific capital structures to become more important. This impacts the decision to invest or not and hence causes further heterogeneity in firm structure. Moreover, the resulting capital structure is also expected to affect firm-specific outcomes, in terms of firm efficiency and actual performance (RO5), as these are known to be affected by differences in capital structures (e.g. Gadanakis et al., 2019).

Summarizing the above, the diverseness of a modern agricultural market is not only expected in the heterogeneity in outcomes (e.g. differences in obtained output prices between firms), but also in heterogeneous responses (with regard to changing policies) as well as in heterogeneity in conditions and requirements (e.g. by considering firm-specific constraints in order to obtain external credit). Although developments in different external environments are likely to affect choices made by primary producers, it is questionable whether producers are subject to changes in conditions in the same manner, given the large heterogeneity in both production strategy and firm structure (Reidsma et al., 2010; Finger and El Benni, 2020). 


\subsection{Objectives of the thesis}

Resulting from the developments described above, the overall objective of this thesis is to analyse heterogeneous and firm-specific behaviour of Dutch horticultural firms operating in changing market, institutional and financial environments. This thesis does so by addressing the following sub-objectives:

i. Describe heterogeneity in firm structure by analysing underlying drivers of firmgrowth

ii. Analyse heterogeneity in market positioning between firms via differences in output prices

iii. Examine heterogeneous firm responses due to changes in relative energy prices as a result of changes in institutional framework conditions

iv. Examine the impact of firm-specific credit conditions for understanding investment behaviour

v. Evaluate the impact of differences in capital structure on firm performance

As also shown graphically in figure 1.1 , the first two sub-objectives specifically target the interaction between the primary producer and the market environment. The third sub-objective, on the other hand, looks at the relationship between the production process of the primary producer and changes in the institutional environment. The last two sub-objectives specifically focus on the interaction between the financial environment and the primary producer, addressing investment behaviour (research objective 4 on differences in firm structure) and firm performance (research objective 5 on differences in firm output). All these five sub-objectives are addressed in the main body of the thesis in separate chapters.

\subsection{Methodological approach}

In order to achieve the objectives mentioned in section 1.3, microeconomic theories on firm behaviour are used as theoretical background for understanding the decision making process at firm level. Building upon these theories, various micro-econometric techniques are applied which allow for modelling heterogeneity in units and their behaviour.

For meeting the first objective of the thesis, the production of primary producers is analysed by studying both their cost structure, as well as the differences in firm revenues. This is done for firms of different size groups. Based on a descriptive analysis of cost shares between firms, a Tukey Honest Significant Difference (HSD) test is applied in order to analyse structural differences between the identified groups.

The second objective is analysed by constructing a heterogeneous price equation. Where traditional micro-economic theory assumes that producers are pricetakers, recent price data in Dutch horticulture in contrast reveals large differences in 
the obtained output prices between producers. A Markov transition analysis is applied in order to study the structural character of this price distribution over time. Moreover, a hybrid panel model is estimated for examining the impact of firm-specific characteristics on the price distribution. In contrast to conventional Fixed Effects (FE) panel models, a hybrid model allows for the inclusion of firm-specific factors that remain relatively stable over time (Schunck, 2013), such as firm size and organizational structure.

In order to meet the third research objective, it is first assumed that producers aim to minimize their production costs in the short-run. This assumption corresponds to the context of Dutch horticulture, given that production capacity is largely determined by the total acreage of glasshouses, which cannot be adjusted easily in the short-run. Using a normalized quadratic cost function, a system of demand equations for the main energy inputs, namely (natural) gas and electricity, is obtained. Consequently, relative input prices are considered for analysing the impact of relative price changes as a result of a proposed taxation on natural gas (Climate Agreement, 2019). Where the impact of more restrictive climate polices is mostly estimated at aggregated level (e.g. Baker et al., 2010; Babcock, 2015) the usage of a Bayesian random coefficient model allows for estimating firm specific price parameters in the system of energy demand equations. As a result, heterogeneity in responses to these relative price changes can be taken into account. As earlier described, conventional models in agricultural production assume homogeneous responses based on fixed slope parameters (Koutchade et al., 2018) and hence are unable to cope with firmspecific responses. These firm-specific responses however might be very relevant given the differences in e.g. energy systems, energy contracts and production strategies between firms. Applying a random coefficient model allows for capturing this heterogeneity in firm responses in order to meet the third research objective.

The impact of firm-specific credit conditions on investment decisions is studied by expanding a theoretical dynamic model of investment with firm-specific financial variables. The most frequently used procedure to evaluate the profitability of an investment is by using the Net Present Value method (NPV), where investments are considered as economically feasible if the annual net cash flow exceeds both the principal and interest payments (Magni, 2009). Since traditional financing literature for long assumed unlimited access to capital (e.g. Modigliani and Miller, 1958), the role of firm-specific credit constraints in investment decisions and NPV calculation is often neglected (Henning and Jordaan, 2016). This however becomes problematic in the context of Dutch agriculture, as firms are often dependent on external credit in order to finance their investments, given the high capital intensity of the sector (Skevas et al., 2018a). Since banks and other credit suppliers often put additional emphasis on the financial structure of the firm, the NPV of an investment is likely to depend on firm-specific financing costs. In order to address this heterogeneity, a 
theoretical dynamic model of investment is expanded with firm-specific financial variables. Estimating this intertemporal condition via a panel Tobit-model allows for examining the relation between primary producers and their financial environment (in particular credit suppliers), which is important given the larger focus on firm-specific elements as cashflows for obtaining credits.

The fifth objective requires the analysis of firm efficiency. This is done in a nonparametric manner via Data Envelopment Analysis (DEA), which allows for including firm-specific factors in the second stage of the analysis. Consequently, this enables to examine the impact of differences in capital structures and debt position on firm efficiency (see e.g. Davidova and Latruffe, 2007; Gadanakis et al., 2019). Further elaborating on the previous research objective, examining the relation between debt and efficiency is particularly relevant in the context of capital intensive sectors such as Dutch horticulture given the high financial risks involved.

\subsection{Outline of the thesis}

The remainder of the thesis is organized as follows. All the research objectives stated in section 1.3 are addressed in one of the chapters of this thesis (chapters 3 to 7 ). These main chapters are preceded by an additional introductory chapter. Chapter 2 pays attention to the specific study area and the data used in the subsequent chapters. Furthermore, it provides a discussion on the use of alternative data sources compared to classical farm survey data as for example collected in farm accountancy data networks. Following the main body of the thesis, chapter 8 provides overall conclusions on the main findings and discusses policy and research implications that go beyond the findings discussed in the individual chapters. 


\section{Chapter 2}

\section{Data and the study area}




\subsection{Data in agricultural production research}

For assessing impacts and responses at firm-level, production and input data from individual firms is required. The majority of empirical studies in agricultural production studies research relies on surveyed firm-level data, such as Farm Accountancy Data Network (FADN) data (Roesch and Lips, 2013). A large drawback of collecting data in this manner relates to the large amounts of financial and human resources needed in order to maintain the data, as well as the problem of non-response (Ge et al., 2018). Hence, there is a considerable risk that a large share of firms are left out of the analysis. Via various weighing procedures applied to the collected data, the overall data might be representative and adequate for showing trends at sectoral-level, yet it complicates showing the underlying variability within agricultural subsectors. Vrolijk and Poppe (2016) argue that this is in particular worrisome in the case of agricultural sectors with a large dispersion in firm size. Hence, indicators such as averages become more difficult to interpret (Lund and Price, 1998).

In particular in studying heterogeneity within a sector, it is therefore indispensable to exploit firm-level data with sufficient observations for individual firms. Consequently, the usage of classical survey data is problematic. This holds especially in the case of horticultural sectors with large differences between firms, e.g. in the actual crops grown as well as in organizational structure of a firm (e.g. Poppe and Vrolijk, 2019). Hence, using surveyed data sources such as the FADN has its limitations, given that they e.g. only capture 23 bell pepper, 23 cucumber and 27 tomato firms in 2015 in the Netherlands (Ge et al., 2018). Depending on the specific crop, this is between $13 \%$ and $16 \%$ of the total number of firms. The low percentage itself is not necessarily problematic, yet the low absolute number of firm observations per crop strongly complicates the use of econometric techniques, which require sufficient firm-level observations.

In order to overcome these problems, the empirical analysis in this thesis relies on firm-level data derived from the Analysis Tool Rabobank (ATR). Rabobank, as the largest credit supplier in the agricultural sector in the Netherlands (Groeneveld, 2016), holds track of the accountancy data of a large number of firms in the sector. As an example, ATR contains 92 of the 190 active vine tomato producers in 2010, 83 of 276 cucumber firms and 140 of 322 bell pepper firms. This ensures both a large number of absolute observations, as well as a high percentage of the total number of firms, with - depending on the specific product - between 30 and $50 \%$ of the total number of producers included. A potential drawback is that the available data is not stratified or weighed such as the FADN data, causing potential risks in terms of generalizability. However, the large number of firms and the high percentage covered per crop allow for a better examination of firm-specific responses and outcomes and moreover ensure that overall sectoral trends are captured by the data. Hence, the next section provides a further background of the origin of the data used and the study area. 


\subsection{Data and the study area}

The empirical analyses in this thesis focus on vegetables grown in glasshouse horticultural firms in the Netherlands, with particular attention for the three main crops: cucumber, bell pepper and (vine) tomato. Table 2.1 shows the total number of firms and total production area for the Netherlands, based on numbers of Statistics Netherlands (2020). Furthermore, it provides the number of firms and total production area covered by the ATR-database, and the percentage of the production area and the number of firms covered. For all products, the total number of firms decreases over the years, particularly for bell pepper and cucumber producers. With respect to the total production area in hectares, there is a considerable growth in vine tomato production, whereas the production of bell pepper and cucumber declines from 2010 onwards. During this period some of the latter firms also switched to the production of vine tomatoes (Kas Magazine, 2017).

Depending on the specific product, the area covered by the ATR-database is roughly between $45 \%$ (cucumbers) and $70 \%$ (vine tomatoes) of the total production area of those specific products. The percentage of firms covered by the database is somewhat lower, indicating that the average firm size in the ATR-database is higher compared to the overall average firm size. This can largely be explained as smaller (and most often less modernized) firms are not included in the dataset given their lower dependence on external credit. Furthermore, note that for 2015, the actual number of observations (and hence the production area covered) is lower given the unavailability of data at the start of the research.

Table 2.1: Comparison of production area and number of firms between ATR-dataset and total production (based on Statistics Netherlands) during the study period (2008-2015).

\begin{tabular}{llllllllll}
\hline \multirow{5}{*}{ StN } & Bell pepper & $\mathbf{2 0 0 8}$ & $\mathbf{2 0 0 9}$ & $\mathbf{2 0 1 0}$ & $\mathbf{2 0 1 1}$ & $\mathbf{2 0 1 2}$ & $\mathbf{2 0 1 3}$ & $\mathbf{2 0 1 4}$ & $\mathbf{2 0 1 5}$ \\
& Area (ha) & 1184 & 1331 & 1402 & 1357 & 1313 & 1243 & 1162 & 1163 \\
& No. of firms & 373 & 348 & 324 & 300 & 288 & 266 & 248 & 246 \\
& Area (ha) & 732 & 841 & 979 & 906 & 845 & 823 & 794 & 515 \\
& No. of firms & 134 & 140 & 140 & 125 & 118 & 112 & 97 & 58 \\
& \%-area & 61.90 & 63.19 & 69.89 & 66.82 & 64.41 & 66.21 & 68.38 & 44.36 \\
& \%-firms & 35.92 & 40.22 & 43.21 & 41.67 & 40.97 & 42.10 & 39.11 & 23.57 \\
& Vine tomato & & & & & & & & \\
StN & Area (ha) & 1077 & 1046 & 1148 & 1171 & 1191 & 1256 & 1259 & 1259 \\
& No. of firms & 223 & 200 & 190 & 207 & 201 & 208 & 191 & 190 \\
ATR & Area (ha) & 604 & 734 & 883 & 864 & 861 & 884 & 825 & 518 \\
& No. of firms & 75 & 82 & 92 & 90 & 89 & 90 & 71 & 42 \\
& \%-area & 56.14 & 70.18 & 76.96 & 73.81 & 72.36 & 70.42 & 65.56 & 41.15 \\
& \%-firms & 33.63 & 41.00 & 48.42 & 43.47 & 44.27 & 43.26 & 37.17 & 22.10 \\
& Cucumber & & & & & & & & 544 \\
StN & Area (ha) & 621 & 625 & 663 & 655 & 621 & 615 & 597 & 544 \\
& No. of firms & 310 & 292 & 279 & 274 & 253 & 246 & 234 & 221 \\
& Area (ha) & 292 & 307 & 317 & 297 & 289 & 273 & 232 & 118 \\
& No. of firms & 84 & 87 & 84 & 76 & 71 & 65 & 47 & 24 \\
& \%-area & 46.95 & 49.08 & 47.77 & 45.38 & 46.56 & 44.41 & 38.85 & 21.75 \\
& \%-firms & 27.09 & 29.79 & 29.74 & 27.73 & 28.06 & 26.42 & 20.08 & 10.85 \\
\hline
\end{tabular}

Source: Statistics Netherlands (2020a) and Rabobank (2016). 
It is important to note that almost all these firms are specialized producers, meaning they most often only grow one specific product. Figure 2.1 first shows the development in product revenue per square meter for the three studied products during the studied period. Depending on the specific production system, most cucumber producers are able to grow around 170 to 200 cucumbers per square meter per year, with producer output prices around $€ 0.25$ per piece. This results in average product revenues around $€ 45$ per square meter. As also shown in tables 2.2-2.4, this fluctuation in revenues coincides largely with the volatility in output prices. Vine tomato firms are most often able to obtain similar revenues per square meter, while bell pepper firms are on a somewhat lower level, with average production levels around 30 kilogram per square meter and average output prices close to $€ 1$ per kilogram.

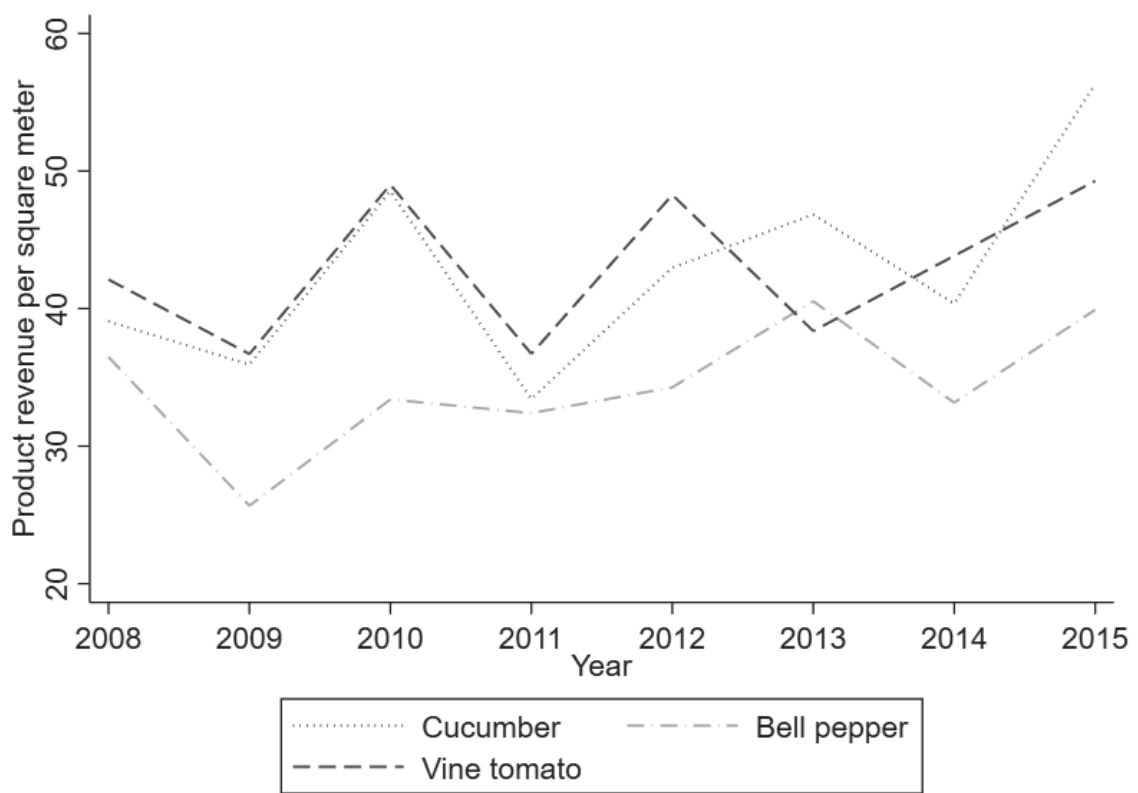

Figure 2.1: Average product revenue per square meter for the studied crops (period 2008-2015).

When considering the production levels over time, the production per square meter of vine tomatoes and bell pepper remains relatively stable during the observation period. Note however that this period also coincides with the larger focus on product quality and taste, which can be at odds with further productivity-increases. The fact that the standard deviations for the average production levels for vine tomato firms grow over time, also points at a growing divergence in production orientation between firms.

For cucumber firms, there is however a more clear increase in productivity over time as measured by the kilogrammes produced per square meter. This is partly due to the more widespread use of high-wire cultivation in the later years. This ensures 
that plants grow more into the height, which enables a more efficient growth of the cucumbers (Bac et al., 2014).

Table 2.2: Production results for cucumber firms (2008-2015).

\begin{tabular}{ccccc}
\hline Year & $\begin{array}{c}\text { Average output } \\
\text { price }(\mathbf{C})\end{array}$ & $\begin{array}{c}\text { Production in } \\
\text { pieces }\end{array}$ & Product revenue & EBT \\
2008 & $0.23(0.02)$ & $172.0(19.3)$ & $39.08(9.18)$ & $-3.39(6.11)$ \\
2009 & $0.21(0.05)$ & $170.3(27.1)$ & $35.94(9.42)$ & $-6.73(7.31)$ \\
2010 & $0.27(0.04)$ & $170.1(27.4)$ & $48.54(9.92)$ & $5.05(5.98)$ \\
2011 & $0.19(0.04)$ & $167.5(35.2)$ & $33.43(8.70)$ & $-5.90(6.39)$ \\
2012 & $0.24(0.03)$ & $178.7(35.4)$ & $42.97(10.30)$ & $0.34(5.75)$ \\
2013 & $0.25(0.02)$ & $178.8(23.8)$ & $46.84(11.49)$ & $3.00(4.05)$ \\
2014 & $0.21(0.02)$ & $194.2(28.5)$ & $40.36(10.95)$ & $-1.92(5.83)$ \\
2015 & $0.28(0.02)$ & $193.2(34.7)$ & $56.33(9.16)$ & $11.60(6.30)$ \\
\hline
\end{tabular}

Note: the production numbers are presented in pieces per square meter. The product revenue and net operating profit are measured in $€$ per square meter. Standard deviations are provided between brackets.

Table 2.3: Production results for bell pepper firms (2008-2015)

\begin{tabular}{ccccc}
\hline Year & $\begin{array}{c}\text { Average output } \\
\text { price }(\mathbf{C})\end{array}$ & Production in kg & Product revenue & EBT \\
2008 & $1.22(0.10)$ & $29.87(3.69)$ & $37.56(10.62)$ & $0.52(6.47)$ \\
2009 & $0.82(0.12)$ & $31.02(2.80)$ & $26.90(9.73)$ & $-8.86(6.08)$ \\
2010 & $1.14(0.12)$ & $29.40(2.79)$ & $34.88(8.72)$ & $0.70(5.56)$ \\
2011 & $1.02(0.08)$ & $31.76(3.60)$ & $33.87(8.59)$ & $-0.36(5.35)$ \\
2012 & $1.11(0.09)$ & $30.99(3.04)$ & $35.04(5.53)$ & $0.43(4.09)$ \\
2013 & $1.32(0.11)$ & $30.68(3.50)$ & $40.39(8.31)$ & $5.18(5.18)$ \\
2014 & $1.04(0.13)$ & $31.80(3.62)$ & $34.15(6.91)$ & $1.32(4.88)$ \\
2015 & $1.26(0.13)$ & $31.73(3.75)$ & $40.80(5.50)$ & $8.30(3.22)$ \\
\hline
\end{tabular}

Note: the production numbers are presented in kilograms per square meter. The product revenue and net operating profit are measured in $€$ per square meter. Standard deviations are provided between brackets.

Table 2.4: Production results for vine tomato firms (2008-2015)

\begin{tabular}{ccccc}
\hline Year & $\begin{array}{c}\text { Average output } \\
\text { price }(\mathbf{C})\end{array}$ & Production in kg & Product revenue & EBT \\
2008 & $0.80(0.32)$ & $54.88(9.84)$ & $42.12(5.69)$ & $-1.12(6.37)$ \\
2009 & $0.68(0.30)$ & $56.15(11.17)$ & $36.70(8.39)$ & $-4.37(7.68)$ \\
2010 & $0.91(0.28)$ & $54.90(10.82)$ & $49.02(11.36)$ & $9.78(8.00)$ \\
2011 & $0.70(0.44)$ & $54.97(13.28)$ & $36.71(13.70)$ & $-2.13(8.70)$ \\
2012 & $0.94(0.42)$ & $54.46(11.77)$ & $48.27(14.84)$ & $4.60(6.86)$ \\
2013 & $0.75(0.37)$ & $54.77(13.36)$ & $38.37(10.77)$ & $-3.31(6.90)$ \\
2014 & $0.83(0.33)$ & $56.41(15.07)$ & $43.84(8.80)$ & $3.57(5.85)$ \\
2015 & $0.91(0.32)$ & $56.49(14.61)$ & $49.29(10.29)$ & $8.03(5.77)$ \\
\hline
\end{tabular}

Note: the production numbers are presented in kilograms per square meter. The product revenue and net operating profit are measured in $€$ per square meter. Standard deviations are provided between brackets.

Next to the average production and price levels, tables 2.2, 2.3 and 2.4 also provide an overview of the average operating results (or EBT, earnings before taxes). This is calculated by subtracting the operating expenses and debt and interest payments from the product revenue. In order to enable comparison between firms of different sizes, these are divided over the total area of glasshouses in square meters. The low and often negative operating profits particularly stand out. They are predominantly low in years with low average output prices. This points at the fragile financial situation of most horticultural firms. In years with higher average output prices, most firms are 
able to obtain high positive margins, yet the vulnerability with respect to market volatility weighs heavily on the financial results. Moreover, the high standard variation in the earnings show that some of the firms are also able to obtain positive incomes in years with low prices.

Figure 2.2 shows an overview of the input cost shares for the three products. The labour intensive character of the production process can be clearly seen from the high share of labour costs. The high dependence on external labour leads to a cost share of above $25 \%$ for most firms. Given the energy intensity of the production process (Verreth et al., 2015), also energy inputs form a large share of the total costs. However, due to the usage of Combined Heat Power (CHP) engines, a large share of firms generate their own electricity. In case electricity is delivered back to the grid, firms are able to lower their net energy costs (e.g. Compernalle et al., 2011). Furthermore, figure 2.2 shows that costs for plant-related material such as plants, fertilizer and pesticides, most often only form a relatively modest share of the total costs.

\section{Cucumber}

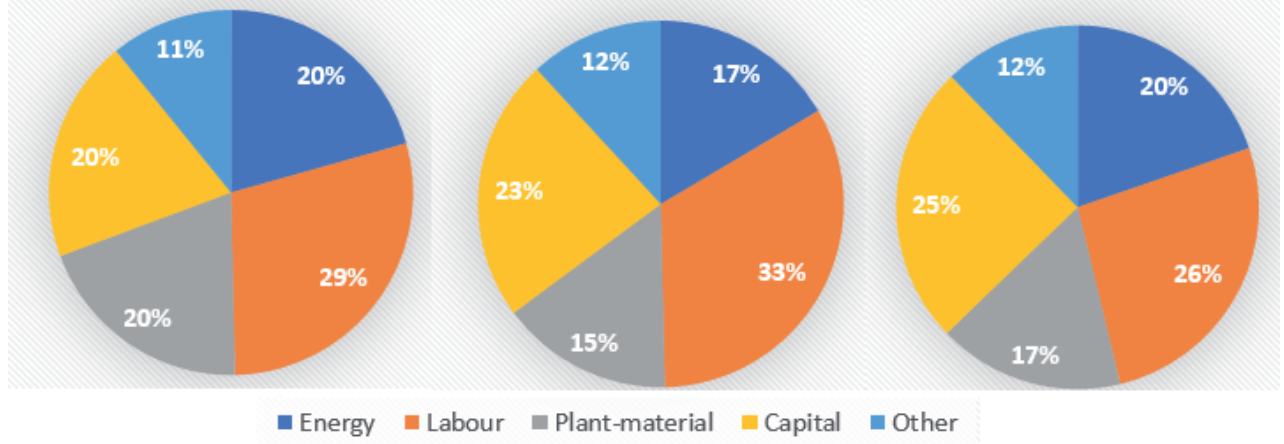

Figure 2.2: Average relative shares of input costs in the production of horticultural products (period 2008-2015).

When looking at earlier described developments regarding the organizational structure of primary producers, it is striking that for all three products more firms are operating as a private limited liability company (LLC), as can be seen in figure 2.3 . This indicates the increased complexity in organizational structures, in which it is less self-evident that primary producers operate as traditional family businesses. 


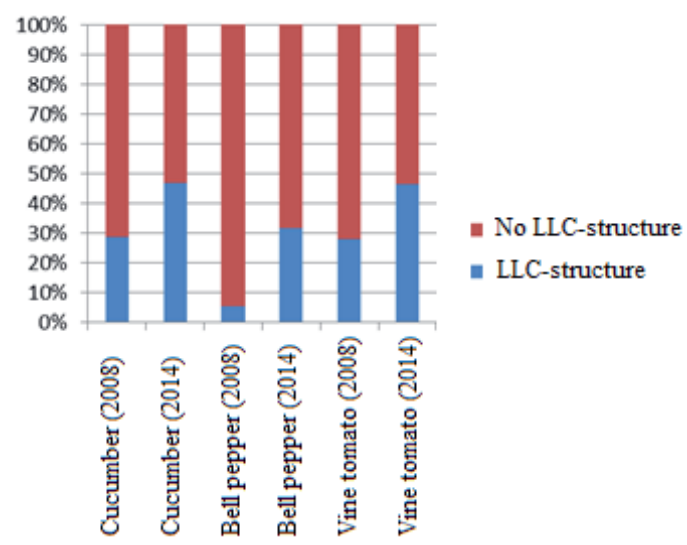

Figure 2.3: Differences in organizational structure for the main horticultural crops (2008-2014).

\subsection{Conclusion}

The above description of the data also points at the considerable differences between firms. The figures and tables presented in this chapter mainly focus on the average production levels, yet a large spread between firms is underlying these averages. As pointed out in the introductory chapter, this heterogeneity is a central topic in the subsequent chapters of this thesis. The ATR dataset introduced in this chapter forms the building block of the empirical analysis in the following chapters. 
Chapter 3 - Firm growth in Dutch horticulture 


\section{Chapter 3}

\section{EXPLAINING RECENT FIRM GROWTH IN DUTCH HORTICULTURE}




\section{EXPLAINING RECENT FIRM GROWTH IN DUTCH HORTICULTURE ${ }^{1}$}

ABSTRACT: Dutch horticultural firms have expanded rapidly in recent decades, both in terms of their production area as well as in number of employees. In particular in the production of fresh fruits and vegetables, a number of very large horticultural firms emerged with often more than one hundred employees, operating on tens of hectares of greenhouses. A standard explanation for firm growth is that firms want to benefit from economies of scale, where the increased scale of production would ensure lower average (fixed) production costs. This article however shows that cost reduction due to economies of scale is not the main driver behind the growth in horticultural firm size. In fact, our empirical evaluation shows that larger horticultural firms face higher average production costs as compared to smaller firms. However, these higher production costs are compensated by the on average higher and more stable output prices obtained by larger firms. This positive effect of firm size on the firm revenues therefore provides a different rationale for the recent growth in average size of Dutch horticultural firms. As a result, our findings demonstrate that revenue-related aspects are becoming more important in understanding firm growth of primary producers in the horticultural sector.

\footnotetext{
${ }^{1}$ This chapter is based on the article: Los, E.J., Gardebroek, C. and Huirne, R.B.M. (2019). Explaining recent
} firm growth in Dutch horticulture. Eurochoices, 18(3), pp. 38-43. 


\subsection{Introduction}

Dutch horticultural firms have expanded rapidly in recent decades, both in terms of production area as well as in number of employees. Recently, however, a number of very large horticultural firms emerged with often more than one hundred employees and tens of hectares of greenhouses. These firms also differ from traditional family farms in their management and organizational structures (Verdouw et al., 2014).

A standard explanation for firm growth is that firms want to benefit from economies of scale. A larger scale of production lowers average (fixed) production costs (Kimura and Le Thi, 2013). However, research shows that the cost reductions due to scale economies often decline when firms grow even further. The largest average cost reductions are often found between small and medium sized firms rather than between medium and large sized firms (Van der Meulen et al., 2011).

Recently, other explanations for production expansion have been given. Large production quantities can also lead to a better bargaining position towards input suppliers, processors and retail partners (Sexton, 2013). For example, most retail partners want a fresh and consistent supply of fruits and vegetables throughout the year. Therefore, they prefer buying from a limited number of very large suppliers instead of multiple small producers. Dealing with fewer large suppliers also reduces transaction costs (Sauer et al., 2012).

This article examines recent scale increases in Dutch horticulture. We focus on the scale economies argument as well as the bargaining position of firms. For the latter we look at the relation between firm size and output prices. To analyse these developments, we use unique firm-level data from Rabobank. This dataset contains observations for firms specialized in growing cucumber, bell pepper and vine tomatoes, which are considered main greenhouse vegetables in the Netherlands. All these firms are connected to Rabobank, which is the biggest credit supplier in Dutch horticulture with a market share of about 80 per cent. For the analysis, data of more than 250 horticultural firms in the period 2008 to 2015 are used, providing more than 1000 observations. Data are available on all operational costs, individual firm output prices, production numbers as well as various firm characteristics and indicators of (financial) firm performance.

\subsection{Firm size growth in Dutch horticulture}

table 3.1 shows that the average size (measured in hectares of greenhouses) of Dutch horticultural firms is steadily increasing. For all three products, almost half of the firms had at least five hectares of greenhouses in 2014. In addition, we see the development towards very large firms, with more than ten hectares of greenhouses, particularly for vine tomatoes. Although such acreages may not sound large compared to e.g. arable or dairy farms, it should be noted that the value of output per hectare in greenhouse horticulture is much larger. On average the production value of 1 hectare of fresh 
vegetables is $€ 400,000$, which compares to the production value of e.g. a dairy farm of roughly 100 dairy cows (Eurostat, 2017).

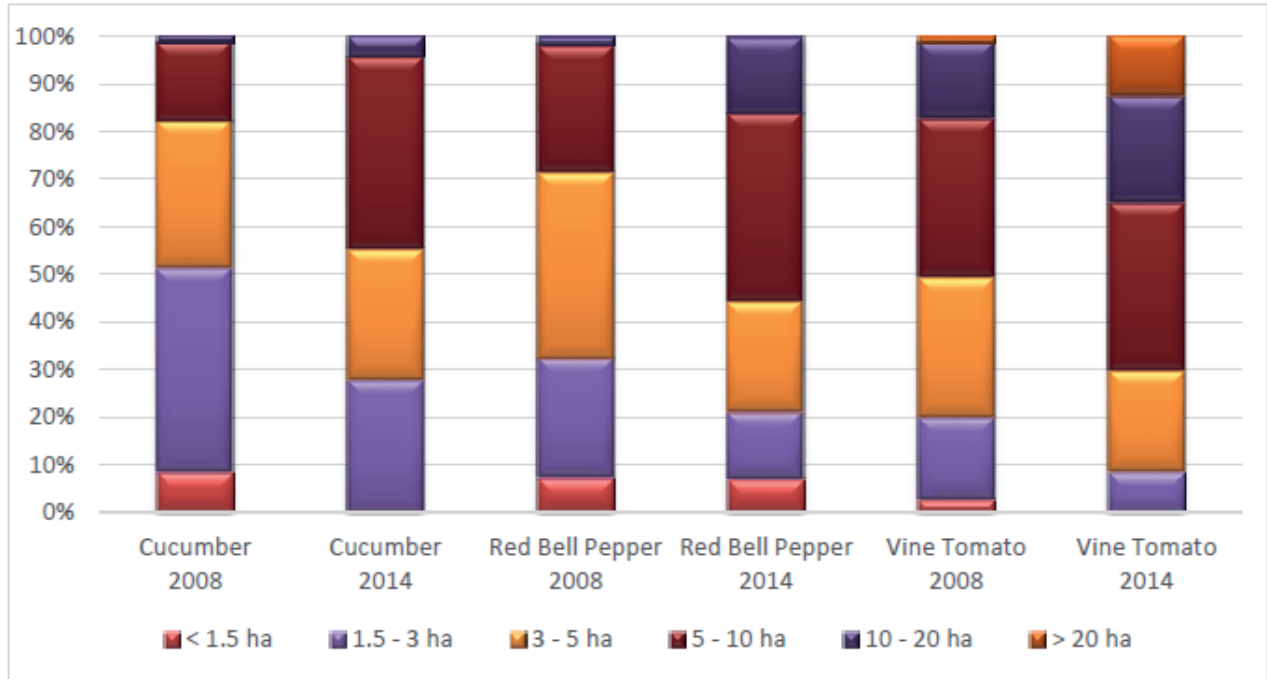

Figure 3.1: Development of firm size in vine tomato, bell pepper and cucumber production between 2008-2014.

\subsection{The effect of firm size on cost structure}

In order to see whether larger firms can reduce average costs due to scale economies, table 3.1 shows the average production costs per unit production for small, medium and large cucumber firms. The results show that both capital costs and labour costs increase with firm size, implying that larger firms on average face higher costs in order to meet their labour and capital requirements. In contrast, energy costs per cucumber are highest for the smallest firms and decrease for medium and larger firms. So, large firms benefit from scale effects in energy.

The observed differences could also be due to differences in technology between small and large producers. For example, large cucumber firms often use high wire cultivation. This is a form of cultivation where the plants grow towards a 4 meters high wire. Once the top of the plant reaches the wire, it is dropped down for about 50 centimetres. This enables a more efficient growth of the cucumbers, yet also creates additional labour requirements. In this light, it is relevant to note that it is often difficult to disentangle the effects of firm size and the use of advanced technologies on firm performance, as they are often related (Sheng et al., 2015). Moreover, quality differences might arise due to such underlying differences in the production process. 
Table 3.1: Differences in cost structures for cucumber firms based on firm size

\begin{tabular}{|c|c|c|c|}
\hline & $<2.1$ ha & $>2.1 \&<5.2 \mathrm{ha}$ & $>5.2$ ha \\
\hline Energy costs per unit production (C) & $0.060(0.03)$ & $0.052(0.02)^{*}$ & $0.046(0.02)^{* * *}$ \\
\hline Labour costs per unit production $(C)$ & $0.054(0.02)$ & $0.068(0.02) * * *$ & $0.072(0.01)^{* * *}$ \\
\hline Plant and seed costs per unit production (C) & $0.045(0.02)$ & $0.050(0.01) *$ & $0.050(0.01)^{*}$ \\
\hline Capital costs per unit production (C) & $0.034(0.02)$ & $0.059(0.02) * * *$ & $0.063(0.03) * * *$ \\
\hline Marketing costs per unit production (C) & $0.032(0.01)$ & $0.027(0.02)$ & $0.023(0.01)^{* *}$ \\
\hline Average size (ha) & 1.686 & 3.515 & 7.104 \\
\hline $\mathbf{N}$ & 131 & 273 & 135 \\
\hline
\end{tabular}

The main conclusion from table 3.1, however, is that average production costs are in fact lowest for the smallest companies. This is mainly caused by their lower average expenditure on capital and labour. Especially in the production of crops that are sensitive to variations in the amount of daylight and sunshine, sudden changes lead to a highly irregular demand for labour. Large scale production in such a case involves high transaction costs for organizing this temporary labour, whereas smaller scale producers are able to manage such changes more smoothly. A similar pattern is observed for vine tomato firms, where the input costs per square meter for firms of different sizes are shown in Figure 2. These findings therefore contradict the idea that larger firms in this industry are able to produce more cost efficiently.

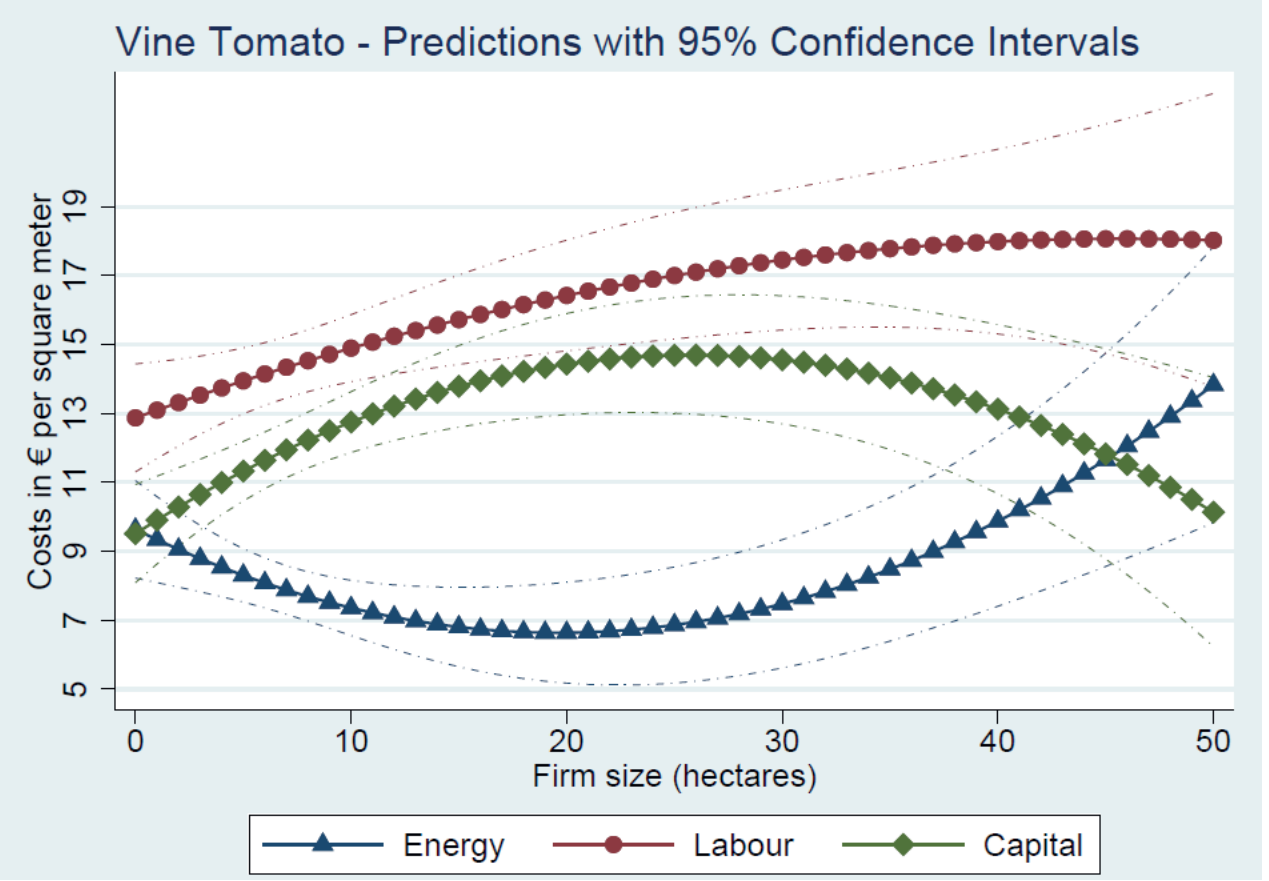

Figure 3.2: Costs of main inputs per square meter for vine tomato firms based on firm size. 


\subsection{The effect of firm size on output prices}

Next, we turn to the effect of firm size on bargaining power. The market for fresh fruit and vegetables is increasingly dominated by large retail partners, who demand a large and consistent supply of products (Camanzi et al., 2011). In Dutch horticulture, with a high degree of seasonality in production, the ability to supply fresh products yearround is therefore becoming more important. To meet such demands primary producers can choose to bundle their outputs via producer organisations. However, at individual firm level they can also opt for a more year-round production through investments in e.g. artificial growing light or through producing at different locations (Van der Meulen et al., 2011). Such investments, however, require a considerable scale of production. In combination with the increased emphasis on shorter supply chains (where primary producers tend to have more direct contact with retail partners), these developments might render large horticultural firms a better bargaining position. This should be reflected in a positive relation between firm size and the marketed value of the firm output.

In order to study this relation, we performed two regression analyses. In the first analysis, firm size (measured in hectares) is regressed on the firm-specific output prices. In order to correct for specific product characteristics, we also include a few control variables. Production per square meter is considered in our model in order to correct for various product-specific characteristics. Beyond, since markets and production technologies differ for the three vegetables, indicator variables for bell pepper and vine tomato are included to distinguish firms producing these crops from cucumber firms. The results show that firm size is significantly and positively related to the obtained output prices. The positive coefficient of 0.009 implies that, if we control for other product characteristics, an increase in firm size of 1 hectare is associated with a 0.9 eurocent higher output price per kilogram produced. We also tested whether this effect differs per crop, but did not find any significant differences. This implies that the positive relation between firm size and output prices is consistent for the whole set of cucumber, tomato and bell pepper firms.

In the second regression analysis, firm size is regressed on the stability of these output prices, as measured by the coefficient of variation (CV). The lower the CV, the more stable the prices are for a given firm over the years. The results here show a negative and significant effect of firm size on the coefficient of variation. This means larger firms have more stable output prices over time. An increase in firm size of 1 hectare is found to lower price variability over time by $0.2 \%$. Although this seems a small effect, one should not forget that most price variation is due to yearly conditions.

Overall, the regression results confirm the idea that larger firms have an advantage when it comes to their market positioning. This can be attributed either to their better bargaining position, or due to the fact that for handling and trading larger volumes lower transaction costs are incurred. These lower transaction costs may be 
partially passed on by retailers to the primary producer in the form of a higher output price (Sauer et al., 2012). Furthermore, the modernity of the firm might also play a role here (Sheng et al., 2015), as the use of advanced technologies is often associated with firm size and can arguably lead to better quality products.

\subsection{A synthesis: operational costs, product revenue and firm size}

Figure 3.3 shows the relation between costs, revenues, profits and firm size of vine tomato producing firms (in total 627 observations). The blue line indicates the average operational costs (the sum of all expenses on energy, labour and plant materials) per square meter. The orange line represents the average product revenue per square meter (measured by the output price times the production per square meter). The cost line shows that the smallest firms face the lowest operational costs (on average below $€ 35$ per square meter), whereas costs go up to around $€ 50$ per square meter for the largest firms. With respect to revenues, we observe steady increase in revenues per square meter as size increases, with the highest values obtained by the largest firms. The difference between these two lines is represented by the green line that indicates the operational profit per square meter.

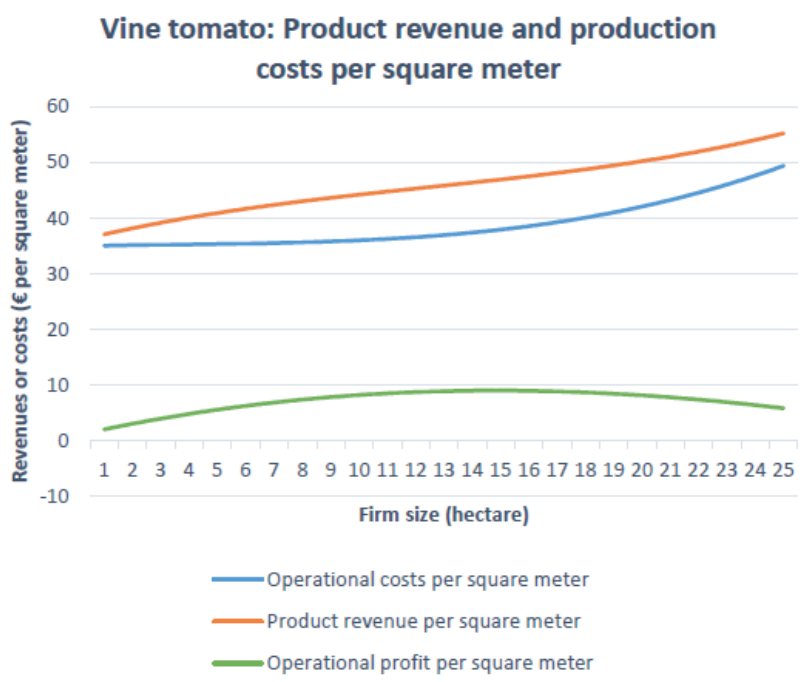

Figure 3.3: Operational costs and product revenue for specialized vine tomato firms by firm size.

Thus, the main driver of firm growth in the Dutch horticultural sector would seem to be the positive relation between firm size and firm revenues, rather than the potential of scale increases to reduce production costs. This is in line with the positive relation between firm size and firm-specific output prices that was found in the regression analysis. 


\subsection{Conclusion}

Dutch horticulture is increasingly composed of large firms that stray away from the traditional family-farm model. When taking a closer look at these developments, we observe that firm size growth is not primarily driven by cost-reductions due to economies of scale. Our findings show that increases in firm size have a mixed effect on cost structures: some costs per unit do decrease when firms grow, i.e. energy costs; whereas other costs (e.g. labour costs per unit of product) rise as firm size increases. On average, however, lower production costs are found in the smaller firms.

Therefore, the logic behind firm growth does not seem to lie in the alleged relationship between firm size and lower production costs. Rather, the positive effect of firm size on the revenue side seems to drive firm growth. This is supported by the finding that larger firms are able to obtain higher and less volatile output prices as well as higher product revenue per square meter.

With respect to the potential to generalize these findings towards other agricultural sectors, one important aspect of horticultural production should be kept in mind. Within horticulture, primary producers are mostly growers of an end-product that can be directly transported to retail partners. It is therefore unclear how our results compare to farm sectors where product, such as milk, require further processing. Moreover, the central role of producer organizations in linking individual producers and retail is not considered in our analysis. Nevertheless, the results show that differences in product revenue and individual firm output prices are of considerable importance and deserve more attention when studying growth in farm size in modern agricultural markets. 


\section{Chapter 4}

\section{EXPLAINING OUTPUT PRICE HETEROGENEITY IN DUTCH HORTICULTURE}




\section{EXPLAINING RECENT FIRM GROWTH IN DUTCH HORTICULTURE²}

ABSTRACT: Recent empirical literature pays increasing attention to farmer-retail power relations in agricultural supply chains, yet seems to neglect potential differences between prices that primary producers receive for their products. Via both a Markov chain analysis and a hybrid panel data model, we empirically test whether primary producers receive prices in a consistent way and what explains any price differences. Using a unique dataset containing individual firm-specific output prices in various horticultural markets, we show substantial price dispersion across firms and reveal relations between firm characteristics and observed output prices. The Markov analysis shows that the same firms are constantly found in the higher and lower quartiles of the price distribution, implying prices are not distributed randomly. The results of the hybrid panel data model show that characteristics as firm size and productionorientation are strongly associated with differences in the obtained output prices as well as the price/cost ratio between firms.

\footnotetext{
2 This chapter is based on the article: Los, E.J., Gardebroek, C. and Huirne, R.B.M. (2020). Explaining output
} price heterogeneity in Dutch horticulture. Revised and resubmitted to Agribusiness: an international journal. 


\subsection{Introduction}

The profitability of primary agricultural producers is to a large extent determined by the output prices received at firm level. This is particularly the case in sectors and regions with low agricultural policy support (Sauer et al., 2012). With agricultural policies becoming more liberalized, primary producers are increasingly expected to produce in a market-oriented way and to supply specific products that meet consumer demand. This implies a larger emphasis on value-added agriculture and hence a shift from the production of homogenous products towards more distinguished products (Grashuis and Magnier, 2018; Knudson et al., 2004). This especially holds in modern agricultural markets, with abundance of food for most consumers in developed countries (e.g. Koning et al., 2008; Sexton, 2013), as well as increased concentration of the largest global retail companies (Hovhannisyan et al., 2018).

Very few empirical studies however pay attention to what extent primary producers can differentiate their products in markets and as a result are able to obtain higher output prices or price mark-ups. Despite the wide presence of studies looking at output price heterogeneity in other economic sectors (e.g. Kugler and Verhoogen, 2011; Roberts and Supina, 1996), research for agricultural primary producers is lacking. Current studies that do challenge the assumption of perfect competition in agricultural markets mainly focus on aspects as price transmission (Liu et al., 2019; Assefa et al., 2017; Bakucs et al., 2014) and the distribution of rents among various partners in the food supply chain, hereby mostly emphasizing the low bargaining power of primary producers (Bonanno et al., 2018a; Sexton, 2013). Potential output price differences between primary producers are however barely studied, Falkowski et al. (2017) being one of the few exemptions. In contrast, most studies on price dispersion and the ability of producers to obtain higher prices in food markets focus on food manufacturers (e.g. Bonanno et al., 2018b).

This chapter aims to fill this gap by studying differences in output prices and cost/price ratios of Dutch horticultural firms, in particular specialized firms growing vine tomatoes, bell peppers and cucumbers. These products are fitting cases for different reasons. With a combination of both traditional family firms as well as larger firms with a more industrial organizational structure (Verdouw et al., 2014), horticulture allows us to study variability in output prices due to differences in firm structure. In addition, the extent of product differentiation and other differences in quality vary by crop. Cucumber, e.g., is known to be a standardized product with limited potential for product variation (Vermeer, 2009), whereas tomatoes are more differentiated products, with a more important role for quality aspects in consumer demand (Dorais et al., 2001). This also allows us to study differences between these markets.

Our analysis follows a three-step procedure. First, we describe output price heterogeneity by providing an overview of price developments for individual Dutch 
horticultural firms. Second, we use a Markov-transition analysis to test whether the same firms are able to obtain high prices over time. This tells us whether firms randomly receive higher prices, or whether this is based on certain firm (or product) characteristics that are persistent over time. Third, we analyse how both within and between variation in several firm characteristics explains differences in the observed output prices and the price/cost-ratios between firms. The latter allows us to correct for any price differences resulting from product heterogeneity caused by differences in input usage (see e.g. Roberts and Supina, 1996). For studying the factors associated with price dispersion, our empirical analysis builds on notions of earlier theoretical and empirical work which challenges the paradigm of perfect competition and homogenous prices in agricultural markets. Based on this, a heterogeneous price equation as well as a price/cost equation are specified. Both equations are estimated using a hybrid panel data model (Schunck, 2013).

As a result, this chapter contributes by expanding the literature on pricing in agricultural markets by specifically addressing price heterogeneity and differences in price/cost-ratios between primary producers. By studying the persistence of the output price distribution over time, we aim to deepen the understanding of structural differences in the position of primary producers on output markets. Moreover, by using a unique dataset containing firm-specific output prices and production costs for Dutch horticultural firms and through applying a non-standard hybrid panel data model, we are able to empirically assess the effect of time-varying as well as time-invariant variables (such as most firm-characteristics) on differences in output prices and the price/cost ratio. To our best knowledge this approach has not yet been applied in order to study output price differences between primary producers.

The remainder of this chapter is organized as follows. The next section discusses various potential drivers of price dispersion in the context of modern agricultural markets. Section 4.3 introduces the context of Dutch horticulture and presents the data used in the empirical analysis. The methodological approach is described in section 4.4 and introduces both the Markov transition analysis of the price distribution as well as the hybrid panel approach to study factors associated with differences in both the output price distribution and the price/cost ratio. Section 4.5 presents the estimation results and the last section draws conclusions and provides a discussion on these findings.

\subsection{Theoretical Background}

A vast majority of studies in agricultural economics assumes that agricultural producers are price-takers (see e.g. Norwood and Lusk, 2018; Arnade and Pick, 2000), meaning they face a market price $P$ in period $t$ depending on the total quantity produced $Q$ in period $t$. Nevertheless, considerable differences in firm-specific output prices can be observed in various agricultural markets (Falkowski et al. 2017). In order 
to explain price dispersion, it is most often assumed that some form of price heterogeneity exists (Sauer et al., 2012). If we assume a vector of variables $Z$ containing factors causing price heterogeneity, which can differ over time as well as per firm $i$, we obtain:

$$
P_{i t}=f\left\{Q_{t}, Z_{i t}\right\}
$$

The next sections describe the factors hypothesised to cause price heterogeneity and groups these into three categories, relating to product heterogeneity (section 4.2.1), firm heterogeneity (4.2.2) and context heterogeneity (4.2.3).

\subsubsection{Product heterogeneity and quality aspects}

For long, increasing production by means of specialization and concentration used to be the dominant farm strategy (Den Ouden et al., 1996). The introduction of niche products, such as cherry tomatoes (Dorais et al., 2001), however put more emphasis on differences in the quality of the product, as well as an increase in the importance of marketing and (direct) contact with retail - especially in comparison with more bulkoriented products. Further developments include the expansion of firms to secondary activities, such as packing the products at firm-level (Van der Noll et al., 2010). In contrast to concentration and specialization, these developments allow firms to opt for strategies with a focus on product differentiation and additional activities that might generate extra value added, also potentially resulting in higher average output prices and a price mark-up for the primary producer.

Spence (1976) and Dixit and Stiglitz (1977) were among the first to formalize the notion of differentiated products in a setting of monopolistic competition. They show that if producers supply different varieties, the standard perfect competition result of price equals marginal costs is adapted by including a mark-up on the price, depending on the degree of substitution between varieties (substitution elasticity).

If varieties are perfect substitutes, a price increase in one variety implies that demand drops infinitely (in favour of the other varieties). In such a case the price mark-up is zero since producers are forced to price according to the perfect competition rule. However, when consumers prefer to keep buying a specific variety, despite higher prices, there is scope for a price mark-up. This shows that price premiums can be obtained by producers who are able to grow products with certain premium characteristics, if consumers do not consider these to be perfectly substitutable.

\subsubsection{Firm heterogeneity and scale effects}

Scale effects are most likely to play a role in the output prices received due to their impact on transaction costs (Sauer et al., 2012). Transaction costs are often defined 
as the costs related to arranging and carrying out the exchange of products (Holloway et al., 2000). These costs mainly play an important role in explaining price dispersion as retail partners often show preferences for large and consistent supply of fresh fruits and vegetables throughout the year (McCorriston, 2002; Wohlgenant, 2001), which might benefit larger firms. Making agreements with large parties can therefore reduce transaction costs, which potentially results in better prices for primary producers involved, as buyers may pass on some portion of the saved costs to larger producers (Sauer et al., 2012).

In particular differences in bargaining power might play a role in explaining variation in output prices. Most often, a business partner is assumed to have bargaining power over the other partner if it can easily substitute the products it requires by making use of another business partner (Falkowski et al., 2017). Firms or parties who are able to deliver retailers (year-round) large amounts of products, or specific products that meet the consumer demand, are more attractive from the perspective of the retailer since they lower transaction costs of the retailer. The relative bargaining positions of the retailer and supplying firm will determine how these transaction cost savings are distributed among supplier and retailer. As a result, we hypothesize that dealing with larger firms benefits retailers (Sauer et al., 2012).

What should be noted though is that traditionally, horticultural firms are part of producer organisations, which are able to trade larger volumes and arrange the further marketing of the products. However, large firms increasingly tend to move away from this constellation and search for more direct contact with retail partners ${ }^{3}$.

Furthermore, a variety of other firm factors are found to play a role in explaining differences in output prices and price/cost ratios between producers. E.g. Costanigro et al. (2010) point at the existence of reputation-based price premia, where particularly firm longevity in business is associated with differences in output prices since consumers are willing to pay premium prices for products from producers and/or regions with good reputation.

\subsubsection{Context heterogeneity: uneven competition in time and space}

Seasonality in prices for horticultural products occurs as the supply of the respective good is concentrated seasonally while the demand is roughly continuous throughout the year (Hanf and Kuhl, 1986). Given the length of the dominant growing season (for most fresh vegetables in north-western Europe roughly from March until October), average prices are lower during this period given the higher domestic supply. Price data shows that, e.g. in the market for tomato, average producer prices are often twice as high in December - February compared to the period May - September (European Commission, 2017). Firms delivering products during the winter season and

\footnotetext{
${ }^{3}$ Beyond, within agricultural cooperatives, various dynamics might lead to an unbalanced power distribution, which potentially benefits larger sized members (Banerjee et al., 2001; Zussman and Rausser, 1994).
} 
early spring, e.g. possible due to the usage of artificial growing light (Verhaegh, 1998), are therefore likely to end up with higher average annual output prices. Given the higher costs involved in producing off-season, the effect on the actual price/cost ratio is however not clear.

Aside from seasonal aspects, spatially uneven competition might also result in differences in observed prices and price/cost ratios. Hallak and Sivadasan (2013) find that exporting firms are able to charge higher prices. Given the high share of exports for Dutch horticultural products (Nijdam et al., 2019), the export position of firms is also a potential factor influencing the price heterogeneity between firms.

\subsection{Price dispersion in the Dutch horticultural sector}

\subsubsection{Developments in Dutch horticulture}

The Netherlands is globally a leading country in horticultural production, where most primary producers have undergone significant changes in firm structure in recent years (Van der Meer et al., 2019). The average firm size e.g. increased considerably in recent decades. Consequently, the sector is composed of a growing number of large-scale enterprises, with often tens to hundred employees on their payroll, as well as a group of horticultural firms producing on a smaller scale (Van der Meer et al., 2019). This also leads to a considerable heterogeneity in organizational structure. Despite these differences in firm structure and production technologies, as the introduction of artificial growing light, variations in external production factors which could affect prices and cost-levels - such as climatological circumstances or potential differences in the proximity of markets - are relatively modest. This is in particular the case given the small size and the relatively densely populated character of the country.

\subsubsection{Data source}

For analysing price dispersion in the Dutch horticultural sector, we use firm-level data obtained from the Analysis Tool Rabobank (Rabobank, 2016a), which is the largest bank active in the Netherlands as a credit supplier for the agricultural sector (Rabobank, 2016b). The quality and completeness of our sample can be assessed by comparing it to the total number of firms and the total acreage in the whole sector. According to Statistics Netherlands (2011), in 2009, 199 firms were active in the specialized production of vine tomatoes, with a total acreage of 1047 ha. In contrast, our total sample holds 82 vine tomato firms in 2009, covering an acreage of over 661 ha. This means over $40 \%$ of the total firms and around $60 \%$ of the total acreage are represented in our sample. Looking at other years of observation, we find a coverage of consistently above $40 \%$ of the number of firms and around $60 \%$ of the total acreage of a certain crop. Only for cucumber firms, these numbers are somewhat lower, with slightly above $30 \%$ of the number of firms and just below $50 \%$ of the total acreage. As a result, the firms in our sample are - on average - somewhat larger as compared 
to the average firm size in these sectors. Nevertheless, given the large number of firms represented in our sample, it provides a well-informed representation of wider changes in the horticultural sector ${ }^{4}$.

The sample contains annual firm-level observations for the period 2008-2015. First, it provides information on firm characteristics, as firm size in hectares, organizational structure and the use of specific production technologies. Organizational structure is measured by a dummy variable (LLC) indicating whether a firm is a limited liability company (1) or has a different organizational structure, such as family farms (0). Differences in production technology are reflected in the usage of artificial growing light. Furthermore, as the data contains production and marketing information (output level, operational costs and firm-specific output prices). All these numbers are on an annual basis, which means that e.g. the observed prices and costs per product are yearly averages. This has the advantage that very short-lived price fluctuations have already been filtered out (Syverson, 2007). The output level denotes the total annual production in kilogrammes or units produced. Operational costs include all costs related to operational activities (paid labour, gas and electricity expenses, plantmaterials and related expenses as well as other expenses related to e.g. transport). ${ }^{5}$ Based on the observed operational costs and output prices, the cost/price ratio can be calculated as well.

\subsubsection{Descriptive statistics}

Table 4.1 shows a relatively high variation in output prices as denoted by the standard deviation, in particular in the market for vine tomatoes. Note however that the overall standard deviations are a combination of variation due to differences between firms, as well as changes in prices over time (see also figure 4.1). Furthermore, substantial differences in production costs arise between products, as well as between firms producing the same product. The same holds for firm size, where both smaller firms of around one hectare as well as large firms are visible. In addition, firms producing cucumber or bell pepper barely make use of artificial growing light installations, both scoring below ten percent. The LLC-structure is most prevalent for vine tomato firms.

\footnotetext{
${ }^{4}$ As a comparison, note that e.g. the more widely used Dutch FADN only contains data for 20 to 30 firms per main horticultural crop (Ge et al., 2018).

${ }^{5}$ Note that these are only costs directly associated with operational activities, hence depreciation or interest costs are not considered.
} 
Table 4.1: Descriptive statistics of the main variables.

\begin{tabular}{lccc}
\hline & Bell Pepper & Vine Tomato & Cucumber \\
\hline Average annual Output price $(\epsilon)$ & $1.099(0.195)$ & $0.809(0.372)$ & $0.234(0.042)$ \\
& $(0.099-\underline{0.167)}$ & $(0.389-\underline{0.142})$ & $(0.044-\underline{0.031})$ \\
Growing light (1=yes) & $0.090(0.287)$ & $0.247(0.431)$ & $0.059(0.236)$ \\
& $(0.186-\underline{0.056})$ & $(0.415-\underline{0.155})$ & $(0.293-\underline{0.050})$ \\
Firm Size (ha) & $6.970(7.451)$ & $9.432(9.265)$ & $3.969(2.242)$ \\
& $(6.309-\underline{2.442})$ & $(8.704-\underline{2.054})$ & $(2.158-\underline{0.754})$ \\
LLC (1=yes) & $0.255(0.436)$ & $0.378(0.485)$ & $0.337(0.473)$ \\
& $(0.382-\underline{0.218})$ & $(0.458-\underline{0.191})$ & $(0.434-\underline{0.180})$ \\
Production per square meter $\left(\mathrm{kg} /\right.$ piece) ${ }^{6}$ & $30.731(3.131)$ & $55.426(12.365)$ & $175.071(25.691)$ \\
& $(3.021-\underline{1.083})$ & $(11.984-\underline{4.521})$ & $(26.404-\underline{10.073})$ \\
Average operational costs $(€$ per & $0.878(0.191)$ & $0.712(0.443)$ & $0.201(0.037)$ \\
kg/piece) & $(0.150-\underline{0.128})$ & $(0.445-\underline{0.121})$ & $(0.039-\underline{0.021})$ \\
Price/Cost ratio & $1.285(0.280)$ & $1.226(0.394)$ & $1.183(0.231)$ \\
& $(0.190-\underline{0.211)}$ & $(0.336-\underline{0.295)}$ & $(0.166-\underline{0.179})$ \\
$\mathrm{N}$ & 704 & 460 & 236 \\
\hline
\end{tabular}

Source: Authors, based on Rabobank (2016a).

Note: The mean is followed by the standard deviations in parentheses. The row below provides a breakdown of the standard deviation in the between standard deviation (given in italic) and the within standard deviation (underlined).

The development of output prices of the three products is shown in figure 4.1. The solid middle line shows the average prices for the studied products in the period 20082015. The dashed lower line shows the price for the $20^{\text {th }}$ percentile of the sample, whereas the dashed upper line shows the price for the $80^{\text {th }}$ percentile. The effect of yearly price volatility is mainly visible in 2009 and 2011, where lower average prices are observed. External market circumstances most often play a role in causing these low prices. 2011 e.g. coincided with the outbreak of Escherichia coli which for long depressed demand for some fresh vegetables and hence caused low prices in these markets (Perez-Mesa et al., 2019)). Next to these strong year effects, we also observe a high variation in output prices between firms within the same year. This effect is particularly strong in the markets for vine tomatoes, yet producers in other markets also deviate from the mean prices in the observed years. E.g. in 2012, 20\% of the vine tomato firms were able to obtain average annual output prices of above $€ 1.26$, while the lower ranked firms in the distribution obtained prices below $€ 0.64$.

\footnotetext{
${ }^{6}$ Note that the production of cucumbers is measured in actual pieces, not in kilograms.
} 
Price variation in horticultural markets $2008-2015$
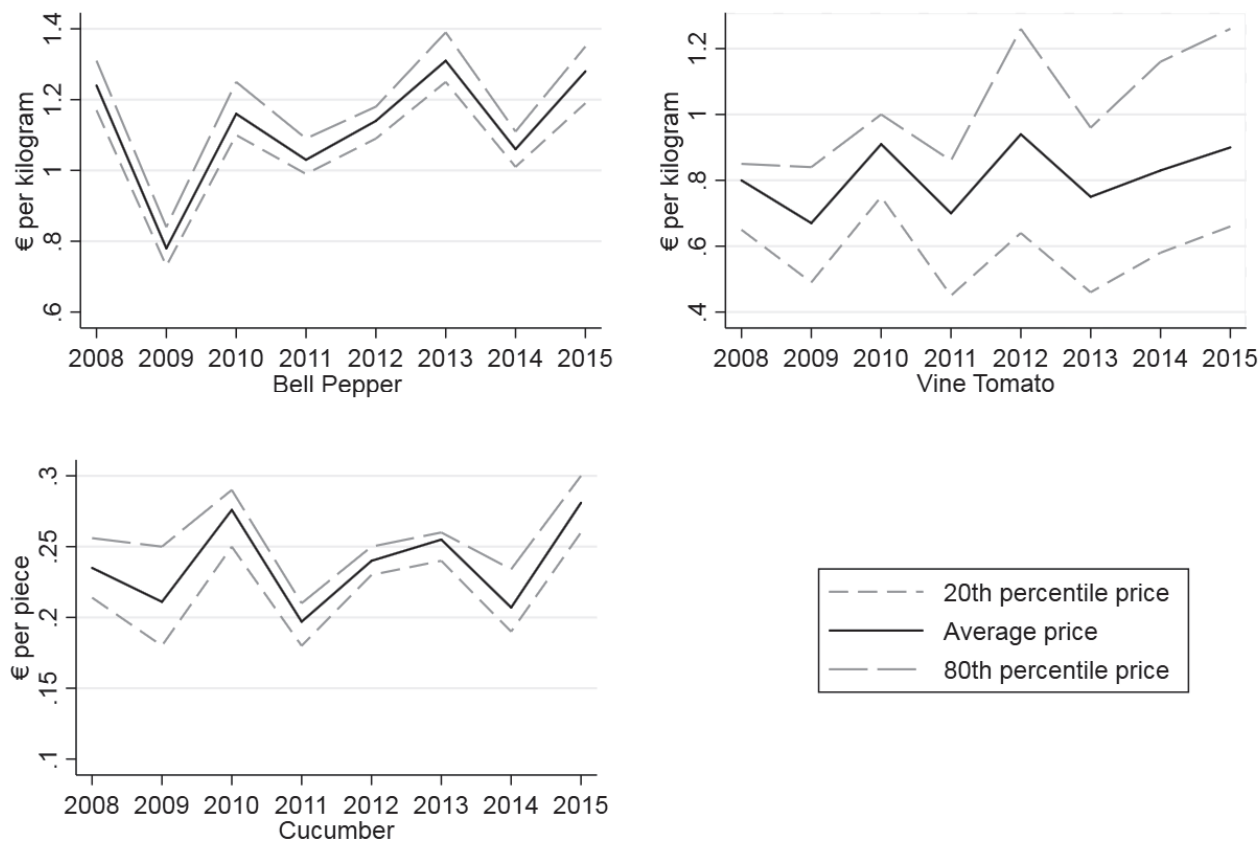

Figure 4.1: Price variation in horticultural markets in the period 2008-2015. Source: Authors, based on Rabobank (2016a).

Despite the fact that a comparison between crops is not straightforward given the different values on the respective $y$-axes, figure 4.1 shows the smallest deviations from the annual year price in markets for cucumber and bell pepper, which are more homogenous products. Nevertheless, there is price dispersion across all three different subsectors. Furthermore, the spread in output prices is relatively stable throughout the observation period, yet seems to grow over time for tomato firms. Arguably, product differences have become more pronounced in this market, reflected in larger differences in output prices between firms over time. Nevertheless, we see that all firms are subject to the yearly price volatility that characterizes the markets for fresh horticultural products. As a result, also firms with relatively high output prices, producing for premium markets, are affected by external effects in the wider market. 

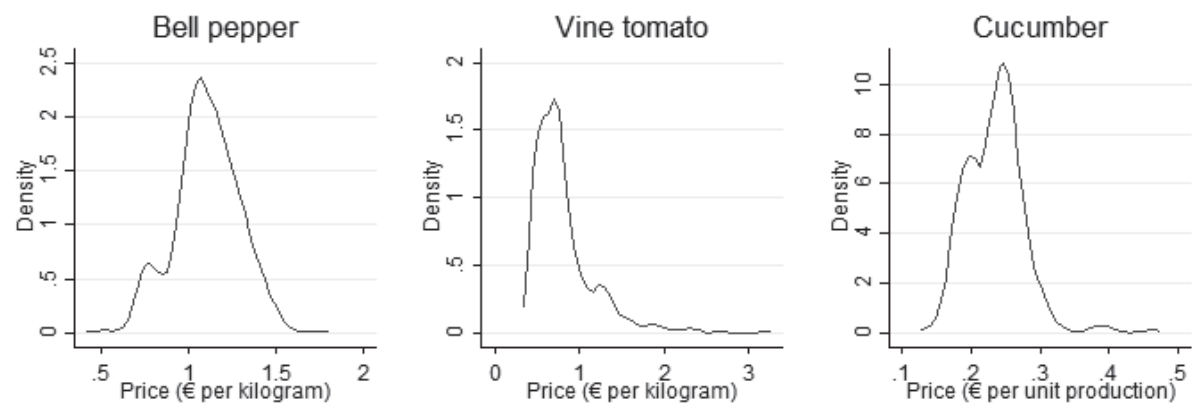

Figure 4.2: Kernel density graphs of output prices in horticultural markets in the period 2008-2015. Source: Authors, based on Rabobank (2016a).

The spread in firm-specific output prices is also visible in figure 4.2, showing the kernel density graphs for the observed firm-specific output prices for all three products. The graph for vine tomato producers stand out with some producers obtaining very high output prices on the right side of the distribution. For cucumber and bell pepper, we observe a single peak in these graphs, pointing at a unimodal distribution of the output prices.

\subsection{Empirical Approach}

\subsubsection{Individual output prices over time: A Markov transition analysis}

In order to study the output price distribution of primary producers over time, we first apply a Markov transition analysis. Markov chain approaches are commonly used in the literature to analyse e.g. firm-size distributions over time (Tonini and Jongeneel, 2007, Huettel and Jongeneel, 2011). Applying this approach to study the output price distributions provides insight in the persistence of prices for individual firms: is this a random process where firms regularly shift from the top to the bottom of the distribution and vice versa, or are rather the same firms able to obtain high output prices? In the latter case, price distributions are likely to be based on inherent characteristics of a firm.

First, individual output prices for every crop and time-period are subdivided in four quartiles $\Pi_{j}$. Firms with an output price in the lowest quartile of a particular year end up in group 1, whereas firms with an output price in the highest quartile end up in group 4 and so forth. Next, we define the following transition probability matrix: 


$$
P M=\left[\begin{array}{llll}
p_{11} & p_{12} & p_{13} & p_{14} \\
p_{21} & p_{22} & p_{23} & p_{24} \\
p_{31} & p_{32} & p_{33} & p_{34} \\
p_{41} & p_{42} & p_{43} & p_{44}
\end{array}\right]
$$

The probability matrix $P M$ provides the average probabilities of moving from one price quartile to another, i.e. $p_{11}$ refers to the average probability of being in price quartile 1 throughout the whole observation period, whereas $p_{12}$ refers to the probability of moving from state 1 to state 2 . As a result, the probability matrix shows the probability of a firm to remain in the same quartile or to transition to a different price quartile over the years. Note that for estimating the transition probability matrix, the price cutoff points differ by year. This removes the influence of yearly price volatility on the level of output prices. E.g. in 2009, the lowest quartile for tomato firms consists of firms with an average output price below $0.50 €$ per kilogram. In 2010 in contrast, only firms with an output price below $€ 0.76$ end up in the lowest price quartile. In order to estimate the exact transition probabilities, two restrictions are imposed:

$$
p_{i j} \geq 0 \text { and } \sum_{j=1}^{m} p_{i j}=1 \quad i=1,2, \ldots, m
$$

By imposing these restrictions, we ensure the transitions to be non-negative and that the sum of the probabilities always equals one, thereby satisfying the Markov constraint (Tonini and Jongeneel, 2007).

\subsubsection{Modelling and estimating price heterogeneity}

Based on the overview given in section 4.2, we expect differences in firm-specific output prices to depend on several factors related to product, firm and production heterogeneity. Due to data limitations, we are not able to empirically assess the association of all these factors. We however can assess heterogeneity in firm structure by considering differences in firm size as well as differences in organizational structure. In the latter case, it allows us to identify whether there are differences in output prices between more traditional family-run horticultural firms and firms with a more distinct organizational structure, e.g. firms described as a limited liability company (LLC). Furthermore, differences in production strategy between firms can be assessed by considering information on the production intensity per square meter.

In order to capture production heterogeneity, we consider differences in the usage of artificial growing light, which potentially lead to differences in average annual prices. By adjusting equation 1 (and currently neglecting differences as a result of product heterogeneity), we obtain: 


$$
P_{i t}=f\left\{Q_{t}, Z_{i t}\right\} ; \text { where } Z_{i t}=f\{\text { Size, Intensity, LLC, Light }\}
$$

Product heterogeneity is mainly reflected in product quality. High-quality products naturally yield higher output prices. However, suppliers of high-quality products may also have more bargaining power, leading to higher output prices (Bonanno et al., 2018a). In order to account for product quality Roberts and Supina (1996) propose to use the ratio of the firm's output price and production costs. Considering such a ratio reduces the influence of quality differences on output prices as long as quality differences are reflected in the firm's production costs, e.g. via the usage of higherquality and more expensive inputs (Roberts and Supina, 1996). Karagiannis et al. (2018) also apply this approach but since they lack information on firm-level quantities and prices they are forced to estimate these values indirectly via the use of pricedeflated production functions. The availability of firm-level prices, operational costs and quantities in our data, however, allows us to calculate such a ratio directly based on observed values for individual firms. Hence, we obtain:

$$
\frac{P_{i t}}{C_{i t}}=f\left\{Q_{t}, Z_{i t}\right\} ; \text { where } Z_{i t}=f\{\text { Size, Intensity, LLC, Light }\}
$$

\subsubsection{Hybrid panel approach}

Equations (2) and (3) are estimated via a set of hybrid panel regressions (Allison, 2009; Schunck, 2013). A common approach would be to estimate these equations using a Fixed Effects (FE) approach (Schmidt et al., 2009). A FE estimation however makes use of a within-transformation, neglecting differences between firms in estimation (e.g. Kohler and Kreuter, 2005). Given our focus on explaining differences in output prices between firms this is undesirable. Beyond, for variables that barely change over time (such as most firm characteristics), the FE estimation procedure is known to be inefficient, given that such variables have very little within variation (Beck and Katz, 2001). The hybrid panel model, in contrast, largely builds upon a Random Effects (RE) model and hence is capable of estimating time-invariant as well as rarely changing variables. Although a standard RE model exploits both within and between variation in estimation, it does not give separate estimates for the within and between variation in estimation, something the hybrid approach is capable of (Allison, 2009). Despite that this approach has been suggested before (e.g. Neuhaus and Kalbfleisch, 1998), it is hardly used in existing studies.

In the hybrid approach, we decompose the time-varying variables into a between $\left(\bar{x}_{i}=n_{i}^{-1} \sum_{t=1}^{n_{i}} x_{i t}\right)$ and a within $\left(x_{i t}-\bar{x}_{i}\right)$ component for each firm $i$. As a result, we estimate the following empirical equations (4) and (5) for all three crops: 


$$
\begin{aligned}
& \ln \left(P_{i t}\right)=\alpha+\beta_{1}\left(\text { Size }_{i t}-\overline{\operatorname{Size}}_{i}\right)+\beta_{2}{\overline{\operatorname{Size}_{i}}}+\beta_{3}\left(\operatorname{Size}^{2}{ }_{i t}-\overline{\operatorname{Size}^{2}}{ }_{i}\right)+\beta_{4} \overline{\operatorname{Size}}^{2}{ }_{i}+ \\
& \left.\beta_{5}{\left(\text { Intensity }_{i t}\right.}-\overline{\text { Intensity }}_{i}\right)+\beta_{6} \overline{\text { Intensity }}_{i}+\beta_{7}\left(L L C_{i t}-\overline{L L C}_{i}\right)+ \\
& \beta_{8} \overline{L L C}_{i}+\beta_{9}\left(\text { Light }_{i t}-\overline{\text { Light }}_{i}\right)+\beta_{10}\left(\operatorname{Light}_{i}\right)+\beta_{11}\left(T_{i}\right)+\sum_{t=1}^{7} \gamma_{t} \cdot \text { dyear }_{t}+\mu_{i}+\varepsilon_{i t} \\
& \ln \left(\frac{P_{i t}}{C_{i t}}\right)=\alpha+\beta_{1}\left(\text { Size }_{i t}-\overline{\text { Size }}_{i}\right)+\beta_{2}{\overline{\text { Size }_{i}}}_{i}+\beta_{3}\left(\text { Size }_{i t}^{2}-{\overline{\text { Size }^{2}}}_{i}\right)+\beta_{4}{\overline{\text { Size }^{2}}}_{i}+ \\
& \beta_{5}\left(\text { Intensity }_{i t}-\overline{\text { Intensity }}_{i}\right)+\beta_{6} \overline{\text { Intensity }}_{i}+\beta_{7}\left(L L C_{i t}-\overline{L L C}_{i}\right)+ \\
& \beta_{8} \overline{L L C}_{i}+\beta_{9}\left(\text { Light }_{i t}-\overline{\text { Light }}_{i}\right)+\beta_{10}\left(\text { Light }_{i}\right)+\beta_{11}\left(T_{i}\right)+\sum_{t=1}^{7} \gamma_{t} \cdot \text { dyear }_{t}+\mu_{i}+\varepsilon_{i t}
\end{aligned}
$$

Equation 4 uses the output prices as a dependent variable, which does not correct for differences in product quality caused by variations in the inputs used. Equation 5 therefore considers the price/cost ratio, which corrects for the influence of using higher-quality and more expensive inputs on the output prices. Including a set of dummy year-variables, with 2008 as base year, allows us to control for the influence of yearly price volatility and external market conditions. As a result, we can correct for annual differences in total quantity supplied or demanded in a specific year $\left(Q_{t}\right)$. Beyond, $T_{i}$ notes the amount of years a firm is included in the data-set. This allows us to correct for the unbalanced nature of the data, due to e.g. bankruptcies. Note that by including $T_{i}$, we also correct for any potential self-selection (see e.g. Baltagi, 2013).

Furthermore, the dependent variable is the natural logarithm of the observed output prices (4) and the ratio of the output price over average production costs per unit of production (5) for each firm $i$ in year $t$. We use natural logarithms for two reasons: first, given the large differences in absolute price levels between crops, it enables us to compare the effects between the different crops. Furthermore, it allows us to interpret the coefficients as a change in percentages of the mark-up, also allowing for a better comparison among crops.

In addition, a squared term of firm size is included in order to capture potential non-linear effects of firm size. By including a variable that measures the usage of artificial growing light, we are able to capture the influence of seasonal production aspects on differences in the output prices and price/cost ratio. This is the case as firms with a growing light installation are able to deliver products earlier in the season, and hence might benefit from different market prices. Note however that firms with growing light often face higher operational costs, hence the effect on the actual price/cost ratio might be less clear-cut.

Given the hybrid approach, the explanatory variables are all composed of two parts. The parameter of the first part (e.g. $\beta_{1}$ ) gives the estimate of the within effect 
of the respective variable. The parameter of the second part (e.g. $\beta_{2}$ ) provides the between effect. The term $a$ is the intercept, whereas the combined residual $\mu_{i}+\varepsilon_{i t}$ consists of an individual, time-invariant component $\mu_{i}$ which only varies between the units (firms), and a remaining error-component $\varepsilon_{i t}$.

Since a hybrid panel procedure relies largely on a random effects estimation, we first assess the validity of using a hybrid estimation by performing Hausman (1978) tests. The results in table A4.1 in the Appendix show the Hausman tests for a comparison of the estimates of a FE model and a RE model for all three crops. The results point at the validity of estimating a RE model for two out of the three models (see e.g. Wooldridge, 2010), and consequently also apply to the hybrid approach. For cucumber firms, however, the null hypothesis of consistent RE estimates is rejected. This means the results for cucumber firms presented in table 4.3 might be inconsistent. Therefore, we also provide the (consistent) estimates of the regular FE model in table A4.1 in the Appendix.

\subsection{Results}

\subsubsection{Results of the Markov transition analysis}

Table 4.2 presents the results of the Markov transition analysis. As can be read from the numbers on the diagonal, most firms remain in the same price-group throughout the whole observation period. For vine tomato firms, this is particularly the case for producers in both the highest (with a probability of 0.819 ) and the lowest $(0.588)$ price group. Beyond, we mainly see shifts to nearby price-categories, i.e. from state 2 to 1 and vice versa. This means that mostly the same firms obtain high output prices and the same firms obtain relatively low output prices, suggesting the price distribution in the market is not random, but is rather based on certain firm (or product) characteristics that are persistent throughout time. 
Table 4.2: Transition probabilities in three horticultural markets (standard errors in parentheses).

\begin{tabular}{|c|c|c|c|c|}
\hline \multicolumn{5}{|c|}{ Bell Pepper } \\
\hline Price Quartile & 1 & 2 & 3 & 4 \\
\hline \multirow[t]{2}{*}{1} & $0.396 * * *$ & $0.347 * * *$ & $0.183 * * *$ & 0.071 \\
\hline & $(0.040)$ & $(0.046)$ & $(0.047)$ & $(0.045)$ \\
\hline \multirow[t]{2}{*}{2} & $0.305^{* * *}$ & $0.316 * * *$ & $0.236 * * *$ & $0.148 * * *$ \\
\hline & $(0.037)$ & $(0.042)$ & $(0.043)$ & $(0.041)$ \\
\hline \multirow[t]{2}{*}{3} & $0.181^{* * *}$ & $0.239 * * *$ & $0.279 * * *$ & $0.269 * * *$ \\
\hline & $(0.036)$ & $(0.040)$ & $(0.041)$ & $(0.039)$ \\
\hline \multirow[t]{2}{*}{4} & $0.117 * *$ & $0.096 *$ & $0.299 * * *$ & $0.510 * * *$ \\
\hline & $(0.037)$ & $(0.042)$ & $(0.042)$ & $(0.040)$ \\
\hline \multicolumn{5}{|c|}{ Vine Tomato } \\
\hline Price Quartile & 1 & 2 & 3 & 4 \\
\hline \multirow[t]{2}{*}{1} & $0.588 * * *$ & $0.293 * * *$ & $0.078^{*}$ & 0.042 \\
\hline & $(0.029)$ & $(0.033)$ & $(0.032)$ & $(0.024)$ \\
\hline \multirow[t]{2}{*}{2} & $0.349 * * *$ & $0.438 * * *$ & $0.157 * * *$ & 0.036 \\
\hline & $(0.027)$ & $(0.031)$ & $(0.030)$ & $(0.023)$ \\
\hline \multirow[t]{2}{*}{3} & $0.062 *$ & $0.258 * * *$ & $0.569 * * *$ & $0.100 * * *$ \\
\hline & $(0.028)$ & $(0.032)$ & $(0.031)$ & $(0.023)$ \\
\hline \multirow[t]{2}{*}{4} & 0.000 & 0.008 & $0.194 * * *$ & $0.819 * * *$ \\
\hline & $(0.028)$ & $(0.032)$ & $(0.031)$ & $(0.023)$ \\
\hline \multicolumn{5}{|c|}{ Cucumber } \\
\hline Price Quartile & 1 & 2 & 3 & 4 \\
\hline \multirow[t]{2}{*}{1} & $0.551^{* * *}$ & $0.259 * * *$ & $0.120 *$ & $0.123 * *$ \\
\hline & $(0.032)$ & $(0.048)$ & $(0.050)$ & $(0.045)$ \\
\hline \multirow[t]{2}{*}{2} & $0.186 * * *$ & $0.415^{* * *}$ & $0.283 * * *$ & $0.101 * *$ \\
\hline & $(0.025)$ & $(0.037)$ & $(0.038)$ & $(0.034)$ \\
\hline \multirow[t]{2}{*}{3} & $0.153 * * *$ & $0.226 * * *$ & $0.324 * * *$ & $0.228 * * *$ \\
\hline & $(0.025)$ & $(0.037)$ & $(0.039)$ & $(0.035)$ \\
\hline \multirow[t]{2}{*}{4} & $0.108 * * *$ & $0.098 *$ & $0.271 * * *$ & $0.547 * * *$ \\
\hline & $(0.026)$ & $(0.039)$ & $(0.040)$ & $(0.036)$ \\
\hline
\end{tabular}

Source: Authors, based on Rabobank (2016a).

Note: $*, * *$ and $* * *$ represent statistical significance at respectively the $5 \%, 1 \%$ and $0.1 \%$ level.

The transition matrix for cucumber firms sketches roughly the same picture, with the highest probabilities on the diagonal, implying that firms are most likely to remain in their initial price group. The diagonal values however tend to be a bit lower as compared to the vine tomato producers, implying more transitions between price groups. Yet, this is as expected as cucumber is known to be a more homogenous crop (Vermeer, 2009), whereas vine tomato is highly differentiated, with room for producers to distinguish themselves by growing a product with premium characteristics. As a result, it is more difficult for cucumber firms to stay in the high price group throughout the whole period, and transitions between different price quartiles are more likely. Nevertheless, nearly half of the cucumber firms remain in their own price group. So even in markets with relatively uniform products, the same producers are able to remain in the high quartile of the price distribution.

In the market for bell pepper again most of the firms that were originally in the highest or lowest quartile remain there throughout the whole period. Despite the underlying differences between the different crops, the distribution of firms based on 
their output price is quite persistent over time, indicating structural differences between primary producers.

\subsubsection{Results of the hybrid panel approach}

For each crop, table 4.3 shows the results of the hybrid panel estimation of equation (3). In particular the significant year effects stand out, showing that price volatility is very much present in these markets. In 2009, e.g. the average annual output prices for bell pepper firms are $38.3 \%$ lower as compared to the baseline level of 2008 . Nevertheless, also factors that differ between firms are found to have a significant association with the obtained output prices. These variables are divided in a between, or mean $(m)$, effect and a within, or differenced (d), effect. The differenced effect takes into account the variation within a firm over time, while the between effect shows the differences between firms.

We find significant between effects of the mean firm size on the prices for bell pepper and vine tomato firms, implying that on average larger firms are able to obtain higher prices. For vine tomato firms, we find that for every hectare a firm is larger, there is an association with a $1.4 \%$ increase in output prices. Note however that this effect of size is only visible for the differences between firms, implying we do not find a direct association between firms expanding in size and output prices. Furthermore, the insignificance of the quadratic effects gives no indication of any potential nonlinear effects. ${ }^{7}$

Beyond, an increased production intensity is associated with a lower annual output price, indicating that firms aimed at high quantities often receive lower output prices. The usage of growing light in contrast is associated with higher prices for bell pepper and vine tomato firms, confirming our hypothesis that growing light enables to supply earlier in the season at higher prices. For cucumber firms, the effect of growing light is not statistically significant. A possible explanation is that only very few firms use artificial growing light (as pointed out in table 4.1 , only 6 and $9 \%$ of these producers, respectively), therefore leading to low variation in the variable itself. ${ }^{8}$ Furthermore, the number of years a firm is included in the dataset is only positively associated with output prices in the case of bell pepper firms. This suggests that bell pepper firms that receive lower prices drop out from the sample sooner, which may be due to bankruptcies or refusal of loan extensions, e.g. due to insufficient business plans.

\footnotetext{
${ }^{7}$ Given that firm size and the outcome variables might be endogenously related, we would like to stress that we do not claim any causal relations, but rather prove a strong association in this section between the identified firm and product factors and the obtained firm-specific output prices and price/cost ratios.

${ }^{8}$ Note that for this reason, the differenced effect of growing light on the price/cost ratio is not estimated for cucumber producers. As shown in table 4.1, the within variation on this variable is very low. Therefore, firms barely change over time from having growing light to not having growing light and vice versa.
} 
Table 4.3: Parameter estimates for factors explaining output price differences in Dutch horticulture.

\begin{tabular}{|c|c|c|c|}
\hline & Bell Pepper & Vine Tomato & Cucumber \\
\hline \multirow[t]{2}{*}{ Size (ha) (d) } & -0.002 & -0.014 & 0.020 \\
\hline & $(0.003)$ & $(0.008)$ & $(0.024)$ \\
\hline \multirow[t]{2}{*}{ Size (ha) (m) } & $0.004 *$ & $0.013^{*}$ & 0.025 \\
\hline & $(0.002)$ & $(0.006)$ & $(0.031)$ \\
\hline \multirow[t]{2}{*}{ Size*Size (ha) (d) } & -0.00004 & 0.0002 & -0.0013 \\
\hline & $(0.000)$ & $(0.000)$ & $(0.002)$ \\
\hline \multirow[t]{2}{*}{ Size*Size (ha) (m) } & -0.00008 & -0.0001 & -0.0023 \\
\hline & $(0.000)$ & $(0.000)$ & $(0.0029)$ \\
\hline \multirow{2}{*}{$\begin{array}{l}\text { Intensity (production in } 10 \mathrm{~kg} \text { per } \\
\text { square meter) (d) }\end{array}$} & $-0.105^{* * *}$ & $-0.146 * * *$ & $-0.024 * * *$ \\
\hline & $(0.018)$ & $(0.012)$ & $(0.001)$ \\
\hline \multirow{2}{*}{$\begin{array}{l}\text { Intensity (production in } 10 \mathrm{~kg} \text { per } \\
\text { square meter) }(\mathrm{m})\end{array}$} & $-0.140 * * *$ & $-0.260 * * *$ & $-0.026 * * *$ \\
\hline & $(0.019)$ & $(0.015)$ & $(0.001)$ \\
\hline \multirow[t]{2}{*}{ LLC (d) } & 0.006 & 0.003 & 0.008 \\
\hline & $(0.014)$ & $(0.029)$ & $(0.028)$ \\
\hline \multirow[t]{2}{*}{$\operatorname{LLC}(\mathrm{m})$} & -0.025 & -0.037 & 0.086 \\
\hline & $(0.014)$ & $(0.038)$ & $(0.046)$ \\
\hline \multirow[t]{2}{*}{ Growing light (d) } & $0.162 *$ & 0.034 & $\#$ \\
\hline & $(0.075)$ & $(0.040)$ & \\
\hline \multirow[t]{2}{*}{ Growing light (m) } & $0.042 *$ & $0.226 * * *$ & 0.068 \\
\hline & $(0.018)$ & $(0.048)$ & $(0.109)$ \\
\hline \multirow[t]{2}{*}{$\mathrm{T}$} & $0.009 * * *$ & 0.006 & 0.006 \\
\hline & $(0.002)$ & $(0.008)$ & $(0.008)$ \\
\hline \multirow[t]{2}{*}{ Year2009 } & $-0.384 * * *$ & $-0.193 * * *$ & $-0.129 * * *$ \\
\hline & $(0.011)$ & $(0.021)$ & $(0.017)$ \\
\hline \multirow[t]{2}{*}{ Year2010 } & $-0.084 * * *$ & $0.124 * * *$ & $0.154 * * *$ \\
\hline & $(0.011)$ & $(0.021)$ & $(0.019)$ \\
\hline \multirow[t]{2}{*}{ Year2011 } & $-0.160 * * *$ & $-0.248 * * *$ & $-0.178 * * *$ \\
\hline & $(0.012)$ & $(0.021)$ & $(0.020)$ \\
\hline \multirow[t]{2}{*}{ Year2012 } & $-0.092 * * *$ & $0.061 * *$ & $0.056 * *$ \\
\hline & $(0.012)$ & $(0.021)$ & $(0.021)$ \\
\hline \multirow[t]{2}{*}{ Year2013 } & $0.081 * * *$ & $-0.169 * * *$ & $0.117 * * *$ \\
\hline & $(0.012)$ & $(0.022)$ & $(0.022)$ \\
\hline \multirow[t]{2}{*}{ Year2014 } & $-0.148 * * *$ & -0.040 & $-0.077 * *$ \\
\hline & $(0.014)$ & $(0.025)$ & $(0.026)$ \\
\hline \multirow[t]{2}{*}{ Year2015 } & $0.041 *$ & $0.075^{*}$ & $0.255^{* * *}$ \\
\hline & $(0.017)$ & $(0.030)$ & $(0.032)$ \\
\hline \multirow[t]{2}{*}{ Intercept } & $0.545 * * *$ & $1.045 * * *$ & $-1.112 * * *$ \\
\hline & $(0.061)$ & $(0.095)$ & $(0.129)$ \\
\hline $\mathrm{N}$ & 698 & 455 & 236 \\
\hline$n$ & 142 & 96 & 64 \\
\hline $\mathrm{R}^{2}$ within & 0.801 & 0.705 & 0.813 \\
\hline $\mathrm{R}^{2}$ between & 0.449 & 0.821 & 0.305 \\
\hline $\mathrm{R}^{2}$ overall & 0.732 & 0.792 & 0.518 \\
\hline Wald $x^{2}$ & $2262.35 * * *$ & $1223.86 * * *$ & $720.36 * * *$ \\
\hline Difference-indicators $\left(x^{2}\right)$ & $41.46 * * *$ & $153.33 * * *$ & $23.48 * * *$ \\
\hline Mean-indicators $\left(x^{2}\right)$ & $61.59 * * *$ & $354.94 * * *$ & $17.79 * *$ \\
\hline
\end{tabular}

Source: Authors, based on Rabobank (2016a).

Notes: d denotes within difference. $*, * *$ and $* * *$ represent statistical significance at respectively the $5 \%, 1 \%$ and $0.1 \%$ level. The Wald tests have a $x^{2}$-distribution with 17 (vine tomato and bell pepper) or 16 (cucumber) degrees of freedom. \# = not estimated due to lack of within-changes. 
The results in table 4.3 however do not yet correct for differences in product quality caused by variations in the inputs used. Table 4.4 therefore shows the results of the hybrid panel estimation on the price/cost ratios (equation 4). Again, year effects play an important role. This also contributes to the high explanatory value of the within variation of the estimated models. Yet, the results also show the significant influence of various firm characteristics. We find a significant and positive effect in all three markets for the initial size-effect, implying that larger firms are able to obtain a higher mark-up as compared to smaller firms. E.g. for bell pepper firms, we find that if a firm increases in size with 1 ha during the observed period, this is associated with a $1.7 \%$ increase in the mark-up. The mean effect points at the differences between firms and shows that, on average, larger firms are able to obtain a $1.4 \%$ increase in the markup per hectare compared to other smaller firms. The squared term of firm size however is negative in most markets, implying that this effect flattens for the largest firms in all the subsamples. For vine tomato producers, this effect is particularly driven by the differences between firms. As can be read in table 4.1, the differences in the between standard deviation are also much larger for vine tomato producers as compared to e.g. cucumber firms, pointing at large differences in firm size between firms in tomato production.

These positive effects for firm size on the output prices and the price/cost ratio are in line with earlier studies in other agricultural sectors (e.g. Falkowski et al. (2017) on dairy firms and Karagiannis et al. (2018) in the brewing sector), showing that larger firms are able to obtain price premiums. Furthermore, the consistent positive signs for production intensity show that firms with a high production intensity are able to gain relatively higher mark-ups. Although these firms received lower average output prices (as shown in table 4.3), they are able to achieve higher ratios. This can be explained due to their lower operational costs per unit production. Surprisingly, the effect of growing light on the ratio is either not statistically significant or negative in all markets. Apparently the higher output prices for these firms (as shown in table 4.3) are outweighed by the higher operational costs involved.

Beyond, the LLC-variable never has a positive effect on the price/cost ratio. This implies that in none of the studied markets, firms with a formal organizational structure are able to obtain a significantly higher ratio compared to classical family farms. Nevertheless, the significant and positive effect of firm size, suggests the ability for firms to obtain on average higher price mark-ups based on their size. Furthermore, for both bell pepper and cucumber firms, we observe that firms that are only present in the data for a shorter number of years obtain lower ratios. 
Table 4.4: Parameter estimates for factors explaining price-cost ratio differences in Dutch horticulture.

\begin{tabular}{|c|c|c|c|}
\hline & Bell Pepper & Vine Tomato & Cucumber \\
\hline \multirow[t]{2}{*}{ Size (ha) (d) } & $0.017 * * *$ & -0.0005 & $0.198 * * *$ \\
\hline & $(0.005)$ & $(0.011)$ & $(0.037)$ \\
\hline \multirow[t]{2}{*}{ Size (ha) (m) } & $0.014 * * *$ & $0.015^{*}$ & -0.052 \\
\hline & $(0.004)$ & $(0.007)$ & $(0.028)$ \\
\hline \multirow[t]{2}{*}{ Size*Size (ha) (d) } & -0.0001 & 0.0001 & $-0.012 * * *$ \\
\hline & $(0.000)$ & $(0.000)$ & $(0.003)$ \\
\hline \multirow[t]{2}{*}{ Size*Size (ha) (m) } & $-0.0002 *$ & $-0.0003 *$ & $0.005^{*}$ \\
\hline & $(0.000)$ & $(0.000)$ & $(0.002)$ \\
\hline Intensity (production in $10 \mathrm{~kg}$ per & $0.132 * * *$ & 0.020 & $0.023 * * *$ \\
\hline$\left.m^{2}\right)(d)$ & $(0.031)$ & $(0.017)$ & $(0.007)$ \\
\hline Intensity (production in $10 \mathrm{~kg}$ per & $0.144 * * *$ & $0.060 * *$ & 0.008 \\
\hline$\left.m^{2}\right)(m)$ & $(0.040)$ & $(0.019)$ & $(0.006)$ \\
\hline \multirow[t]{2}{*}{ LLC (d) } & -0.024 & $-0.117 * *$ & $-0.086 *$ \\
\hline & $(0.025)$ & $(0.041)$ & $(0.043)$ \\
\hline \multirow[t]{2}{*}{$\operatorname{LLC}(\mathrm{m})$} & -0.013 & -0.028 & -0.041 \\
\hline & $(0.030)$ & $(0.047)$ & $(0.042)$ \\
\hline \multirow[t]{2}{*}{ Growing light (d) } & -0.097 & $-0.154 * *$ & $\#$ \\
\hline & $(0.128)$ & $(0.057)$ & \\
\hline \multirow[t]{2}{*}{ Growing light (m) } & $-0.119 * *$ & 0.010 & -0.042 \\
\hline & $(0.039)$ & $(0.060)$ & $(0.096)$ \\
\hline \multirow[t]{2}{*}{$\mathrm{T}$} & $0.012 *$ & -0.012 & 0.019* \\
\hline & $(0.005)$ & $(0.010)$ & $(0.007)$ \\
\hline \multirow[t]{2}{*}{ Year2009 } & $-0.326 * * *$ & $-0.160 * * *$ & $-0.103 * * *$ \\
\hline & $(0.019)$ & $(0.031)$ & $(0.025)$ \\
\hline \multirow[t]{2}{*}{ Year2010 } & -0.010 & $0.260 * * *$ & $0.200 * * *$ \\
\hline & $(0.020)$ & $(0.030)$ & $(0.028)$ \\
\hline \multirow[t]{2}{*}{ Year2011 } & $-0.107 * * *$ & $-0.162 * * *$ & $-0.084 * *$ \\
\hline & $(0.021)$ & $(0.030)$ & $(0.029)$ \\
\hline \multirow[t]{2}{*}{ Year2012 } & $-0.112 * * *$ & 0.021 & 0.034 \\
\hline & $(0.021)$ & $(0.031)$ & $(0.030)$ \\
\hline \multirow[t]{2}{*}{ Year2013 } & 0.006 & $-0.241 * * *$ & 0.051 \\
\hline & $(0.022)$ & $(0.032)$ & $(0.032)$ \\
\hline \multirow[t]{2}{*}{ Year2014 } & $-0.151 * * *$ & $-0.092 * *$ & $-0.084 *$ \\
\hline & $(0.024)$ & $(0.035)$ & $(0.038)$ \\
\hline \multirow[t]{2}{*}{ Year2015 } & 0.026 & 0.049 & $0.213^{* * *}$ \\
\hline & $(0.030)$ & $(0.042)$ & $(0.047)$ \\
\hline \multirow[t]{2}{*}{ Intercept } & $-0.269 *$ & -0.122 & -0.005 \\
\hline & $(0.124)$ & $(0.121)$ & $(0.119)$ \\
\hline $\mathrm{N}$ & 698 & 455 & 236 \\
\hline$n$ & 142 & 96 & 64 \\
\hline $\mathrm{R}^{2}$ within & 0.480 & 0.567 & 0.636 \\
\hline $\mathrm{R}^{2}$ between & 0.268 & 0.292 & 0.315 \\
\hline $\mathrm{R}^{2}$ overall & 0.402 & 0.390 & 0.490 \\
\hline Wald $x^{2}$ & $548.79 * * *$ & $487.10 * * *$ & $312.180 * * *$ \\
\hline Difference-indicators $\left(x^{2}\right)$ & $48.80 * * *$ & $15.60 * *$ & $52.67 * * *$ \\
\hline Mean-indicators $\left(x^{2}\right)$ & $31.67 * * *$ & $18.96 * * *$ & 6.23 \\
\hline
\end{tabular}

Source: Authors, based on Rabobank (2016a).

Notes: d denotes within difference. $*, * *$ and $* * *$ represent statistical significance at respectively the $5 \%, 1 \%$ and $0.1 \%$ level. The Wald tests have a $X^{2}$-distribution with 17 (vine tomato and bell pepper) or 16 (cucumber) degrees of freedom. \# = not estimated due to lack of within-changes. 


\subsection{Conclusion and discussion}

In this chapter we analyse firm-level data on output prices for cucumber, vine tomato and bell pepper firms in order to study the dispersion of these prices, their persistence over time as well as the ability of individual primary producers to obtain price-premia and to influence their price/cost ratio. Our data shows clear patterns in price dispersion among primary producers. The results not only show a considerable price volatility across different periods (as studied extensively in the agricultural literature, e.g. Karali and Power, 2013; Serra and Gil, 2003), but also point at substantial differences in output prices within the same period between firms. A Markov transition analysis shows that the position of firms in the underlying rank of the price distribution is rather stable over time, implying that the same firms are structurally able to obtain higher output prices. Our findings show that the persistence of these price differences between firms are particularly visible in markets for differentiated products, such as tomatoes, yet also hold for more homogenous products as cucumber. Beyond, we find that a larger firm size is associated with higher average output prices in most of the studied markets. Moreover, after controlling for the potential influence of quality differences in the output prices, our findings also show that firm size is associated with higher price/cost ratios.

In line with other studies (e.g. Russo and Goodhue, 2018; Li et al., 2006), we find empirical inconsistencies in food prices which deviate from the expectations derived from perfect competition models. Recent developments, such as the increased power concentration of retailers (Hovhannisyan et al., 2018), led to an increased attention towards farmer-retail relations in agricultural supply chains (Sexton, 2013). Most of these studies however neglect potential output price differences between primary producers, e.g. due to price premia. Our results show the relevance of considering price differences between primary producers. This is particularly the case due to the considerable differences in the output prices they receive, and the more so given that this price distribution between firms is persistent over a longer period.

The use of a hybrid panel model enabled us to estimate the effect on the price/cost ratio of firm characteristics that differ considerably between firms, but remain relatively stable over time. This in contrast to traditional FE models that are only capable of estimating variation within firms (e.g. Kohler and Kreuter, 2005). Decomposing the total effect of the explanatory variables into a differenced and mean effect, allows to estimate the effect of factors that mainly differ between firms, as well as variations over time on the output prices and the price/cost ratio. For all studied markets, our results e.g. show that increases in firm size are significantly associated with higher price/cost ratios, although this effect mostly flattens off for the very largest firms in the sample. According to e.g. Sauer et al. (2012) and Falkowski et al. (2017) larger firms might benefit from the reduced transaction costs for retail partners while transacting with larger primary producers. Our results therefore point out that 
differences between primary producers should not be neglected when studying the power balance in the food supply chain.

In addition, the structural differences in prices obtained between firms further point that there may be further implications for the income position of firms. This holds in particular in liberalized agricultural markets where income largely depends on the obtained output prices. Traditionally, economists focused on economies of scale for explaining a reduction in production costs (e.g. De Roest et al., 2018). Yet, our results show that larger firms on average have additional benefits in marketing their products, generating further incentives for increasing the scale of operation. This finding is also in line with the results of recent empirical studies on various other agricultural sectors (Sauer et al., 2012; Falkowski et al., 2017; Karagiannis et al., 2018). Beyond, recent empirical research also shows that these benefits are not only visible at output markets, as larger firms are also found to be able to obtain discounts when buying inputs from input suppliers (Malak-Rawlikowska et al., 2019). Consequently, this might put further pressure on the current structure of the sector, particularly concerning the economic viability of smaller firms. Further research however would be needed for a better understanding of these potential dynamics at sectoral level.

An important limitation of our approach is that we are not able to identify and assess all potential factors associated with price heterogeneity. Due to data limitations, we were e.g. not able to assess the influence of a firm's reputation or export position. Moreover, the generalizability of our results towards other agricultural sectors is unclear. The Dutch horticultural sector is characterized by a relatively large share of large and modern firms, all producing products which can most often be directly consumed by consumers (Beausang et al., 2017). In other agricultural sectors, such as dairy farming, with a larger dependence on processing industries, these dynamics may be different though. However, given the large investments and increases in e.g. firm size in other agricultural sectors (see e.g. Clapp, 2019; Sexton, 2013), these developments are likely to enhance differences between primary producers in other sectors as well.

Despite the considerable differences between firms and the structural character of the underlying price distribution in the studied markets, it is important to note that the influence of external year effects is strongly prevalent in the markets for fresh vegetables. This is particularly visible as a result of demand shocks caused by e.g. the outbreak of Escherichia Coli (Perez-Mesa et al., 2019). As a result, all producers regardless of their relative position in the price distribution - are still to a large extent subject to external volatility in the market for fresh products. This in turn complicates the further market orientation of primary producers. 


\section{Appendix}

Table A4.1. Results of the FE regression on determinants of price/cost ratios for horticultural products.

\begin{tabular}{|c|c|c|c|}
\hline & Bell Pepper & Vine Tomato & Cucumber \\
\hline Size (ha) & $\begin{array}{l}0.018^{* * * *} \\
(0.005)\end{array}$ & $\begin{array}{l}0.0005 \\
(0.011)\end{array}$ & $\begin{array}{c}0.196 * * * \\
(0.038)\end{array}$ \\
\hline Size $\left(h^{2}\right)$ & $\begin{array}{c}-0.0001 \\
(0.000)\end{array}$ & $\begin{array}{l}0.0001 \\
(0.000)\end{array}$ & $\begin{array}{c}-0.012 * * * \\
(0.003)\end{array}$ \\
\hline Intensity ( production in $10 \mathrm{~kg}$ per $\mathrm{m}^{2}$ ) & $\begin{array}{l}0.134 * * * \\
(0.031)\end{array}$ & $\begin{array}{c}0.021 \\
(0.017)\end{array}$ & $\begin{array}{l}0.023 * * \\
(0.007)\end{array}$ \\
\hline LLC & $\begin{array}{l}-0.023 \\
(0.025)\end{array}$ & $\begin{array}{c}-0.113 * * \\
(0.041)\end{array}$ & $\begin{array}{l}-0.093^{*} \\
(0.044)\end{array}$ \\
\hline Growing light & $\begin{array}{l}-0.101 \\
(0.126)\end{array}$ & $\begin{array}{c}-0.143 * \\
(0.057)\end{array}$ & \# \\
\hline Year2009 & $\begin{array}{c}-0.325 * * * \\
(0.019)\end{array}$ & $\begin{array}{c}-0.161 * * * \\
(0.030)\end{array}$ & $\begin{array}{c}-0.099 * * * \\
(0.027)\end{array}$ \\
\hline Year2010 & $\begin{array}{c}-0.013 * * * \\
(0.019)\end{array}$ & $\begin{array}{c}0.254 * * * \\
(0.030)\end{array}$ & $\begin{array}{c}0.204 * * * \\
(0.030)\end{array}$ \\
\hline Year2011 & $\begin{array}{c}-0.107 * * * \\
(0.021)\end{array}$ & $\begin{array}{c}-0.164 * * * \\
(0.030)\end{array}$ & $\begin{array}{l}-0.079 * \\
(0.032)\end{array}$ \\
\hline Year2012 & $\begin{array}{c}-0.118 * * * \\
(0.021)\end{array}$ & $\begin{array}{c}0.019 \\
(0.031)\end{array}$ & $\begin{array}{c}0.045 \\
(0.033)\end{array}$ \\
\hline Year2013 & $\begin{array}{c}0.001 \\
(0.022)\end{array}$ & $\begin{array}{c}-0.245 * * * \\
(0.032)\end{array}$ & $\begin{array}{c}0.063 \\
(0.034)\end{array}$ \\
\hline Year2014 & $\begin{array}{c}-0.162 * * * \\
(0.024)\end{array}$ & $\begin{array}{c}-0.107 * * \\
(0.036)\end{array}$ & $\begin{array}{l}-0.063 \\
(0.041)\end{array}$ \\
\hline Year2015 & $\begin{array}{c}0.019 \\
(0.030)\end{array}$ & $\begin{array}{c}0.027 \\
(0.043)\end{array}$ & $\begin{array}{c}0.236 * * * \\
(0.051)\end{array}$ \\
\hline Intercept & $\begin{array}{c}0.192 \\
(0.101)\end{array}$ & $\begin{array}{c}0.144 \\
(0.117)\end{array}$ & $\begin{array}{c}-0.735^{* * *} * \\
(0.155)\end{array}$ \\
\hline $\mathrm{N}$ & 700 & 459 & 236 \\
\hline $\mathrm{n}$ & 142 & 98 & 64 \\
\hline $\begin{array}{l}\mathrm{R}^{2} \text { within } \\
\mathrm{R}^{2} \text { between } \\
\mathrm{R}^{2} \text { overall } \\
\mathrm{F}\end{array}$ & $\begin{array}{c}0.481 \\
0.203 \\
0.344 \\
42.13^{* * *}\end{array}$ & $\begin{array}{c}0.567 \\
0.099 \\
0.276 \\
38.17 * * *\end{array}$ & $\begin{array}{c}0.636 \\
0.050 \\
0.167 \\
25.63^{* * *}\end{array}$ \\
\hline Hausman tests & $\lambda^{2}{ }_{(12)} 16.75$ & $\lambda^{2}{ }_{(12)} 19.79$ & $\lambda^{2}(11) 35.62^{* *}$ \\
\hline
\end{tabular}

Source: Authors, based on Rabobank (2016a).

Notes: $*, * *$ and $* * *$ represent statistical significance at respectively the $5 \%, 1 \%$ and $0.1 \%$ level. \# = not estimated due to lack of within-changes. The Hausman tests provide the $\lambda^{2}$ test statistic for a comparison of the FE and a RE model. 
Chapter 5 - Firm-specific responses to energy policies 


\section{Chapter 5}

\section{FIRM-SPECIFIC RESPONSES TO ENERGY POLICIES IN DUTCH HORTICULTURE}




\section{FIRM-SPECIFIC RESPONSES TO ENERGY POLICIES IN DUTCH HORTICULTURE ${ }^{9}$}

ABSTRACT: Reducing the usage of fossil fuels is a central issue in ongoing policy debates. This in particular holds for Dutch horticulture, given its energy intensive production. We analyse differences in energy usage and price responsiveness of horticultural firms by estimating energy demand functions using a Bayesian Random Coefficient Model. Beyond, the effects of a proposed energy tax are assessed. Allowing for firm-specific energy price coefficients gives a better model fit compared to conventional models with fixed slope parameters. This confirms that firms respond differently to energy prices, which is taken into account in simulating the effects of more restrictive energy policies. The results show larger-sized firms use less gas per square meter, yet also point at a considerable spread in additional energy expenses between firms.

\footnotetext{
${ }^{9}$ This chapter is based on the article: Los, E.J., Gardebroek, C. and Huirne, R.B.M. (2020). Firm-specific responses to energy policies in Dutch horticulture. Accepted for publication at European Review of Agricultural Economics, forthcoming.
} 


\subsection{Introduction}

Agricultural firms face strong societal pressure to take the environmental effects of their production into account (Pons et al., 2013; Nishitana et al., 2014). This is particularly the case as new climate policies stress that urgent actions are required in order to reduce global warming (Falkner, 2016). Reducing greenhouse gas emissions in the coming decades is therefore a main policy concern (Cuchiella et al., 2018). Consequently, there are strong political wishes to reduce the extraction and consumption of fossil fuels and spur the transition towards the use of sustainable energy (Mouter et al., 2018).

The aim to reduce greenhouse gasses also affects the agricultural sector and potentially the incomes of primary producers (see e.g. Finger and El Benni, 2020). This holds in particular for glasshouse horticultural production in the Netherlands, where energy is among the main inputs (Aramyan et al., 2007). In recent decades, substantial steps have already been taken towards a more sustainable production in Dutch horticulture. Many firms have invested in energy-saving technologies, such as heat storage, co-generators and energy screens (Aramyan et al., 2007; Pietola and Oude Lansink, 2006). On the other hand, an increasing number of firms uses artificial growing light installations in order to prolong the growing season of the plants, leading to additional energy usage (Van der Velden and Smit, 2018). The presence of these heterogeneous production technologies goes together with large differences between firms in their production structure (Goncharova et al., 2008). The Dutch horticultural sector is characterized by the co-existence of both smaller family farms and larger modern firms with a more distinct organizational structure. Firms also differ in their production orientation, with some focusing on producing high-quality products for niche markets and others focusing at standard products at lowest possible costs. Given the underlying heterogeneity, it is likely that firms respond differently towards changes in the institutional framework, such as more restrictive climate policies (Finger and El Benni, 2020; Reidsma et al., 2010).

Most studies that focus on the impact of climate policies on agricultural incomes (e.g. Baker et al., 2010; Babcock, 2015) do so at an aggregate level. Studies using partial equilibrium (PE) or computable general equilibrium (CGE) models are in particular suited to study impacts of policy interventions at regional or global level (e.g. Beckman et al., 2012; Robertson et al., 2013). Studies analysing the heterogeneous impact of these policies at disaggregated level or on different types of firms are still scarce (e.g. Berger and Troost, 2014). Moreover, panel data models on agricultural production often overlook potential (unobserved) heterogeneous responses to policy and price changes. Most of these models implicitly assume that primary producers respond homogeneously to economic incentives given that the effect of e.g. netput prices are most often specified as a fixed slope coefficient equal across all firms (Koutchadé et al., 2018). 
In this study we investigate the potentially heterogeneous energy demand responses and the resulting income effects of the policy proposals in the Dutch Climate Agreement (2019). These proposals entail, amongst others, additional taxation on the use of natural gas and hence a change in the relative prices of energy inputs. Firms may respond heterogeneously to these proposals since they often differ in production methods, have different energy systems and different contracts with energy suppliers. ${ }^{10}$ We first estimate demand functions derived from a normalized quadratic cost function for natural gas and electricity using panel data from Dutch horticultural firms. In order to capture heterogeneity in energy demand, we apply a Bayesian random coefficient model for estimating firm-specific responses to changes in relative input prices. Second, using the estimated demand functions we simulate the heterogeneous income effects of these climate policies for individual firms. Obtaining firm-specific price coefficients allows us to see how firms respond differently to relative input price changes. In other words, do certain firms react more strongly towards such price increases than others, e.g. because they have more energy-intensive production? As a result, it also allows us to predict the potentially varying effects on the additional firm expenses in the second step of the analysis. This provides policymakers with more accurate and detailed estimates of the income effects of the proposed energy taxation.

The contribution of this chapter to the literature is twofold. First, we estimate a system of demand equations using a Bayesian random coefficient model (Gardebroek, 2006) that allows us to obtain firm-specific price coefficients in the context of relatively short panels. In contrast to conventional random coefficient models (e.g. Swamy, 1970), we allow for the inclusion of prior information, e.g. in the form of theoretically plausible values for price coefficients. This method allows for estimating potentially heterogeneous production effects of changes in relative (input) prices as a result of e.g. policy interventions. Second, we study the short-term heterogeneous effect of stricter energy policies on energy usage and firm expenses. Most studies only focus on aggregate effects or assume homogenous responses among firms.

The remainder of the chapter is organized as follows. Section 5.2 describes the context of energy usage in Dutch horticulture, with particular attention for the proposed climate-related policy interventions. Based on this, a theoretical model is specified in section 5.3 , followed by a discussion of the data-set in section 5.4 and the estimation procedures in section 5.5. The results are presented in section 5.6, followed by the main conclusions in the final section of the chapter.

\footnotetext{
${ }^{10}$ Contracts between primary producers and energy suppliers can differ in e.g. the duration and closing date of
} a contract, as well as certain terms and conditions such as delivery with fixed or flexible annual volumes. 


\subsection{Energy usage and policy interventions in Dutch horticulture}

\subsubsection{Energy usage in Dutch horticulture}

In order to cultivate fruits and vegetables that otherwise would only grow in warmer climates, glasshouses in a relatively cold climate require energy for heating. Hence, energy inputs form a large share of the total inputs, comprising roughly $20 \%$ of the total production costs (Van der Velden et al., 2014). In past decades primary producers already invested considerably in energy saving technologies. In particular the combined heat and power engine has been widely introduced in Dutch horticulture. A combined heat and power engine allows for so-called decentral cogeneration, meaning electricity and heat are both generated at individual firms. As a result, heat that would get lost in case of centrally generated electricity is no longer lost and can be used in order to heat the glasshouses (Aramyan et al., 2007). The electricity generated can either be used at the firm itself or can be supplied back to the electricity grid. Furthermore, investments in other energy-saving technologies, such as energy screens, are widespread. These screens allow for a better insulation of the glasshouse, as heat is retained (Aramyan et al., 2007).

Contrarily, the adoption of technologies consuming additional energy is also visible. An example is the usage of artificial growing light, which is used to extend the growing season of plants. While most products under regular circumstances can only be harvested from (late) spring until autumn, the use of artificial light leads to earlier plant growth, allowing for earlier harvest. This implies that primary producers can already sell their products during periods when prices are higher (European Commission, 2019). This however leads to a larger electricity bill and additional emissions.

Next to differences in technology, the energy intensity and environmental effects of horticultural production are also expected to vary between individual firms due to differences in firm structure (e.g. Balmford et al., 2018; Ren et al., 2019). With considerable heterogeneity in firm size and structure in Dutch horticulture, differences in energy usage and responses to energy prices between firms could be substantial. Many studies e.g. assessed the relation between input usage and farm size. Yet, the findings regarding the effects of firm size on input use are mixed (Alvarez and Aris, 2004; Gailhard and Bojnec, 2015).

\subsubsection{Climate-related policy interventions in Dutch horticulture}

As outlined above, firms are likely to differ in energy usage due to differences in firm structure, production technologies and energy contracts. Hence, more restrictive climate policies may affect horticultural firms differently. Despite such differences horticultural firms can in general expect an increase in energy costs, as governments aim to reduce the usage of fossil fuels among others via price increases. 
In order to reach this reduction, the Dutch government signed a national climate agreement, which aims for a fossil free and climate neutral production in 2050 (De Lauwere et al., 2019). The main overall target is to reduce the amount of greenhouse gas emissions by $49 \%$ in 2030 and $95 \%$ in 2050 compared to the level of 1990 . For the horticultural sector, the total intended emission reduction is scheduled between 1.8 and 2.9 megaton $\mathrm{CO}_{2}$ equivalents. In the long run, heating for glasshouse horticulture has to come from alternative sources as geothermal heat, waste heat and electric heating (Climate Agreement, 2019). In the short-run, however, there is no strict regulation that forces Dutch horticultural producers to abstain from using natural gas in production (De Lauwere et al., 2019). In order to reduce the usage of gas for heating glasshouses and to incentivize the transition towards more sustainable energy sources, it has been agreed to increase taxes on natural gas in 2020 with $€ 0.04$ per cubic meter of gas, or equivalently $€ 1.264$ per gigajoule (Climate Agreement, 2019) $)^{11}$. Given the average gas price in recent years of around $€ 10$ per gigajoule (Statistics Netherlands, 2019a), this corresponds to an increase of roughly $12 \%$ in the price of gas. This in turn causes a change in the relative cost ratio of the respective inputs. Depending on the actual usage of gas and the potential to respond to these price incentives, such a policy intervention is likely to affect the firm expenses and hence the income position of firms.

\subsection{Model specification}

Horticultural production capacity is to a large extent determined by the total acreage of glasshouses, which cannot be adjusted easily in the short-run. So, producers cannot increase their production if prices go up. Therefore, we assume that producers minimize the costs of producing a given quantity in the short-run instead of maximizing their profit by optimizing their supply too ${ }^{12}$. The relation between production costs and input use given a certain production level is modelled using a normalized quadratic cost function. This is a flexible functional form and allows, in contrast to e.g. translog functions, for zero-values in the variables (Baffes and Vasavada, 1989). The form is flexible as no restrictions are placed on the signs of the first and second derivatives. This means the observed data can freely point out any relation between the inputs and output. Economic theory requires the cost function to be monotonically increasing in input prices and output, and concave and linear homogenous in input prices. Whereas the first two properties can either be imposed or tested after estimation, linear homogeneity in input prices is simply imposed by normalizing the costs and input prices by the price of one of the inputs (Martinez-Budria et al., 2003).

\footnotetext{
${ }^{11}$ Assuming 1 gigajoule equals $31.6 \mathrm{~m}^{3}$ of natural gas equivalents (Knowledge Centre Infomil, 2019).

12 When estimating output supply functions derived from a profit function, we did not find a statistical relation between output prices and supply. Besides the glasshouse capacity constraints, the absence of this relation can be explained from the large output price variation between years to which horticultural producers do not seem to respond on a yearly basis.
} 
In line with Dutch horticultural production and given our specific focus on energy demand, we distinguish between three variable inputs, i.e. natural gas, electricity and external hired labour ${ }^{13}$, and three fixed factors, i.e. acreage of glasshouses, growing light, and CHP-engines. Moreover, production costs are conditional on two external weather factors (heating degree days and the daily light integral). It is assumed that costs per square meter decrease in the acreage of glasshouses if larger firms are expected to be more (energy) efficient. Costs are expected to increase with the usage of growing light, and decrease in having a CHP-engine. Moreover, total costs are increasing in the number of heating degree days (days in which the weather is too cold, so that the glasshouse needs heating), and decreasing in the daily light integral, which represents the amount of daylight (Van der Velden and Smit, 2018).

In this study we assume that production costs depend heterogeneously on energy prices due to differences in technology and energy contracts. This implies firmspecific slope coefficients for energy prices and their squares in the normalized quadratic cost function. Using the price of external hired labour as numeraire, this function is written as:

$$
\begin{aligned}
c_{k}(w, y, z)= & \alpha_{0 k}+\sum_{i=1}^{2} \alpha_{i k} w_{i k}+\beta_{y} y_{k}+1 / 2 \sum_{i=1}^{2} \sum_{j=1}^{2} \alpha_{i j k} w_{i k} w_{j k}+1 / 2 \beta_{y y}\left[y_{k}\right]^{2}+\sum_{i=1}^{2} \delta_{i y} w_{i k} y_{k} \\
& +\sum_{g=1}^{5} \psi_{g} z_{g k}+\sum_{i=1}^{2} \sum_{g=1}^{5} \rho_{i h} w_{i k} z_{g k}+\sum_{g=1}^{5} \delta_{y g} y_{k} z_{g k}+1 / 2 \sum_{g=1}^{5} \sum_{h=1}^{5} \psi_{g h} z_{g k} z_{h k}
\end{aligned}
$$

where $c_{k}$ are the normalized costs for firm $k, w_{i k}$ are normalized input prices for input $i$ ( $i=1$ for natural gas; $i=2$ for electricity), $y_{k}$ is output and $z_{g k}$ are conditional factors ( $g=1$ for acreage; $g=2$ for growing light; $g=3$ for CHP-engine; $g=4$ for heating degree days; $g=5$ for daily light integral). $a, \beta, \delta, \psi$ and $\rho$ are coefficients to be estimated. Note that all coefficients $a$ are firm-specific. The remaining slope coefficients are equal across firms.

Applying Shephard's Lemma to the quadratic cost function (Baffes and Vasavada, 1989; Martinez-Budria et al., 2003) gives demand functions for natural gas $\left(x_{1 k}\right)$ and electricity $\left(x_{2 k}\right)$ :

$$
x_{i k}(w, y, z)=\frac{\partial c_{k}}{\partial w_{i k}}=\alpha_{i k}+\sum_{j=i}^{2} \alpha_{i j k} w_{j k}+\delta_{i} y_{k}+\sum_{g=i}^{5} \rho_{i g} z_{g k}
$$

The demand equations contain firm-specific intercepts $\left(a_{i k}\right)$ and firm-specific energy price coefficients $\left(a_{i j k}\right)$. Multiplying these factor demands with the corresponding input

\footnotetext{
${ }^{13}$ Family labour is not considered given the high dependency on external labour in the production process, with a share of almost $90 \%$ of external labour in the total labour requirement (Wageningen Economic Research, 2020a).
} 
prices yields the energy expenses for a firm. Hence, these equations can be used to simulate the effects of energy price increases as proposed in the Dutch Climate Agreement. The estimation strategy is described in section 5.5.

\subsection{Data and descriptive statistics}

Our empirical analysis uses firm-level data obtained from the Analysis Tool Rabobank (ATR). The sample contains 238 observations for specialized cucumber producing firms, 704 observations for specialized bell pepper producing firms, and 686 for specialized tomato producing firms for the period 2008-201514. These firms are truly specialized in that they only grow one product. The data includes information on both firm characteristics as well as energy-related expenses. More specifically, it provides information on firm size and the use of specific technologies and energy systems such as the use of artificial growing light and a CHP-engine. Regarding the representativeness of our sample, it is important to note that Rabobank is the largest bank active in the Netherlands as a credit supplier for the agricultural sector (Rabobank, 2016). The ATR sample covers over $40 \%$ of the total firms in the horticultural sector, and around $60 \%$ of the total acreage (Statistics Netherlands, 2011). As a result, the firms in the sample are - on average - somewhat larger than the average firm size in the population. In comparison, the Dutch FADN only contains about 20 to 30 firms per main horticultural product (Ge et al., 2018), while the ATRset contains, depending on the product, close to 100 firms per year.

Actual prices for labour, gas and electricity are obtained from Statistics Netherlands (2019a). The gas prices are year-averaged for non-households per gigajoule. Electricity prices are measured per kilowatt-hour (kWh). These prices are transformed into price indices with 2010 as base year. Indicators for weather variables, as the heating degree days and daily light integral, are obtained from the Royal Netherlands Meteorological Institute (2019). Heating degree days are a wellestablished indicator for measuring energy requirements. It assumes that with an average temperature of (or above) $18^{\circ}$ Celsius no additional heating is required, hence giving a score of zero. Every observed day with an average temperature below this threshold value, adds one point for every degree below the $18^{\circ}$ Celsius threshold. The daily light integral in contrast measures the number of photosynthetically active photons that are delivered during a day. The normalized value in the Netherlands is $35010^{3} \mathrm{~J} / \mathrm{cm}$ (Van der Velden and Smit, 2018). Our variable measures the daily light integral for the different years as a percentage of this norm. Note that the weathervariables are the same for all firms, yet the production environment is very identical

\footnotetext{
${ }^{14}$ Note that the studied policy intervention is only scheduled to take place several years after the data observation period is finished. This is however not expected to influence the outcomes of the empirical assessment, given that both the volatility and level of gas and energy inputs (Statistics Netherlands, 2019a), as well as relevant developments in the horticultural sector such as growth in average firm sizes (Wageningen Economic Research, 2020b), show the same trend in most recent years as during the observation period of the dataset.
} 
across the country. Hence, considerable differences across years are expected for these annual weather-indicators, but differences within the country are expected to be limited.

Figure 5.1 shows the unconditional relation between firm size and the annual average energy expenses per firm for each product. The upper row of figure 5.1 presents the energy costs per unit production, whereas the lower row shows the costs per square meter. A downward pattern in the energy expenses is in particular visible for cucumber and bell pepper firms, implying that on average, larger sized firms are able to meet their energy requirements more efficiently. Yet, also for firms of similar size, we observe considerable differences in energy costs. Hence, aside from acreage, various other determinants explain differences in energy costs. Moreover, the overall net energy costs might be negative, as also visible for several firms in figure 5.1, which is due to firms with a CHP-engine supplying surplus electricity to the grid.
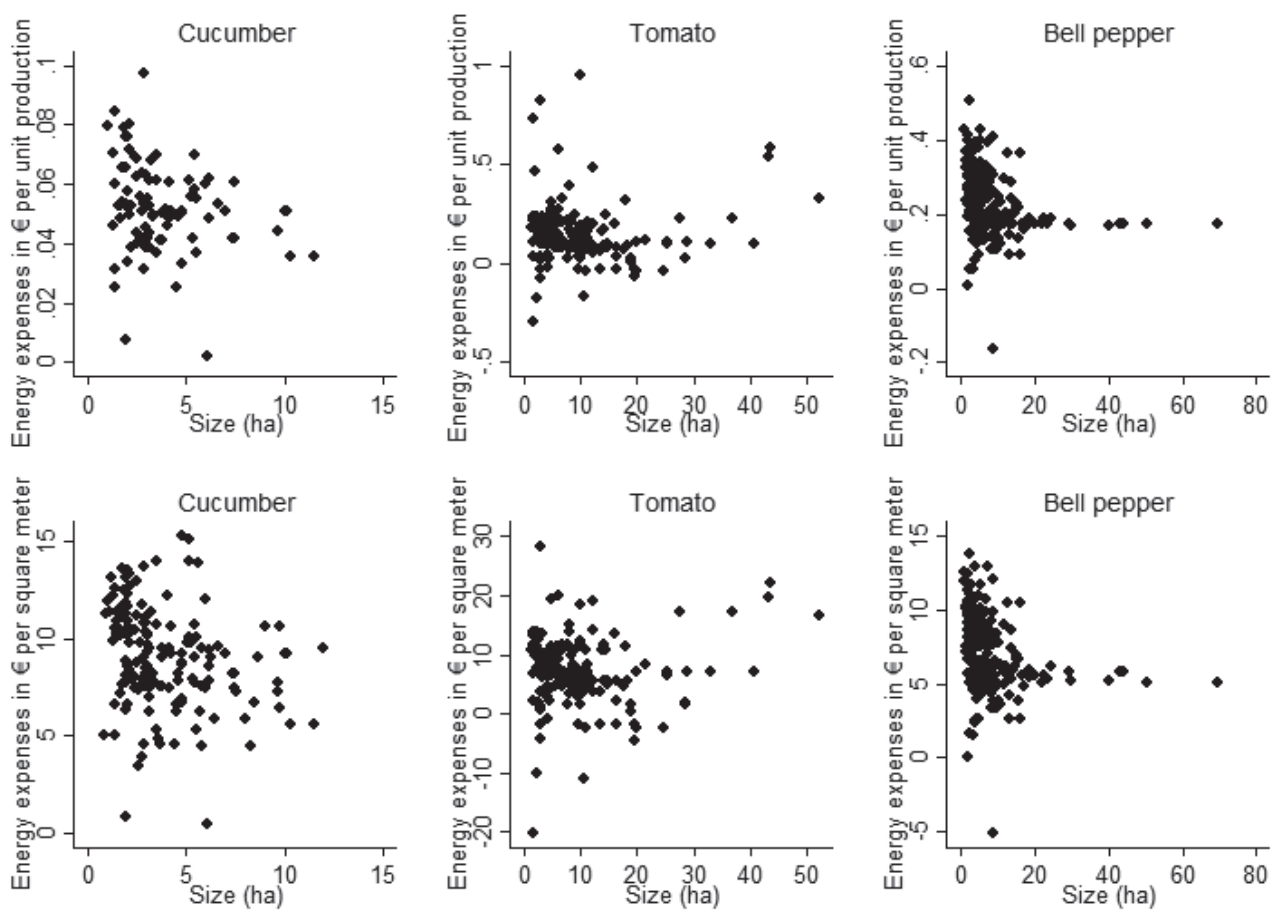

Figure 5.1: Relation between firm size and energy expenses in the cultivation of cucumber, tomato and bell pepper (Source: authors based on ATR-data).

Descriptive statistics of the model variables are given in table 5.1. The use of a CHPengine and artificial growing light is most widespread in the cultivation of tomatoes, with $88.3 \%$ of the firms having a CHP-engine and $14.1 \%$ using artificial light. Most of the variation in the usage is between firms, rather than within firms, implying only a 
limited number of firms change their energy-systems. With respect to firm size, also the differences between cucumber firms (with an average size of $3.8 \mathrm{ha}$ ) and tomato producers (an average size of $8.6 \mathrm{ha}$ ) stand out.

Regarding the usage of gas and electricity per square meter, again tomato firms are the ones with the highest usage. Furthermore, the relatively high within and between standard deviations are visible. This implies considerable differences in the energy usage over time (depending on e.g. differences in external weather circumstances), as well as differences between firms due to e.g. heterogeneity in production technologies.

Table 5.1: Descriptive statistics of the main variables.

\begin{tabular}{lccc}
\hline & Cucumber & Tomato & Bell Pepper \\
\hline Gas usage (normalized G] per & $14.036(5.884)$ & $18.691(6.445)$ & $14.805(5.562)$ \\
square meter) & $(5.548 ; 2.826)$ & $(6.541 ; 3.705)$ & $(4.613 ; 3.292)$ \\
Electricity usage (normalized & $0.826(2.100)$ & $0.835(1.488)$ & $0.604(0.895)$ \\
kWh per square meter) & $(2.679 ; 0.628)$ & $(1.687 ; 0.747)$ & $(0.710 ; 0.483)$ \\
Normalized gas price index & $0.986(0.153)$ & $0.955(0.155)$ & $0.979(0.156)$ \\
& $(0.116 ; 0.121)$ & $(0.101 ; 0.135)$ & $(0.097 ; 0.138)$ \\
Normalized electricity price index & $1.032(0.067)$ & $1.029(0.066)$ & $1.032(0.066)$ \\
& $(0.031 ; 0.064)$ & $(0.029 ; 0.065)$ & $(0.028 ; 0.065)$ \\
Production quantity (in kg or & $173.687(29.692)$ & $55.928(12.337)$ & $31.400(10.236)$ \\
pieces per square meter) & $(32.917 ; 10.031)$ & $(12.192 ; 4.595)$ & $(9.826 ; 5.344)$ \\
CHP-engine (1=yes) & $0.613(0.487)$ & $0.883(0.321)$ & $0.815(0.388)$ \\
& $(0.491 ; 0.138)$ & $(0.339 ; 0.086)$ & $(0.403 ; 0.078)$ \\
Artificial light (1=yes) & $0.050(0.219)$ & $0.141(0.348)$ & $0.089(0.285)$ \\
& $(0.174 ; 0.000)$ & $(0.341 ; 0.136)$ & $(0.292 ; 0.041)$ \\
Acreage (ha) & $3.802(2.176)$ & $8.618(7.981)$ & $7.223(7.570)$ \\
& $(2.016 ; 0.613)$ & $(8.150 ; 1.756)$ & $(6.449 ; 2.485)$ \\
Heating Degree Days $(* 100)$ & $25.304(5.730)$ & $26.018(5.353)$ & $25.371(5.670)$ \\
& $(3.943 ; 4.997)$ & $(2.678 ; 5.042)$ & $(2.991 ; 5.307)$ \\
Daily Light Integral & $106.228(2.832)$ & $106.270(2.841)$ & $106.323(2.804)$ \\
& $(1.601 ; 2.580)$ & $(1.397 ; 2.698)$ & $(1.040 ; 2.714)$ \\
N (n) & & & $704(142)$
\end{tabular}

Note: The mean is followed by the standard deviations in parentheses. The second row provides a breakdown of the standard deviation in the between standard deviation followed by the within standard deviation.

\subsection{Empirical procedure}

\subsubsection{System estimation of demand equations}

Equation (2) presented in section 5.5.3 defines two demand equations for natural gas $(i=1)$ and electricity $(i=2)$. Since both demand equations are derived from the same cost function, it holds that $a_{12 k}=a_{21 k}$. Therefore, the two equations are estimated jointly as a system with this restriction imposed in estimation. In both frequentist and Bayesian econometrics this is referred to as the Seemingly Unrelated Regression (SUR) model. In short, this requires writing the individual equations as one combined equation that can be estimated with single-equation techniques with the data belonging to the individual equations stacked and the covariance matrix of the residuals corrected for heteroscedasticity. In the combined equation it is 
straightforward to impose the restriction $a_{12 k}=a_{21 k}$. See Koop (2003: 137-143) for more details.

\subsubsection{Approaches for estimating heterogeneous coefficients}

Both demand equations contain firm-specific intercepts ( $\left.a_{i k}\right)$ as well as firm-specific price coefficients $\left(a_{i j k}\right)$, which for ease of notation are both denoted as $a_{k}$. This requires an estimation approach that allows for estimating unit-specific or heterogeneous coefficients. In the econometric panel data literature a distinction is often made between fixed and random heterogeneous coefficient models (Biørn, 2016: 107-131; Hsiao, 2015). In fixed heterogeneous coefficient models, the unit-specific slope coefficients $a_{i j k}$ are estimated directly but this typically requires a large number of observations per unit, which in short micro-economic panels are usually not available.

E.g., the average time span in our sample is 5.07 years, leaving only very few degrees of freedom for individual regressions. In the random heterogeneous coefficient approach it is assumed that the unit-specific slope coefficients $a_{i j k}$ are the sum of a common value $a_{i j}$, representing the average response over all units, and a stochastic unit-specific element $u_{i j k}$. The product of $u_{i j k}$ and the corresponding model variable become part of a composite disturbance, requiring a generalized least squares (GLS) procedure for estimation. Swamy (1970) proposed a feasible GLS procedure, which can also be used to predict the random coefficients ex post (Biørn, 2016: 127). A drawback of this GLS procedure however is that it requires least squares estimates of the individual slope coefficients, which just like for the fixed heterogeneous coefficient model may be very imprecise or even infeasible in case the number of observations for a unit is too small.

In the broader statistical literature a class of models known as mixed-effects models generalizes the above random heterogeneous coefficient model by allowing for more intricate heterogeneous coefficient structures, e.g. by allowing heterogeneous coefficients to depend also on other variables (e.g. Verbeke and Molenberghs, 2000). When applied to panel data these mixed-effects models are also denoted as multilevel or hierarchical models, since individual observations may be clustered at multiple levels (e.g. firm, region or country), which allows for hierarchical structuring of the random coefficient distributions at different levels.

\subsubsection{Bayesian hierarchical random coefficient estimation}

In a Bayesian hierarchical model (see e.g. Lindley and Smith, 1972) the firm-specific coefficients are structured according to a hierarchical prior distribution, which has the advantage that it allows the unit-specific coefficients to have their own specific distribution at firm-level, but still to be connected to a more general overall distribution. In other words, the firm-specific coefficients are allowed to differ, but due to the hierarchical structure they are not too different from an overall mean (Koop, 
2003: 155). In our model the hierarchical prior consists of two stages. In the first stage the firm-specific coefficients $a_{k}$ are independent draws from a multivariate normal distribution, with mean $\mu_{a}$ and variance $\Sigma_{\alpha}$, or $\alpha_{k} \sim N\left(\mu_{a}, \Sigma_{\alpha}\right)$. In the second stage distributions are defined for both the means $\mu_{a}$ and the variances $\Sigma_{\alpha}$. The means $\mu_{a}$ are drawn from a prior distribution with prior means $\underline{\mu}_{a}$ and prior variances $\underline{V_{a}}$, or $\mu_{a} \sim N\left(\underline{\mu}_{a}, \underline{V}_{\alpha}\right)$. The inverse of the variance, $\Sigma_{\alpha}^{-1}$, follows a Wishart distribution with degrees of freedom $\underline{v}_{\alpha}$ and a prior precision matrix given by $\underline{\Sigma}_{\alpha}^{-1}$, or $\Sigma_{\alpha}^{-1} \square W\left(\underline{v}_{\alpha}, \underline{\Sigma}_{\alpha}^{-1}\right)$ (Koop, 2003: 156). The lower bars indicate the prior values. This twostage structure allows for defining average prior values, from which firm-specific coefficients can deviate. The extent to which they can deviate from this depends on the prior value specified for the variance but also on the data for the individual firms.

Following Bayes' rule, the prior distributions are combined with a likelihood function (representing the data), resulting in the following (conditional) posterior distributions for $a_{k}$ (Koop, 2003: 156):

$\alpha_{k} \mid x, h, \mu_{\alpha}, \Sigma_{\alpha} \sim N\left(\bar{\alpha}_{k}, \bar{\Sigma}_{k}\right)$

with $\bar{\sum}_{k}=\left(h X_{k}^{\prime} X_{k}+\sum_{\alpha}^{-1}\right)^{-1}$ and $\bar{\alpha}_{k}=\bar{\sum}_{k}\left(h X_{k}^{\prime} y_{k}+\sum_{\alpha}^{-1} \mu_{\alpha}\right)=\frac{\left(h X_{k}{ }^{\prime} y_{k}+\sum_{\alpha}^{-1} \mu_{\alpha}\right)}{\left(h X_{k} X_{k}+\sum_{\alpha}^{-1}\right)}$

The upper bars inequation (3) indicate posterior values. The posterior expression for our coefficients of interest $\left(a_{k}\right)$ is a function of two main elements, arising in both the numerator and the denominator, namely the sum of squares multiplied by $h$ (the error precision), as well as the posteriors of the hierarchical parameters $\mu_{a}$ and $\Sigma_{\alpha}$, which in turn are based on both the specified priors and the average value of the coefficients. The size of the first part (concerning the sum of squares) depends on the number of observations per firm in the data. A larger number of observations leads to a bigger sum of squares, resulting in a larger influence on the posterior. On the other hand, for a firm with only very few observations in the dataset, this number is small and hence, the posterior is rather driven by the hierarchical parameters. This allows us to deal with the unbalanced nature of the dataset, as firms with many observations in the data are allowed to deviate more from the overall average values than firms with a smaller number of observations.

\subsubsection{Defining prior information and estimation procedure}

As indicated in the previous subsection, the hierarchical prior naturally connects to the idea of hierarchical modelling, i.e. specifying coefficient distributions at different levels, which in our application are the overall level and the firm level. Prior information in 
general represent the beliefs or information the researcher has on the coefficients ex ante. In our model there are several pieces of information that can be included as prior information. First, the hierarchical model implies that the heterogeneous coefficients are distributed around a sample mean. In other words, pooled least squares coefficients and their covariances provide natural prior information for the mean and variance in the first stage of the hierarchical prior. This provides a first set of prior values that are denoted as Least Squares priors. Second, concavity of the cost function implies that the energy demands are decreasing in their own prices and increasing in the prices of other variable inputs. This provides information on the sign of the heterogeneous price coefficients that can be included. Third, and related to the previous point, given the importance of energy in Dutch horticulture energy demand is expected to be inelastic with respect to own and other prices. In other words, the own price elasticities are assumed to be between -1 and 0 , whereas the cross-price elasticities are expected to be between 0 and 1 . Rewriting the expression for the price elasticity into an expression for the slope of the demand equation, i.e. $\frac{\partial x_{i k}}{\partial w_{j}}=\varepsilon_{x, w} * \frac{x_{i k}}{w_{j}}$ using average values for $x_{i k}$ and $w_{j}$, and assuming the own price elasticities to have an expected value of -0.5 this leads to a range of prior values for the own price coefficients in equation (2). For the cross-price coefficient that appears in both equations and which is imposed to be similar, we assume a mean value of 1 for the coefficient. These prior distributions based on theoretically consistent values for the price coefficients are summarized in table 5.2:

Table 5.2: First-stage hierarchical prior distributions for unit-specific price coefficients in the system of energy demand equations

\begin{tabular}{lccc}
\hline & Cucumber & Tomato & Bell Pepper \\
\hline Own gas price $\left(a_{11}\right)$ & $N(-7.29 ; 6.28)$ & $N(-9.70 ; 2.72)$ & $N(-7.51 ; 1.96)$ \\
Cross price $\left(a_{12}=a_{21}\right)$ & $N(1 ; 1.57)$ & $N(1 ; 0.431)$ & $N(1 ; 0.251)$ \\
Own electricity price $\left(a_{22}\right)$ & $N(-0.316 ; 3.83)$ & $N(-0.405 ; 1.80)$ & $N(-0.292 ; 1.04)$ \\
\hline
\end{tabular}

For the remaining (fixed) coefficients we also use least squares values as prior information. This second set of prior values is referred to as Least Squares and elasticity priors. Note that all final posterior estimates may deviate from the initial prior values.

The system of equations with firm-specific price coefficients is estimated using both sets of prior information for the three products. In addition, the system of equations is also estimated as a pooled model, and a model with only firm-specific intercepts, in order to compare with the system with firm-specific price coefficients. This gives a total of 18 models that were estimated. The models were estimated in Matlab using Gibbs sampling (Koop, 2003: 148-162). This procedure sequentially draws from the conditional posterior distributions of the various model coefficients resulting in the empirical posterior distributions. Posterior distributions were simulated 
based on 25,000 draws plus 5,000 burn-in draws. See Gardebroek (2006) for another application and further explanation. Note that a supplementary file at ERAE online contains the code of the Matlab files for obtaining the estimates of the pooled and random coefficient model for tomato producing firms.

Due to the hierarchical nature of the models, which increases the parameter dimensionality, and the fact that pooled and random intercept models are nested within the more general random coefficient model, a proper way of comparing the models is on the basis of marginal likelihoods (Koop, 2003: 157-158), which are defined as the product of the likelihood and the prior distribution, divided by the posterior distribution. Since the models are estimated using Gibbs sampling, the method of Chib (1995) is used for calculating the marginal likelihoods.

\subsubsection{Effects on energy usage and expenses}

In the last step of the analysis, the system of estimated demand equations is used to assess the impact of gas price increases on the energy usage and expenses. First, baseline predictions for gas and electricity demand $\left(x_{i k}^{*}\right)$ are made for each observation. Multiplying these baseline predictions with the actual prices of gas and electricity provides a prediction for the original energy expenses: $c_{i k}^{*}=w_{i k} x_{i k}^{*}$.

In order to obtain the new energy prices $w_{i k}^{N}$, we add the proposed taxation of $€ 1.264$ per $\mathrm{GJ}$ on the gas prices. The electricity prices remain unchanged. Replacing the original input prices with the increased energy input prices allows us to obtain predictions for the new factor demands $x_{i k}^{* N}$. The simulated energy expenses for the energy tax scenario are then obtained by multiplying the simulated energy demands and increased energy prices: $c_{i k}^{*_{N}}=w_{i k}^{N} x_{i k}^{*_{N}}$.

Comparing the expenses of the baseline prediction with the scenario prediction gives the impact of the policy intervention on firm expenses. Given that Dutch horticultural firms face competition on international markets from in particular producers in southern countries (who grow products in more favourable climatological circumstances requiring less heating of glasshouses (Elzen et al., 2012)), it is expected that the additional expenses in the production process are not translated into higher output prices.

\subsection{Results}

\subsubsection{Estimation results: comparison of model specifications and prior values}

Based on the two different sets of prior values and the three different model specifications (pooled, random intercept, and random intercept plus random price 
coefficients), six different models were estimated for each product. These models were compared on the basis of the log marginal likelihood values, presented in table 5.3:

Table 5.3: Log marginal likelihood values of the estimated models.

\begin{tabular}{lccc}
\hline & Pooled model & Random intercepts & $\begin{array}{c}\text { Random intercepts } \\
\text { and price coefficients }\end{array}$ \\
\hline $\begin{array}{l}\text { Cucumber } \\
\quad \text { Least squares priors }\end{array}$ & -1320.70 & -1047.99 & -193.17 \\
$\quad \begin{array}{l}\text { Least squares and elasticity priors } \\
\text { Tomato }\end{array}$ & -1380.40 & -1065.62 & -160.75 \\
$\quad$ & & \\
$\quad$ Least squares priors & -3988.41 & -3458.35 & -993.53 \\
$\quad$ Least squares and elasticity priors & -4001.02 & -3506.39 & -1292.25 \\
$\begin{array}{l}\text { Bell Pepper } \\
\quad \text { Least squares priors } \\
\quad \text { Least squares and elasticity priors }\end{array}$ & -3804.21 & -3374.03 & -1584.60 \\
\hline
\end{tabular}

A log marginal likelihood value closer to zero implies that the model is better than the model it is compared with. A number of observations can be made. First, all models with random intercepts and price coefficients are favoured over the more restrictive random intercept and pooled models. This implies that it is preferred to model energy price responses of Dutch horticultural firms as heterogeneous over modelling these as fixed for all firms. Table 5.3 also shows that the random intercept models are superior over the pooled models. Second, it can be concluded that for cucumber the model with combined least squares and elasticity priors has a better log marginal likelihood than the model based on least squares priors only. However, for both tomato and bell pepper the model based on least squares priors only is favoured. The remainder of this results section is based on these preferred models.

\subsubsection{Estimation results: posterior coefficient distributions}

For the selected models based on the highest log marginal likelihood, table 5.4 gives the posterior means and standard deviations of the coefficients from the system of gas and electricity demand functions. Note that for the random coefficients, the intercepts $a_{i k}$ and price coefficients $a_{i j k}$ the table provides the mean value of all the individual coefficients. Furthermore, the $95 \%$ highest posterior density intervals are given, indicating the range of values that the estimated coefficient can have with $95 \%$ certainty (Koop, 2013: 43-45). The overall gas demand equation shows results largely in line with a well-behaved normalized quadratic cost function, meaning we find a negative own price effect for all products. The cross-price effects however show mixed results, where - on average - only tomato firms have a positive cross-price effect. Beyond, we see that more intensive production is associated with a higher demand for gas for all products. Furthermore, our conditional climate variables are in line with the expectations: colder years (so years with a higher number of heating degree days) are associated with a higher demand for gas, whereas years with a higher light integral are associated with a lower demand for gas. 
Regarding the remaining conditional factors, we find a negative effect for acreage for tomato and cucumber firms. This implies larger firms - holding other conditional factors constant - are able to use less gas in their production per square meter as compared to smaller firms. The magnitude of the effect is particularly visible for cucumber firms, and to a lesser extent for tomato firms. Beyond, we observe positive relations between usage of a CHP-engine and artificial growing light on gas usage.

Table 5.4: Posterior distributions of coefficients for the system of gas and electricity demand functions.

\begin{tabular}{|c|c|c|c|}
\hline & Cucumber & Tomato & Bell Pepper \\
\hline \multicolumn{4}{|l|}{ Gas demand equation } \\
\hline \multirow[t]{2}{*}{ Gas price } & $-4.876(1.409)$ & $-10.021(1.075)$ & $-6.303(0.981)$ \\
\hline & {$[-7.177,-2.472]$} & {$[-11.786,-8.272]$} & {$[-7.935,-4.721]$} \\
\hline \multirow[t]{2}{*}{ Electricity price } & $-0.127(0.815)$ & $1.440(0.498)$ & $0.209(0.351)$ \\
\hline & {$[-1.458,1.202]$} & {$[0.621,2.260]$} & {$[-0.378,0.789]$} \\
\hline \multirow[t]{2}{*}{ Production quantity } & $0.030(0.007)$ & $0.060(0.013)$ & $0.018(0.013)$ \\
\hline & {$[0.018,0.042]$} & {$[0.037,0.082]$} & {$[-0.004,0.039]$} \\
\hline \multirow[t]{2}{*}{ Acreage } & $-0.458(0.114)$ & $-0.063(0.025)$ & $0.005(0.020)$ \\
\hline & {$[-0.645,-0.270]$} & {$[-0.103,-0.023]$} & {$[-0.027,0.037]$} \\
\hline \multirow[t]{2}{*}{ CHP-engine } & $5.953(0.471)$ & $5.986(0.534)$ & $6.185(0.376)$ \\
\hline & {$[5.181,6.730]$} & {$[5.114,6.865]$} & {$[5.567,6.801]$} \\
\hline \multirow[t]{2}{*}{ Artificial growing light } & $4.286(1.154)$ & $2.972(0.509)$ & $1.616(0.514)$ \\
\hline & {$[2.382,6.178]$} & {$[2.137,3.814]$} & {$[0.775,2.465]$} \\
\hline \multirow[t]{2}{*}{ Heating Degree Days } & $0.170(0.030)$ & $0.001(0.000)$ & $0.123(0.018)$ \\
\hline & {$[0.121,0.219]$} & {$[0.001,0.001]$} & {$[0.095,0.152]$} \\
\hline \multirow[t]{2}{*}{ Daily Light Integral } & $-0.176(0.035)$ & $-0.501(0.029)$ & $-0.337(0.021)$ \\
\hline & {$[-0.240,-0.124]$} & {$[-0.552,-0.459]$} & {$[-0.373,-0.302]$} \\
\hline \multirow[t]{2}{*}{ Intercept } & 25.678 (3.799) & $69.355(3.620)$ & $47.495(2.518)$ \\
\hline & {$[19.889,32.388]$} & {$[64.460,76.064]$} & {$[43.308,51.622]$} \\
\hline \multicolumn{4}{|l|}{ Electricity demand equation } \\
\hline \multirow[t]{2}{*}{ Gas price } & $-0.127(0.815)$ & $1.440(0.498)$ & $0.209(0.351)$ \\
\hline & {$[-1.458,1.202]$} & {$[0.621,2.260]$} & {$[-0.378,0.789]$} \\
\hline \multirow[t]{2}{*}{ Electricity price } & $-0.064(1.222)$ & $-1.824(0.910)$ & $-0.927(0.719)$ \\
\hline & {$[-2.163,1.810]$} & {$[-3.362,-0.281]$} & {$[-2.160,0.227]$} \\
\hline \multirow[t]{2}{*}{ Production quantity } & $-0.020(0.004)$ & $0.002(0.006)$ & $0.005(0.005)$ \\
\hline & {$[-0.027,-0.014]$} & {$[-0.008,0.011]$} & {$[-0.003,0.014]$} \\
\hline \multirow[t]{2}{*}{ Acreage } & $-0.085(0.059)$ & $0.029(0.009)$ & $-0.004(0.007)$ \\
\hline & {$[-0.182,0.011]$} & {$[0.013,0.044]$} & {$[-0.016,0.008]$} \\
\hline \multirow[t]{2}{*}{ CHP-engine } & $0.625(0.250)$ & $-0.278(0.223)$ & $0.145(0.138)$ \\
\hline & {$[0.212,1.034]$} & {$[-0.645,0.087]$} & {$[-0.083,0.371]$} \\
\hline \multirow[t]{2}{*}{ Artificial growing light } & $0.831(0.586)$ & $1.249(0.212)$ & $0.102(0.186)$ \\
\hline & {$[-0.126,1.799]$} & {$[0.904,1.600]$} & {$[-0.203,0.408]$} \\
\hline \multirow[t]{2}{*}{ Heating Degree Days } & $-0.007(0.020)$ & $0.000(0.000)$ & $-0.012(0.010)$ \\
\hline & {$[-0.039,0.026]$} & {$[-0.000,0.000]$} & {$[-0.028,0.005]$} \\
\hline \multirow[t]{2}{*}{ Daily Light Integral } & $-0.053(0.025)$ & $-0.017(0.018)$ & $-0.010(0.014)$ \\
\hline & {$[-0.100,-0.014]$} & {$[-0.048,0.008]$} & {$[-0.038,0.009]$} \\
\hline \multirow[t]{2}{*}{ Intercept } & $10.376(3.187)$ & $2.930(2.407)$ & $2.571(1.872)$ \\
\hline & {$[5.909,16.816]$} & {$[-0.186,7.056]$} & {$[5.909,16.816]$} \\
\hline $\mathbf{N}$ & 238 & 686 & 704 \\
\hline $\mathbf{n}$ & 65 & 142 & 142 \\
\hline
\end{tabular}

Notes: Posterior mean values and standard deviations are given for each coefficient in the upper row. The $95 \%$ highest posterior density intervals (hpdi's) are given in square brackets. The presented values for the price coefficients and intercepts are overall mean values. 
As a result of imposing the symmetry restriction, cross-price effects are equal in the gas and electricity demand equation. The own price effect for electricity is negative, yet the range of the HDPI is considerable. This holds for most coefficients in the electricity demand equation, as in most cases the $95 \%$ posterior density interval includes zero. Yet, our results do point out that firms with an artificial growing light installation on average have a higher electricity demand. In years with a high daily light integral, the demand for electricity drops, which is in line with our expectations.

The obtained price coefficients allow us to calculate the price elasticities. At the mean values for prices and quantities for the respective products, the gas price elasticity for the average cucumber firm equals $-0.342(-4.876 *(0.986 / 14.036))$, for tomato firms -0.512 and for bell pepper firms -0.416 . This means that, on average, tomato firms respond strongest to changes in gas prices. Based on the estimated firmspecific (price) coefficients also firm-specific price elasticities were calculated. The histograms in figure 5.2 show the spread in these price elasticities. We find that the majority of the firms are concentrated around the mean value of the elasticities. A limited number of firms however have elasticities that are in the tails of the distribution. This implies these firms either react stronger (for firms with a large negative elasticity) or less strong (for firms with elasticities close to zero) on the energy price changes. These differences in price responsiveness of firms can be attributed to e.g. differences in energy contracts as well as differences in production structure. In line with the obtained estimation results shown in table 5.4, the results on the cross-price elasticities are somewhat inconclusive, with some firms (particularly cucumber firms) obtaining negative cross-price elasticities. Also, the own-price elasticities for gas and electricity show unexpected positive effects in some of the cases. In cases where specific observations have a deviating value (e.g. a high gas demand in a year with a similarly high price), this might result in a firm-specific price coefficient in the unexpected direction. Yet, for most firms elasticities are found with the expected signs. 

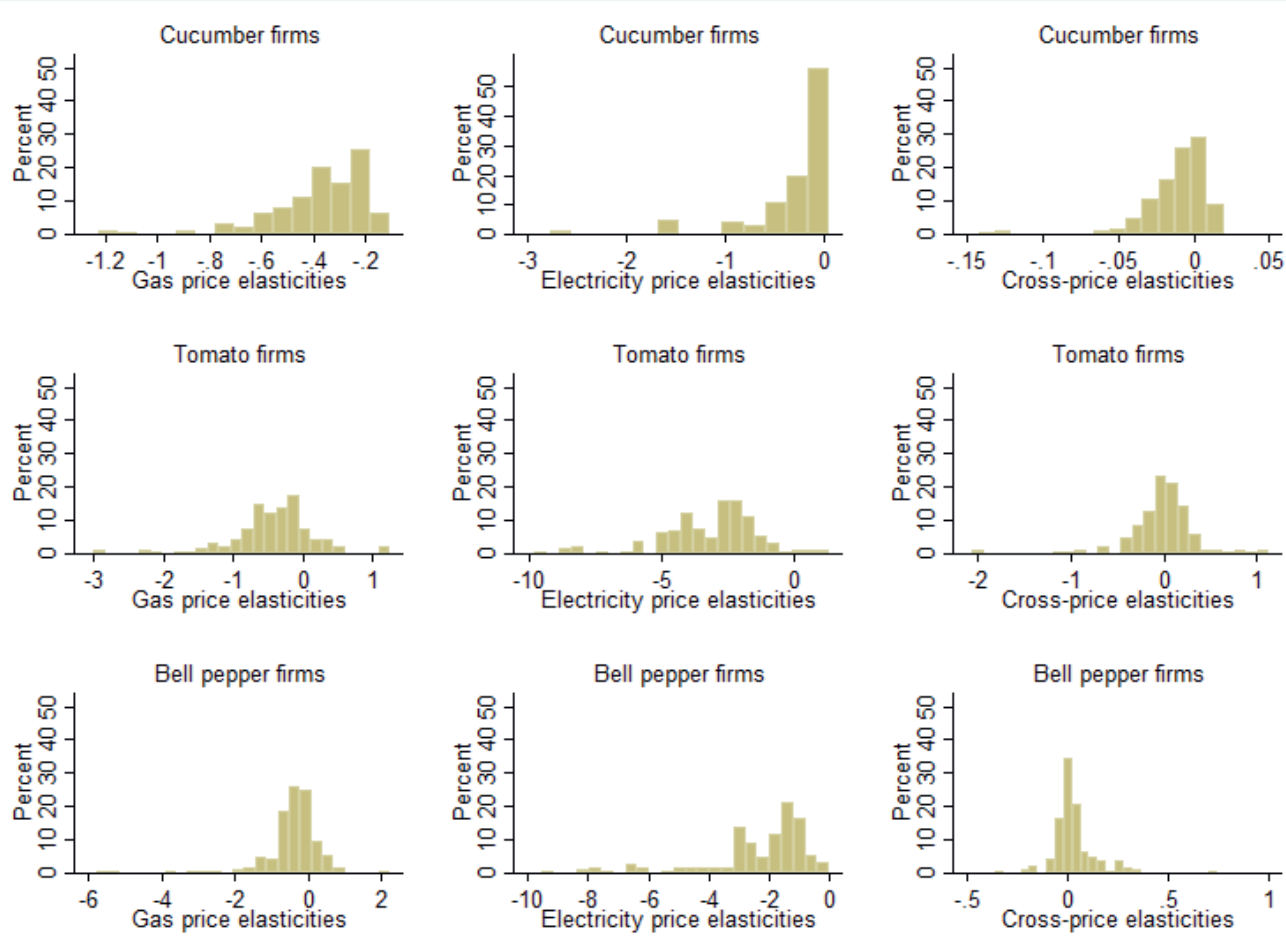

Figure 5.2: Histograms of firm-specific price elasticities for cucumber, tomato and bell pepper firms.

\subsubsection{Effects of gas price increases on energy usage and expenses}

The effects of the increased gas expenses on the actual energy usage of the firms are shown in table 5.5. The results show a lower usage of gas for all products as a result of the input price-increase. This effect is most visible for tomato firms, with an average decrease of $9.13 \%$ in the demand for gas. On the other hand, for bell pepper and tomato we find that the electricity usage increases. This results from the largely positive cross-price elasticities shown in table 5.4, implying that firms substitute some of the gas inputs for electricity as a result of the price-increase. Remarkably, in the market for cucumbers the usage of electricity decreases resulting from the increase in gas prices. Moreover, it should be noted that due to the unexpected cross-price effect in some of the cases (resulting in some negative coefficients), we obtain negative demand predictions for electricity for a considerable number of observations. These observations are not considered in the remaining analysis. 
Table 5.5: Descriptive overview of effects on energy usage per square meter

\begin{tabular}{lccc}
\hline & Cucumber & Tomato & Bell Pepper \\
\hline Gas usage (baseline prediction) & $14.014(5.149)$ & $18.158(5.367)$ & $14.070(4.482)$ \\
Gas usage (scenario prediction) & $13.466(5.096)$ & $16.500(5.396)$ & $13.658(4.600)$ \\
Electricity usage (baseline prediction) & $2.395(0.837)$ & $3.197(3.644)$ & $1.026(0.743)$ \\
Electricity usage (scenario prediction) & $2.382(0.835)$ & $3.628(4.055)$ & $1.0830 .825)$ \\
$\mathrm{N}(\mathrm{n})$ & $238(65)$ & $329(76)$ & $564(124)$ \\
\hline
\end{tabular}

Note: Overall standard deviation is given in parentheses.

Gas usage is in normalized gigajoule per square meter and electricity in normalized kWh per square meter.

Multiplying the predicted input demands with the corresponding input prices yields the impact on the energy expenses as shown in table 5.6. Given the substitution of mainly tomato firms from gas to electricity usage, we see that their actual expenses on gas increased only very moderately. Yet, their electricity expenses increase resulting from the higher usage. For cucumber and bell pepper firms, the effects on the electricity expenses are relatively modest. Hence, they are mainly affected by the higher gas expenses resulting from the price-increase.

Table 5.6: Effects on energy expenses in euros per square meter

\begin{tabular}{lccc}
\hline & Cucumber & Tomato & Bell Pepper \\
\hline Gas expenses (baseline prediction) & $13.476(4.633)$ & $16.653(4.167)$ & $13.458(4.230)$ \\
Gas expenses (scenario prediction) & $14.491(5.110)$ & $16.983(4.835)$ & $14.634(4.857)$ \\
Electricity expenses (baseline prediction) & $2.473(0.853)$ & $3.289(3.780)$ & $1.060(0.775)$ \\
Electricity expenses (scenario prediction) & $2.460(0.852)$ & $3.731(4.202)$ & $1.119(0.860)$ \\
Energy expenses (baseline prediction) & $15.950(4.512)$ & $20.002(6.403)$ & $14.497(3.981)$ \\
Energy expenses (scenario prediction) & $16.952(4.990)$ & $20.769(6.785)$ & $15.735(4.629)$ \\
N $(\mathrm{n})$ & $238(65)$ & $329(76)$ & $564(124)$ \\
\hline
\end{tabular}

Note: Overall standard deviation is given in parentheses.

In order to show the underlying variability in additional energy expenses between firms, figure 5.3 shows the difference in energy expenses per square meter between the baseline and scenario prediction for every firm set out against the acreage per firm. The spread in additional expenses between firms is visible for every product, yet the largest differences can be seen for tomato firms. The figures show that the differences in increased energy expenses are considerable for both smaller as well as for larger-sized firms. However, it should be noted that other conditional factors (such as differences in energy systems) are most likely to play a role in the relation between acreage and the additional expenses resulting from the policy intervention. 

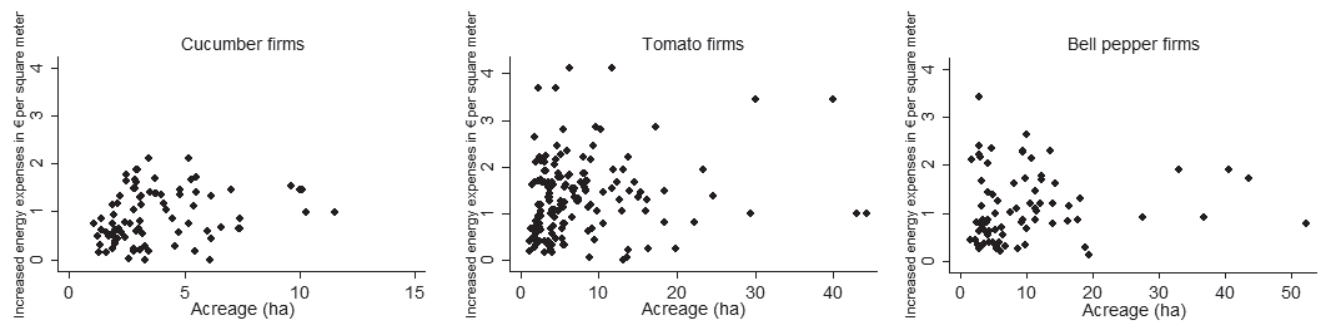

Figure 5.3: Relation between acreage and differences in energy expenses in $€$ per square meter between the baseline and scenario prediction.

\subsection{Conclusions}

In this chapter we analysed differences in energy usage for Dutch horticultural firms and the consequences of a proposed gas price increase on incomes of horticultural firms. Given the high energy-intensity in combination with the increased attention for reducing greenhouse gas emissions and the usage of fossil fuels, the aim for a further energy transition is a central policy issue in the horticultural sector.

By first estimating a system of gas and electricity demand equations, we obtain results that satisfy theoretical consistency and plausibility in terms of the input-price effects. However, the empirical results on the cross-price elasticities between gas and electricity are for most firms close to zero and therefore hard to interpret. Beyond, we find that acreage is most often negatively related with the energy usage per square meter. Hence, larger-sized firms use relatively less gas in their production process. In addition, substantial differences arise between firms based on their further production structure, in particular depending on the usage of artificial growing light and a CHPengine. As a result, large differences in the energy usage between firms are observable.

Given these differences in actual input usage, as well as due to differences in production technologies and e.g. energy contracts, it is relevant to allow for flexibility in the estimation of our model coefficients. In a more conventional setting with fixed coefficients, we would assume every firm to react similarly to potential price changes. In contrast, the estimation of a Bayesian random coefficient model allows for obtaining firm-specific price coefficients and intercepts. A potential drawback however is that this approach is prone to data-outliers. In cases where specific observations have a deviating value (e.g. a high gas demand in a year with a similarly high price), this might result in a firm-specific price coefficient in the unexpected direction. In more conventional estimation methods, the impact of these outliers is most often less visible, as all observations are actually pooled in order to obtain a fixed slope coefficient. The comparison of different models based on their log marginal likelihood values however shows that allowing for random intercepts and price coefficients is preferred for all studied products. 
Our results point at considerable differences in the price elasticities between firms, implying that not all firms react similarly to price changes. This implies that policy interventions aimed at increasing or decreasing certain input prices lead to different responses at firm-level. In contrast to earlier research on the income effect of policy interventions, which focused particularly on aggregated effects (e.g. Babcock, 2015), the use of random coefficients explicitly allows for firm-specific responses to policy interventions. This is of particular importance as heterogeneity in firm structure and production technologies becomes more prevalent in many agricultural sectors (Renner et al., 2020). Hence, responses to changes in policy arrangements and market conditions are highly firm specific (Finger and El Benni, 2020; Reidsma et al.se, 2010).

Based on the proposals of the Dutch climate agreement (2019) for increasing energy taxes, we simulated the effects of this policy intervention on the income positions of the different firms. The main effect of these policies are additional costs arising from the increased gas prices. Given the considerable differences in energy usage between firms, as well as the heterogeneous responses to relative input price changes, our results show that more restrictive energy policies can have very different effects on the expenses and income position of firms in the sector. These expenses can even become higher when considering the large-scale investments that are needed to make the full transition towards the usage of other energy sources. This may put further pressure on the future structure of the sector, where currently both classical family firms, as well as more larger-sized corporations co-exist. As many policies, e.g. the subsidy-schemes as part of the EU's Common Agricultural Policy, aim to reduce inequalities between farms (Piet and Desjeux, 2020), it is therefore highly relevant to properly monitor potentially unwanted effects of climate policies on future income inequalities in different sectors.

One of the main limitations of our analysis is the focus on short-term effects. Due to the potentially large transition and change in production structure needed for horticultural firms to switch to alternative energy sources, it is difficult to predict these income effects based on existing data. Nevertheless, the Bayesian approach applied in this chapter provides a useful contribution to the empirical literature on assessing heterogeneous and disaggregated effects of policy interventions. In particular in the case of heterogeneous agricultural sectors, where differences in firm structure and production technologies are clearly present, the use of a random coefficient model for estimating a system of demand equations provides a useful framework in order to assess heterogeneous firm-specific responses.

While the empirical focus of this chapter was specifically on modelling responses resulting from changes in energy policy, further research on heterogeneous responses due to other changes in policy environments or market conditions is likely to be very relevant. This is of particular interest when considering responses to price dynamics on input markets with high volatility, as these cause changes in relative input prices 
and potentially give rise to firm specific responses. The fact that it is already relevant to study firm-specific responses in a small geographic area such as the Dutch horticultural sector, indicates that there is great potential for further studies in agricultural production areas with a larger degree of heterogeneity in production circumstances, which might be difficult to control by observable variables. 
Chapter 6

\section{IMPACT OF CREDIT CONSTRAINTS ON INVESTMENTS IN DUTCH HORTICULTURE}




\section{IMPACT OF CREDIT CONSTRAINTS ON INVESTMENTS IN DUTCH HORTICULTURE ${ }^{15}$}

ABSTRACT: Glasshouse horticulture is a capital-intensive sector and investments often rely on external capital. Most empirical analyses on investment however neglect the role of credit constraints, assuming perfect capital markets with unlimited availability of capital. Yet, after the 2007-2008 financial crisis banks apply stricter conditions in lending out capital, making it harder for horticultural firms to invest. The objective of this study is to investigate whether and to what extent credit constraints have an impact on investments in the Dutch horticultural sector. Therefore, we first expand a theoretical dynamic model of investment by including credit constraints. Second, based on the theoretical framework a panel Tobit model is estimated using panel data of horticultural firms over the period 2008-2015.

15 This chapter is based on the article: Los, E.J., Gardebroek, C. and Huirne, R.B.M. (2020). Impact of credit constraints on investments in Dutch horticulture. To be submitted. 


\subsection{Introduction}

The agricultural sector in most developed countries is becoming more and more capital intensive (e.g. Skevas et al., 2018a). Dutch horticultural firms are no exception to this and are often perceived among the most modern and capital-intensive agricultural producers in the world. Despite high land prices due to competing claims on land, the average Dutch horticultural firm continues to increase in size rapidly. Between 2000 and 2019, the average size of a Dutch horticultural firm has more than tripled (Wageningen Economic Research, 2020c) and the solvency (equity/total capital) has drastically decreased. Differences between comparable firms are, however, considerable.

The decision of a firm to invest in e.g. expanding their size of operation is typically made after comparing the expected long-term benefits of new capital goods with their current and future costs. As a result, both the expectations of the firm's cost structure as well as expectations on future output prices play a role in determining whether the investment will be economically viable or not. One of the cost factors that plays an important role is the cost of capital (e.g. O' Toole et al., 2014). Although horticultural firms sometimes have access to internal capital, investments are usually of such magnitude that external capital is required for financing the expansion. Traditionally, economists assumed perfect capital markets implying that investment decisions are not related to the financial structure of a firm (Modigliani and Miller, 1958). As a result, most empirical and theoretical work on investment largely ignored financial variables for explaining investment decisions. Later research (see e.g. Rajan, 2012) however challenged this view more and more, recognizing that the assumptions of perfect information and perfect markets underlying the Modigliani-Miller model do not hold.

In particular the ability of a firm to raise financial capital is an important and often neglected issue (Henning and Jordaan, 2016). In order to take advantage of possible profitable business opportunities, firms ideally have full access to credit and other forms of external financial capital. In reality not all firms have access to credit, and further frictions at capital markets (such as asymmetric information problems) in fact cause a separation between investment and financing decisions (Hernando and Martinez-Carrascal, 2007). This separation of investment and financing decisions implies that firms may face additional financing costs.

As a result of the Basel-III agreements, banks in the last decades are forced to apply stricter conditions in lending out capital (Blundell-Wignall and Atkinson, 2010; Brester and Watts, 2019). These conditions are likely to be further continued in forthcoming Basel-IV agreements, in which the liquidity and rentability of a lender are expected to become more important (Schneider et al., 2014). Hence, the potential to raise capital is increasingly becoming an essential factor in investment decisions of Dutch horticultural firms. Therefore, it is very relevant to understand how changing 
financial circumstances and restrictions affect the investment behaviour of individual firms and the sector as a whole. This chapter provides an empirical analysis of the impact of financial constraints on expansion decisions of Dutch horticultural firms.

The aim of this chapter is threefold. First, we extend the theoretical framework for modelling investment decisions by explicitly modelling the role of financial variables. Second, we empirically assess whether these variables affect the firms decision process by estimating a panel Tobit regression. We do so by applying the Wooldridge (2005) correction in order to account for firm specific effects. Third, we estimate whether differences between firms based on their initial characteristics play a role in explaining their investment behaviour.

Existing empirical work, such as Guariglia et al. (2011), specified a dynamic model to investigate the effect of credit constraints on agricultural firms in China. A drawback of their approach however is that their model is rather ad hoc, i.e. there is no underlying theoretical framework. Moreover, the investment equation is only based on financial variables whereas other costs or expected profitability are not included. The theoretical model of this chapter builds upon Gardebroek (2004) who developed a generalised investment model that combines adjustment costs and asset fixity theory. We add to this model by including interest payments on debt in de cash-flow expression, assuming that the interest rate applied to firms depends on their financial situation. Horticultural firms with a weak financial position are charged with a risk premium on top of the market interest rate, leading to higher cost of finance. This results in a dynamic optimality condition for investment that considers expected profitability over time periods, adjustment costs and financial costs.

Furthermore this chapter provides an econometric analysis of investments in glasshouses in Dutch horticulture. Given the high capital-intensity of this sector, and its relatively large dependency on external capital for financing investments, this sector can be seen as a highly relevant case for studying the effects of financial constraints on investments in modern agricultural sectors.

The remainder of the chapter is organized as follows. Section 6.2 provides the theoretical background on modelling investment decisions used in this study. Based on this, we formulate an investment equation including financial variables which can be estimated by using a panel Tobit model. Section 6.3 discusses the origins of the data used in the study and provides a descriptive overview of the main variables. The results of the empirical analysis are provided in section 6.4 , whereas the last section discusses conclusions and implications based on these findings.

\subsection{Modelling investment decisions}

Investments in glasshouses, but also investments in energy-saving or productionenhancing technologies are often considered by horticultural firms. This is in particular the case since technological developments, as well as changing market conditions can 
generate incentives for agricultural firms to increase production volumes and make additional investments (Skevas et al., 2018b). The decision to invest is often made after an ex ante evaluation of the effects the investment has on the firm's expected results, also known as capital budgeting (Oude Lansink et al., 2001). The most frequently used procedure to evaluate the profitability of an investment is the Net Present Value method (NPV), where investments are considered as economically feasible if the annual net cash flow exceeds both the principal and interest payments.

Recognising the additional costs that are associated with an investment, such as reorganization costs, the adjustment cost theory provided an important extension to the NPV approach (Gardebroek, 2004). E.g. for horticultural firms, one could think of the extra costs involved for organizing additional labour when producing on a larger scale, administrative costs required for obtaining building licenses or general costs associated with the restructuring of the production process (Silva et al., 2015; Gardebroek and Oude Lansink, 2004).

Besides adjustment costs, firms may also face additional costs of financing their investments E.g. Van Ees et al. (1997) show that firms with a higher chance of going bankrupt, or being unable to meet their financial obligations, often pay a risk premium on their interest rate. Van der Meulen and Venema (2005) also state that banks often charge higher interest rates when lending to firms with a weak financial position. According to Asquith et al. (2005) and Demerjian and Owens (2016), such methods of performance pricing ensure that the interest rates charged on a bank loan are a function of the borrowing firm's credit rating or their profitability. In addition, reputational aspects, such as the history of past debt repayment, can impact trust between banks and borrowers and hence influence the interest rate charged (Curtiss, 2012).

The relevant interest rate should therefore be seen as a combination of the base interest rate combined with an additional firm-specific risk premium. This implies that due to the financial structure of the firm, the expected net present value of investments can vary by firm, given any differences in financing costs. Abel and Eberly (2011) e.g. show that the cash flow of a firm has a significant impact on the actual investment. This result is often interpreted as empirical evidence of financing constraints faced by firms.

To formalize these issues in the firm's investment decision, we start with writing the expected present value (PV) of firm $h$ at time $t$ of an investment, where it is assumed that the horticultural firm maximizes the stream of future cash flows (CF) at time $t$ :

$$
P V_{h t}=E\left[\sum_{n=0}^{\infty} \rho^{n} C F_{h, t+n} \mid \Omega_{h t}\right]
$$


where $E$ is an expectations operator, which is dependent on the information set $\Omega_{t}$ available for firm $h$ at time $t$. The cash flow (CF) is defined as:

$$
C F_{h t}=p_{t} F\left(\mathbf{x}_{h t}, \mathbf{k}_{h t}, \mathbf{z}_{h t}\right)-\mathbf{w}_{t} \mathbf{x}_{h t}-\mathbf{i}_{h t} \mathbf{p}_{t}^{\mathbf{i}}-\psi\left(\mathbf{i}_{h t}\right)-d_{h t} r_{h t}
$$

Cash flows are a function of all revenues derived from production $\left(p_{t} F()\right)$ minus variable production costs $\left(\mathbf{w}_{t} \mathbf{X}_{h t}\right)$, expenditures on investment (i $\left.\mathbf{i}_{h t} \mathbf{p}_{t}^{i}\right)$, adjustment costs $\psi\left(\mathbf{i}_{h t}\right)$ and the cost of debt $\left(d_{h t r h t}\right)$. The production function $F($.$) is based on a vector of$ variable inputs $\mathbf{x} h t$, a vector of quasi-fixed factors $\mathbf{k} h t$ as well as a vector of fixed factors $\mathbf{z}_{h t}$. Variable costs are defined as a vector of non-negative input prices $\mathbf{w}_{t}$ times variable inputs $\mathbf{x}_{h t}$. In addition, we assume that firms can decide every period whether to invest or not. The value of gross investments is the product of the investment quantity (i $\mathbf{i}_{h t}$ ) and the investment price $\mathbf{p}_{t}^{i}$. For such investments, it is generally assumed additional adjustments costs are made as well (e.g. Cooper and Haltiwanger, 2006), which are denoted by $\psi(\mathbf{i} h t)$, a function that is increasing in investment.

The last element in the expression for cash flows are the costs of debt. This consists of the size of the external debt $\left(d_{h t}\right)$ multiplied by a firm-specific interest rate $r_{h t}$ that may also vary over time. The interest rate differs among firms due to differences in their financial position. The time-varying nature allows for general changes in interest rates, but also for changes due to renegotiation of the debt, e.g. in case of investment (see e.g. Roberts, 2015). This renegotiation of debt is in particular relevant for investments in glasshouses, as they often involve long-term loans, in which the specific interest rates can be renegotiated over time.

Substituting equation 2 into 1 and assuming that firms maximize their present value over subsequent periods (implying intertemporal optimization), gives us:

$$
\left.P V_{h t}=E_{h t}\left[\begin{array}{l}
p_{t} F\left(\mathbf{x}_{h t}, \mathbf{k}_{h t}, \mathbf{z}_{h t}\right)-\mathbf{w}_{t} \mathbf{x}_{h t}-\mathbf{i}_{h t} \mathbf{p}_{t}^{\mathbf{i}}-\psi\left(\mathbf{i}_{h t}\right)-d_{h t} r_{h t} \\
+\rho\left\{p_{t+1} F\left(\mathbf{x}_{h t+1}, \mathbf{k}_{h t+1}, \mathbf{z}_{h t+1}\right)-\mathbf{w}_{t+1} \mathbf{x}_{h t+1}-\mathbf{i}_{h t+1} \mathbf{p}_{t+1}^{\mathbf{i}}-\psi\left(\mathbf{i}_{h t+1}\right)-d_{h t+1} r_{h t+1}\right\} \\
+\rho^{2}\left\{p_{t+2} F\left(\mathbf{x}_{h t+2}, \mathbf{k}_{h t+2}, \mathbf{z}_{h t+2}\right)-\mathbf{w}_{t+2} \mathbf{x}_{h t+2}-\mathbf{i}_{h t+2} \mathbf{p}_{t+2}^{\mathbf{i}}-\psi\left(\mathbf{i}_{h t+2}\right)-d_{h t+2} r_{h t+2}\right\} \\
+\rho^{3}\left\{p_{t+3} F\left(\mathbf{x}_{h t+3}, \mathbf{k}_{h t+3}, \mathbf{z}_{h t+3}\right)-\mathbf{w}_{t+3} \mathbf{x}_{h t+3}-\mathbf{i}_{h t+3} \mathbf{p}_{t+3}^{\mathbf{i}}-\psi\left(\mathbf{i}_{h t+3}\right)-d_{h t+3} r_{h t+3}\right\} \\
\cdots \\
+\rho^{n}\left\{p_{t+n} F\left(\mathbf{x}_{h t+n}, \mathbf{k}_{h t+n}, \mathbf{z}_{h t+n}\right)-\mathbf{w}_{t+n} \mathbf{x}_{h t+n}-\mathbf{i}_{h t+n} \mathbf{p}_{t+n}^{\mathbf{i}}-\psi\left(\mathbf{i}_{h t+n}\right)-d_{h t+n} r_{h t+n}\right\}
\end{array}\right] \Omega_{t}\right]
$$

where $\rho$ is a discount factor.

In the above expressions, quasi-fixed capital is denoted by $\mathbf{k}_{h t}$, which is the sum of current investment $\mathbf{i}_{h t}$ and the capital stock of the previous period, corrected for depreciation with $\delta$ as depreciation factor: 


$$
\mathbf{k}_{h t}=\mathbf{i}_{h t}+(\mathbf{1}-\boldsymbol{\delta})^{\prime} \mathbf{k}_{h t-1}
$$

The firm-specific interest rate $r_{h t}$ is defined as the interest rate of the previous period plus a risk premium that depends on the financial situation of the firm, reflected by a vector of financial variables $\mathbf{f}_{h t}$. This firm-specific interest rate is re-negotiated when new investments take place:

$$
r_{h t}=r_{h t-1}+\mathbf{i}_{h t} G\left(\mathbf{f}_{h t}\right)
$$

This specification allows for higher interest rates for firms with a weak financial position.

Substituting $\mathbf{i}_{h t}$ using equation (4) into equation (3) and differentiating the latter with respect to the element $k_{t}$ in $\mathbf{k}_{h t}$ gives the following dynamic f.o.c.:

$$
E\left[p_{t} \frac{\partial F(.)}{\partial k_{j h t}}-p_{j t}^{i} \frac{\partial i_{j h t}}{\partial k_{j h t}}-\frac{\partial \psi_{t}(.)}{\partial i_{j h t}} \frac{\partial i_{j h t}}{\partial k_{j h t}}-d_{h t} \frac{\partial r_{h t}}{\partial i_{j h t}} \frac{\partial i_{j h t}}{\partial k_{j h t}}-\rho\left(p_{j h, t+1}^{i} \frac{\partial i_{j h t+1}}{\partial k_{j h t}}+\frac{\partial \psi_{t+1}(.)}{\partial i_{j h t+1}} \frac{\partial i_{j h t+1}}{\partial k_{j h t}}+d_{h t+1} \frac{\partial r_{t+1}}{\partial i_{j h, t+1}} \frac{\partial i_{j h t+1}}{\partial k_{j h t}}\right)\right]=0
$$

Cancelling out and rewriting terms in the above equation gives:

$$
E\left[p_{t} \frac{\partial F(.)}{\partial k_{j h t}}-p_{j t}^{i}-\frac{\partial \psi_{t}(.)}{\partial i_{j h t}}-d_{h t} G\left(\mathbf{f}_{h t}\right)+\rho\left(1-\delta_{j}\right)\left(p_{j h, t+1}^{i}+\frac{\partial \psi_{t+1}(.)}{\partial i_{j h, t+1}}+d_{h t+1} G\left(\mathbf{f}_{h t+1}\right)\right)\right]=0
$$

In order to rewrite the first order condition into an empirical equation, we use linear quadratic specifications for both the production function and the adjustment cost function:

$$
\begin{aligned}
& F\left(\mathbf{x}_{h t}, \mathbf{k}_{h t}, \mathbf{z}_{h t}\right)=\alpha_{0}+\sum_{g=1}^{8} \alpha_{g} x_{g h t}+\frac{1}{2} \sum_{g=1}^{8} \sum_{n=1}^{8} \alpha_{g n} x_{g h t} x_{h h t} \\
& \psi\left(\mathbf{i}_{h t}\right)=\mathbf{i}_{h t} \boldsymbol{\beta}_{l h}+0.5 \mathbf{i}_{h t}^{2} \boldsymbol{\beta}_{2}
\end{aligned}
$$

It is assumed that adjustment costs increase with investment at an increasing rate. So, small increases in firm size are not necessarily leading to large adjustment costs. Large increases however, may generate additional adjustment costs, such as the transaction costs involved for hiring extra personnel, as well as costs related to restructuring the production process. As a result, adjustment costs for larger investments are assumed to be substantially higher. Most notably this is the case since in particular expansions in scale often involve high adjustment costs (Bareille and Letort, 2018). 
For the interest risk premium function we assume that a firm is charged with a higher interest rate if its ratio of its financial earnings $\left(f_{h t}\right)$ to its debt $\left(d_{h t}\right)$ deteriorates:

$$
G\left(\mathbf{f}_{h t}\right)=\gamma_{0}+\gamma_{1} \frac{f_{h t}}{d_{h t}} \quad \text { so } r_{h t}=r_{h t-1}+\mathbf{i}_{h t} G\left(\mathbf{f}_{h t}\right)=r_{h t-1}+\mathbf{i}_{h t} \cdot\left(\gamma_{0}+\gamma_{1} \frac{f_{h t}}{d_{h t}}\right)
$$

If banks assess it harder for a firm to pay back its debt with its current earnings from operational activities, it is assumed that they charge an additional risk premium on the interest rate.

Using equation (8)-(10) the empirical equation is written as:

$$
p_{t}\left(\alpha_{j}+\sum_{n=1}^{N} \alpha_{j n} x_{n h t}\right)-p_{j t}^{i}-\beta_{j l h}-\beta_{j 2} i_{j h t}-d_{h t}\left(\gamma_{0}+\gamma_{1} \frac{f_{h t}}{d_{h t}}\right)+\rho\left(1-\delta_{j}\right)\left(p_{j h, t+1}^{i}+\beta_{j l h}+\beta_{j 2} i_{j h t+1}+d_{h t+1}\left(\gamma_{0}+\gamma_{1} \frac{f_{h t+1}}{d_{h t+1}}\right)\right)=0
$$

Lagging equation (11) one period, collecting terms and solving for $i_{j h t}$ yields the following equation to be estimated (see Appendix):

$$
i_{j h t}=\lambda_{h}+\theta_{1} p_{j h t}^{i}+\theta_{2} p_{j h t-1}^{i}+\theta_{3} d_{h t}+\theta_{4} d_{h t-1}+\theta_{5} f_{h t}+\theta_{6} f_{h t-1}+\theta_{7} i_{j h t-1}+\theta_{8} p_{t-1}+\sum_{n=1}^{N} \theta_{j 8+n} p_{t-1} x_{n h t-1}
$$

Since $i_{j h t}$ is either zero or positive, equation (12) is basically the underlying equation for a dynamic panel Tobit model with unit-specific effects $\lambda_{h}$. The presence of these effects and the one-period lagged investment variable, $i_{\text {jht }}-1$, allows for disentangling (non-)investment persistence due to state dependence (i.e. (non-)investment in the past increases the probability of (non-)investment in the future) from unobserved heterogeneity (unobserved characteristics matter in explaining (non-)investment) (Wooldridge, 2010: 713-715). Assuming the $\lambda_{h}$ to be fixed effects is problematic since the non-linear nature of the Tobit model does not allow for differencing out the fixed effects. Semi-parametric approaches have been proposed to overcome this problem, but these have several drawbacks (Wooldridge, 2010: 715). Therefore, we use a dynamic random effects Tobit model. A well-known issue in this model is how to deal with the first observation, where no lagged dependent value is observed. An elegant solution to this problem was proposed by Wooldridge (2005) and Akay (2012) suggests that compared to other solutions this Wooldridge approach works rather well for panels longer than 5 periods, which is the case in our study. In short, the Wooldridge solution is to add the first-period observations of the dependent variables plus the individual averages of the exogenous variables to proxy for the individual specific effects. 


\subsection{Data}

The data used for this study is obtained from the Analysis Tool Rabobank (ATR), which includes a large sample of Dutch horticultural firms. ATR covers detailed annual data on various indicators for horticultural firms that have a loan from Rabobank, in particular specialized firms growing cucumber, tomato and bell pepper. The total sample contains almost 3000 observations on nearly 600 fruit and vegetable producing glasshouse-firms for the period between 2008 and 2015 and includes information on both firm characteristics as well as firm performance. It provides information on various firm characteristics, such as firm size (measured in hectares of glasshouses) and the specific crops grown. Beyond, it holds track of the firms production output on firm-level, as well as investments in firm size over time. Furthermore, yearly data on cash flow and net profit as well as on firm debt are available for every individual firm. Cash flow is defined as the annual net profit of a firm plus the depreciation and interest costs. The output price holds track of the average annual output prices received per firm, where for cucumber firms these prices are measured in unit of production, and for tomato and bell pepper firms per kilogram. The investment price is proxied by using the average annual price of agricultural land (NVM, 2020).

With respect to the representativeness of our sample, it is important to note that for all products, we find a coverage consistently above $40 \%$ of the number of firms and around $60 \%$ of the total acreage of a certain crop compared to the total production of these sectors (Statistics Netherlands, 2011). Only in the case of cucumber firms these numbers are somewhat lower, with slightly above $30 \%$ of the number of firms and around $50 \%$ of the total acreage. As a result, the firms in our sample are - on average - somewhat larger as compared to the average firm size in these sectors. Nevertheless, given the large number of firms represented in our sample, it provides a well-informed representation of wider changes in the horticultural sector. Furthermore, the more widely used Dutch FADN only contains data for 20 to 30 firms per main horticultural crop (Ge et al., 2018), complicating further analysis on differences between firms.

Before turning to the main investment-related variables used in our empirical model, figure 6.1 shows the development in average firm size (measured in hectares of glasshouses) for the period 2008-2015 in our dataset. In particular bell pepper and tomato firms have increased rapidly in size during this period. Note however that growth in average firm size is a combination of on the one hand investments in glasshouses, but on the other hand also the effect of smaller firms exiting the industry. Hence, not all growth in average firm size is related to investments. 


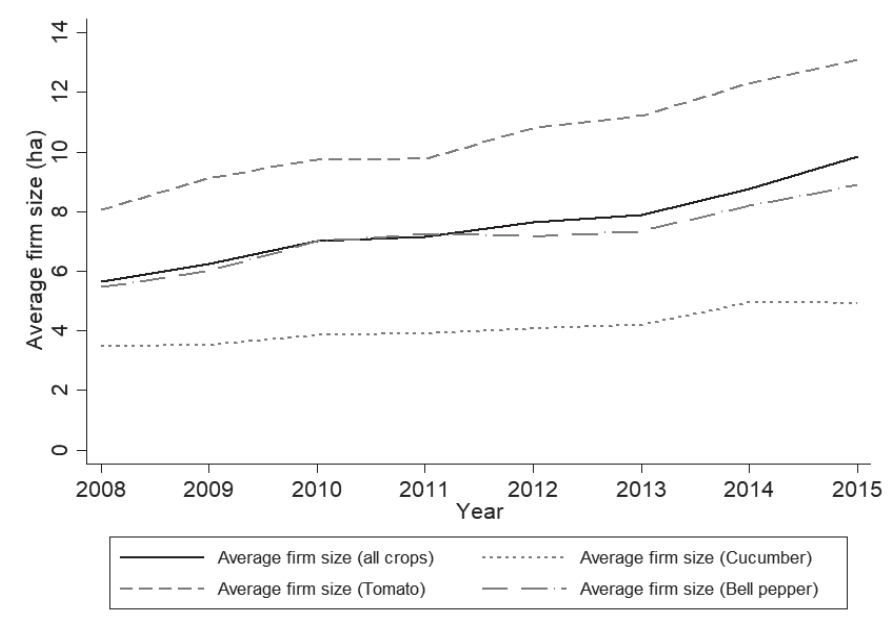

Figure 6.1: Average firm size in horticultural sectors over time (2008-2015).

Table 6.1 summarizes the main investment-related variables for all firms in our sample. Important to note is that firm size not only differs between the three studied products as shown in figure 6.1 , but also shows considerable variation for firms growing the same product. This is reflected by the high overall standard deviation. With regard to investments in greenhouses, we see that in $14.4 \%$ of the observations an expansion takes place. The reported annual average investment in table 6.1 is 0.37 ha, but this number is also based on a large number of zero investments. When only considering the actual investments, we observe an average expansion of 3.5 ha. When further looking at the investments for specialized firms, it should be noted that tomato firms on average expanded their firm size most, with an average annual investment of more than 4.6 ha of glasshouses. Cucumber firms in contrast stay a bit behind with an average investment in glasshouses of around 1.8 ha.

The average annual cashflow for all firms lies at $€ 969000$. Again, considerable differences are observable as $5 \%$ of the observations contains a negative cashflow, whereas the largest cashflows are at a level around $€ 10$ million per year. Beyond, the high standard deviation on the cashflow-indicator is caused by both a high between as well as a high within variation. This implies the existence of variation both between firms in the same period, as well as variation in performance over time, the latter caused by, a.o., strong variations in output prices over time (Ait Sidhoum and Serra, 2016). Furthermore, the large differences in total debt between firms points at the coexistence of both highly indebted firms as well as firms relying largely on their own equity. 
Table 6.1: Descriptive statistics of the main variables.

\begin{tabular}{llll}
\hline Background variables (all firms) & N (n) & Mean & Std. dev. \\
\hline Investing in greenhouses (1=yes, 0=no) & $2394(557)$ & 0.102 & 0.303 \\
Size of investment (in hectares, all observations) & $2394(557)$ & 0.370 & 1.633 \\
Size of investment (in hectares, only if invested) & $243(183)$ & 3.542 & 3.784 \\
Firm size (in hectares) & $2981(587)$ & 7.322 & 8.730 \\
Investment price (in $€ 10000$ per hectare) & $2981(587)$ & 4.482 & 0.445 \\
Total debt (in $€ 1000000)$ & $2981(587)$ & 5.865 & 10.76 \\
Cashflow (in $€ 100000)$ & $2981(587)$ & 9.690 & 17.62 \\
Output Price (in $€$ per kg/piece) & $1807(394)$ & 1.035 & 0.884 \\
\hline
\end{tabular}

Aside from differences in investment patterns between firms, we also observe differences in the investment behaviour over time. Most investments took place in 2009 and 2010, with more than $10 \%$ of the firms expanding their size. Due to stricter requirements for labels regarding energy-saving glasshouses, a relatively large number of firms decided to build new glasshouses around 2009 (Jukema, 2013). This is also reflected in table 6.2. The last column shows the average expansion of all firms that actually invested during that year. Note however the relatively high standard deviations, suggesting substantial variation in investment.

Table 6.2: Investment behaviour over time (2009-2015).

\begin{tabular}{|c|c|c|c|}
\hline Investment & $\mathbf{N}$ & $\begin{array}{l}\text { Investing in greenhouses } \\
(1=\text { yes; } 0=\text { no })(\text { std. dev) }\end{array}$ & $\begin{array}{l}\text { Increase (in ha) if invested } \\
\text { (std. dev) }\end{array}$ \\
\hline 2009 & 417 & $0.134(0.341)$ & $3.268(3.243)$ \\
\hline 2010 & 431 & $0.113(0.317)$ & $4.179(5.166)$ \\
\hline 2011 & 409 & $0.064(0.244)$ & $2.450(2.441)$ \\
\hline 2012 & 406 & $0.113(0.317)$ & $3.340(3.189)$ \\
\hline 2013 & 391 & $0.084(0.278)$ & $3.084(2.778)$ \\
\hline 2014 & 331 & $0.063(0.244)$ & $5.798(5.110)$ \\
\hline 2015 & 194 & $0.077(0.267)$ & $2.802(2.406)$ \\
\hline
\end{tabular}

The differences in the size of the actual investments are also visible in figure 6.2, where the cash-flow of the previous period is set out against the investment in the year after. Note that for reasons of space and clarity, only the firms who actually invested in expanding their size are considered in the figure below. The grey dots show all firms that invested during the observation period, whereas the highlighted black dots point at the firms for every specific crop. First, it can be noted that there is a positive trend visible in all studied markets between the previous cashflow and the investment. Hence, on average firms with a large positive cash-flow seem more likely to invest in expanding their size. Furthermore, both the cash-flow as well as the investments in acreage for cucumber firms are smaller as compared to the other products. As visible in figure 6.2, large expansions in size mainly took place at specialized tomato and bell pepper firms. 

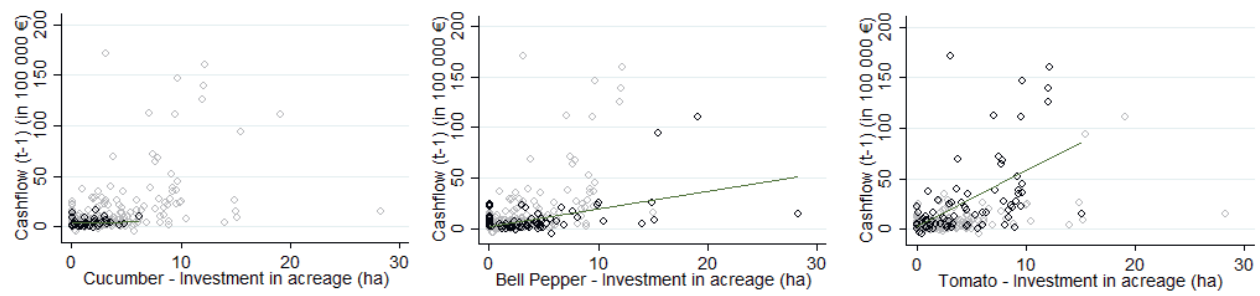

Figure 6.2: Relation between cash-flow and investment in firm size (2008-2015)

The unconditional relation between firm size in the previous period and the investment in the next period is shown in figure 6.3. Again, a positive trend is visible for most products, implying that larger firms are more likely to expand their business. Cucumber firms however are an exception, as it is not so much large firms that expand, but rather the relatively small firms with a scale between 3 and 5 hectares. More strikingly, however, the figures below show no clear indication of any catch-up in these sectors of a large number of small firms aiming to invest in order to grow. Samson et al. (2016) e.g. do find such an effect in the Dutch dairy sector. For horticultural firms, however the unconditional relation between size and investment shows that the already larger firms are among the firms that invest in additional greenhouses.
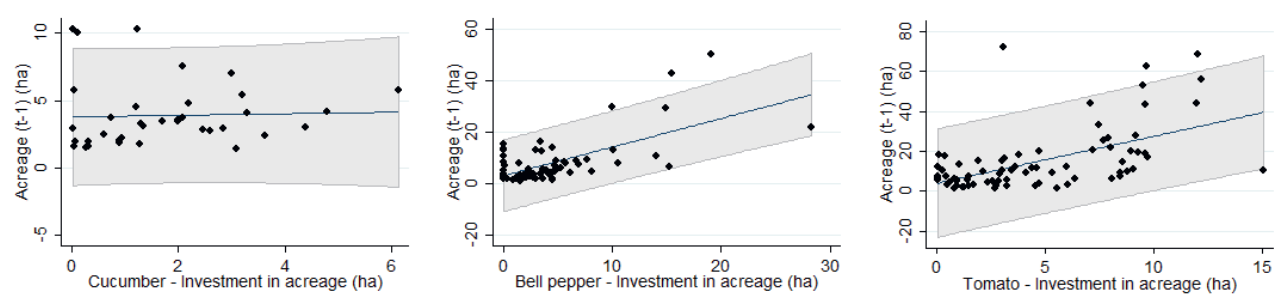

Figure 6.3: Relation between firm size ( $t-1)$ and investment in firm size (2008-2015). The shaded grey area shows the $95 \%$-confidence interval of the blue trend line.

\subsection{Results}

The dynamic panel Tobit model was estimated using 1119 observations on 328 horticultural firms. Only 80 out of the 1119 observations were positive investments, the remainder zero. The null hypothesis of all slope parameters equal to zero was firmly rejected given the Wald $x^{2}$ test statistic of 130.07 . The first column shows the coefficients and accompanying standard errors as obtained via estimating the dynamic panel Tobit model. The marginal effects of the explanatory variables as specified in equation (12) are presented in table 6.3. The second column present the marginal effects on the probability to invest $(\partial P / \partial x)$, whereas the second column shows the marginal effects on the level of investment, conditional on positive investment $(\partial E(i) / \partial x)$. Note that marginal effects are only presented for the original model 
variables, not for the variables that are included due to the Wooldridge correction for the initial condition.

Table 6.3: Panel Tobit coefficients and marginal effects of explanatory variables on investment

\begin{tabular}{|c|c|c|c|}
\hline & Coefficient (std. error) & $\partial P / \partial x$ & $\partial E(i) / \partial x$ \\
\hline \multicolumn{4}{|l|}{ Explanatory variables } \\
\hline land price ${ }_{t}$ & $-2.578(1.307)^{* *}$ & $-0.039(0.019) * *$ & $-0.340(0.171) * *$ \\
\hline land price $e_{t-1}$ & $2.459(1.995)$ & $0.037(0.030)$ & $0.324(0.262)$ \\
\hline$d e b t_{t}$ & $0.770(0.191)^{* * *}$ & $0.012(0.003)^{* * *}$ & $0.102(0.025)^{* * *}$ \\
\hline$d e b t_{t-1}$ & $0.116(0.193)$ & $0.002(0.003)$ & $0.015(0.025)$ \\
\hline cashflowt & $0.047(0.066)$ & $0.001(0.001)$ & $0.007(0.009)$ \\
\hline cashflowt-1 & $-0.041(0.067) * * *$ & $-0.006(0.001) * * *$ & $-0.054(0.009) * * *$ \\
\hline investment $_{t-1}$ & $-0.096(0.201)$ & $-0.001(0.003)$ & $-0.013(0.027)$ \\
\hline outputprice $_{t-1}$ & $-1.602(2.875)$ & $-0.024(0.043)$ & $-0.211(0.379)$ \\
\hline outputprice $_{t-1} *$ land $_{t-1}$ & $0.890(0.145)^{* * *}$ & $0.013(0.003)^{* * *}$ & $0.117(0.019) * * *$ \\
\hline \multicolumn{4}{|l|}{ Wooldridge correction } \\
\hline investment (first period) & $-0.592(0.235)^{* *}$ & & \\
\hline land price (mean) & $-2.892(2.945)$ & & \\
\hline debt (mean) & $-1.109(0.251)^{* * *}$ & & \\
\hline cashflow (mean) & $0.776(0.152)^{* * *}$ & & \\
\hline outputprice (mean) & $2.187(2.828)$ & & \\
\hline outputprice*land (mean) & $-1.031(0.197)^{* * *}$ & & \\
\hline cucumber & $2.048(2.599)$ & & \\
\hline bell pepper & $1.379(2.020)$ & & \\
\hline tomato & $0.303(2.156)$ & & \\
\hline$N$ & 1119 & & \\
\hline$n$ & 328 & & \\
\hline Wald $X^{2}$ & $-130.07 * * *$ & & \\
\hline Rho & -0.147 & & \\
\hline Log likelihood & -392.547 & & \\
\hline
\end{tabular}

First, as expected, a higher land price in year $t$ has a negative effect on investment in that same year, whereas the land price in the previous period does not. A land price that is 10000 euros higher reduces the probability of investment by 0.039 and the investment itself by 0.34 ha.

Considering the financial variables, which is our main interest in this chapter, it is found that current period debt has a positive significant effect on investment, but lagged debt has not. This rather counterintuitive effect could be due to the fact that firms that invest see their debt levels increase in the same period. This suggests that it would be better to drop the current debt level from equation (12) or instrument it, but remember that this equation was derived from an intertemporal optimality condition, equalizing costs and benefits of investment in the current and previous period. In other words, one could also interpret this result as current debt being important in this intertemporal optimality condition. The insignificant one-period lagged debt then suggests two things. First, lagged debt is not considered in the 
intertemporal condition for optimal investment. Second, investment is not constrained by past debt levels, in other words banks do not restrict credit based on past debt levels. Another potential explanation for this finding is that firms with a relatively high debt are firms that take additional risks and hence choose to invest in expanding their firm size. Despite the higher costs of capital, increasing their scale of operation might lead to higher future earnings and hence an improvement of their solvency-ratio.

With respect to cash-flows, which was included to account for the risk-premium on the interest rate, we find that current cash-flows do not have a statistically significant effect on investment, but lagged cash-flow have a significant negative effect. In other words, firms with lower cash-flows in the previous period, are more likely to invest. A cash-flow in year $t-1$ that is hundred thousand euros higher, reduces the probability of investment by 0.006 and for those that do investment it reduces the investment by 0.05 ha. This finding might suggest that firms see themselves being put on the spot, suggesting that negative cash-flows form an additional incentive to modernize and expand their business. Note however that figure 6.2 in our descriptive analysis showed a positive (unconditional) relation between previous cash-flows and actual investments. This in turn suggests that controlling for e.g. the total size of the operation as well as the debt position of a firm alters the relation between cash-flows and investment behaviour.

Whereas we estimated a dynamic Tobit model based on our theoretical model, it is found that investment in the previous period does not have a statistically significant effect on current investment. This is actually not surprising, given the rather low frequency of investment in our sample (about $7 \%$ of our observations), so that investments in firm size are rather rare and isolated events.

Table 6.3 furthermore shows that the output price in the previous period does not induce investment in the current period. However, the cross-product between output price and the acreage does relate positively to investment in the next period. In other words, the total value of the horticultural operation, which depends on size and output price is positively related to investment. A one euro higher output price for each ha of glasshouses in period $t-1$, increases the probability of investment in period $t$ by 0.013 and the investment itself by 0.117 ha. This finding is also in line with the unconditional relation between firm size and future investments for most studied products as shown in figure 6.3 , indicating a growing divergence between smaller and larger growing firms within these sectors.

With respect to the coefficients of the covariates includes for the Wooldridge correction, it is found that investment in the initial year, and the firm-specific averages for debt, cash-flow, and the interaction term of output price and size, have a statistically significant coefficient. These findings therefore point at the appropriateness of using the Wooldridge correction in order to account for firm-specific effects. 
Our panel contains data for the period 2008-2015. Within this period the BaselIII agreement was made (2010) and initially intended to be implemented in the period 2013-2015. In other words, it could be that banks became stricter in lending during our sample period. To test for this we estimated an alternative model, with the cashflow variable interacting with a time trend to account for higher risk premia on the interest rate in later sample years. The results of this alternative model are shown in table 6.A1 in the Appendix. The results show statistically significant marginal effects of both current and lagged cash-flows interacting with time. For each year further, a current hundred thousand euro cash-flow increases the probability of investment by 0.0003 ( $p$-value 0.080 ) and the investment itself by 0.003 ha ( $p$-value 0.082 ), whereas the one-period lagged cash-flow has a significant negative effect over time; a reduction in the probability of investment by 0.001 ( $p$-value 0.000 ) and a reduction of the investment itself of 0.012 ha ( $p$-value 0.000 ).

\subsection{Conclusions and discussion}

The findings in this study are part of a growing literature examining the influence of financial indicators on investment decisions. By estimating a dynamic random effects Tobit model, we are able to empirically assess the impact of these financial variables on the investment decisions of Dutch horticultural firms. In line with other studies (e.g. Cummins et al., 2006; Abel and Eberly, 2011; Curtis, 2012), our results clearly show the relevance of including firm-specific financial indicators as their debt position and cash-flow in order to predict investment behaviour. Moreover, we not only find the relevance of firm-specific indicators in affecting investment decisions, but also show the influence of external factors on banking decisions and their impact on firm investment. The latter becomes particularly clear from the influence of the included time-trend interacting with the cash-flow variable, reflecting that over time, banks put a stronger focus on the actual cashflow of primary producers. Note however that the empirical results in this study only point at investments in expanding firm size, and hence lack information on the potential developments regarding other investments, such as machinery or investments in new harvesting or climate technologies.

Furthermore, it should be noted that financial institutions most often not only consider financial aspects in determining these conditions, but also consider qualitative entrepreneurial skills and characteristics of a farmer. Henning and Jordaan (2016) e.g. show that reputation, perseverance and business awareness are important indicators regarding the ability to repay farm credit. This in contrast to more conventionally studied aspects as age and education, which only seem to play a minor role. Yet, this shows that, besides studying financial aspects in investment decisions, it is worthwhile to supplement further research by considering these non-financial aspects. In the approach applied in this chapter, these aspects are captured by the firm-specific random effects, yet they are not separately quantified. Beyond, our study thus far has 
not considered how these findings affect the wider structure of the horticultural sector. Other recent studies on e.g. dairy farming in the Netherlands (Samson et al., 2016) show that mainly smaller farms invest in expanding their size in order to increase their profitability. As a result of these smaller firms investing, a catch-up effect occurs, with a smaller spread in average firm size. It is however unclear whether the same holds for the horticultural sector, where we observe the further development of large firms, often operating on a very large scale. Further research would be needed in order to study the implications of these dynamics at an aggregated level.

Nevertheless, our study emphasizes the importance of taking into account firmspecific credit constraints on their investment decisions. This is particularly relevant as firms are becoming increasingly dependent on external capital, as own savings are often insufficient in order to finance the required investments for modernizing and expanding their business (O'Toole et al., 2014). The results show that mainly large firms with an already existing debt continue to invest in scale. Hence, the increased impact of e.g. the cash-flow variable over time is therefore in particular relevant in reducing the financial risks concerning this group of growing firms with a high dependence on external capital. Given these high levels of debt, it is therefore not surprising that more stringent measures are being taken by banks and financial institutions to reduce the financial risks involved (e.g. Basset et al., 2014; Brester and Watts, 2019). Consequently, financial variables are expected to remain a key factor in future investment decisions of agricultural firms. 


\section{A Appendix}

Equation (12) can be derived from equation (11) in the following way:

$$
\begin{aligned}
& p_{t-1}\left(\alpha_{j}+\sum_{n=1}^{N} \alpha_{j n} x_{n h t-1}\right)-p_{j t-1}^{i}-\beta_{j 1 h}-\beta_{j 2} i_{j h t-1}-d_{h t-1}\left(\gamma_{0}+\gamma_{1} \frac{f_{h t-1}}{d_{h t-1}}\right)+\rho\left(1-\delta_{j}\right)\left(p_{j h t}^{i}+\beta_{j l h}+\beta_{j 2} i_{j h t}+d_{h t}\left(\gamma_{0}+\gamma_{1} \frac{f_{h t}}{d_{h t}}\right)\right)=0 \\
& \rho\left(1-\delta_{j}\right)\left(p_{j h t}^{i}+\beta_{j l h}+\beta_{j 2} i_{j h t}+d_{h t}\left(\gamma_{0}+\gamma_{1} \frac{f_{h t}}{d_{h t}}\right)\right)=-p_{t-1}\left(\alpha_{j}+\sum_{n=1}^{N} \alpha_{j n} x_{n h t-1}\right)+p_{j t-1}^{i}+\beta_{j l h}+\beta_{j 2} i_{j h t-1}+d_{h t-1}\left(\gamma_{0}+\gamma_{1} \frac{f_{h t-1}}{d_{h t-1}}\right) \\
& \left(p_{j h t}^{i}+\beta_{j 1 h}+\beta_{j 2} i_{j h t}+d_{h t}\left(\gamma_{0}+\gamma_{1} \frac{f_{h t}}{d_{h t}}\right)\right)=\frac{1}{\rho\left(1-\delta_{j}\right)}\left(-p_{t-1}\left(\alpha_{j}+\sum_{n=1}^{N} \alpha_{j n} x_{n h t-1}\right)+p_{j t-1}^{i}+\beta_{j l h}+\beta_{j 2} i_{j h t-1}+d_{h t-1}\left(\gamma_{0}+\gamma_{1} \frac{f_{h t-1}}{d_{h t-1}}\right)\right) \\
& \beta_{j 2} i_{j h t}=-p_{j h t}^{i}-\beta_{j l h}-d_{h t}\left(\gamma_{0}+\gamma_{1} \frac{f_{h t}}{d_{h t}}\right)+\frac{1}{\rho\left(1-\delta_{j}\right)}\left(-p_{t-1}\left(\alpha_{j}+\sum_{n=1}^{N} \alpha_{j n} x_{n h t-1}\right)+p_{j t-1}^{i}+\beta_{j l h}+\beta_{j 2} i_{j h t-1}+d_{h t-1}\left(\gamma_{0}+\gamma_{1} \frac{f_{h t-1}}{d_{h t-1}}\right)\right) \\
& i_{j h t}=\frac{1}{\beta_{j 2}}\left(-p_{j h t}^{i}-\beta_{j 1 h}-d_{h t}\left(\gamma_{0}+\gamma_{1} \frac{f_{h t}}{d_{h t}}\right)+\frac{1}{\rho\left(1-\delta_{j}\right)}\left(-p_{t-1}\left(\alpha_{j}+\sum_{n=1}^{N} \alpha_{j n} x_{n h t-1}\right)+p_{j t-1}^{i}+\beta_{j l h}+\beta_{j 2} i_{j h t-1}+d_{h t-1}\left(\gamma_{0}+\gamma_{1} \frac{f_{h t-1}}{d_{h t-1}}\right)\right)\right)
\end{aligned}
$$

Collecting terms, the above equation can be simplified to the following expression which is estimated:

$$
i_{j h t}=\lambda_{h}+\theta_{1} p_{j h t}^{i}+\theta_{2} p_{j h t-1}^{i}+\theta_{3} d_{h t}+\theta_{4} d_{h t-1}+\theta_{5} f_{h t}+\theta_{6} f_{h t-1}+\theta_{7} i_{j h t-1}+\theta_{8} p_{t-1}+\sum_{n=1}^{N} \theta_{j 8+n} p_{t-1} x_{n h t-1}
$$


Table 6.A1: Panel Tobit coefficients and marginal effects of explanatory variables on investment (alternative model with cashflow variable interacting with time trend).

\begin{tabular}{|c|c|c|c|}
\hline & Coefficient (std. error) & $\partial P / \partial x$ & $\partial E(i) / \partial x$ \\
\hline \multicolumn{4}{|l|}{ Explanatory variables } \\
\hline land price ${ }_{t}$ & $-2.204(1.307)$ & $-0.031(0.020)$ & $-0.290(0.192)$ \\
\hline land price l-1 & $4.464(2.001)^{* *}$ & $0.066(0.029)^{* *}$ & $0.610(0.261)^{* *}$ \\
\hline$d e b t_{t}$ & $0.908(0.193)^{* * *}$ & $0.013(0.003)^{* * *}$ & $0.119(0.025) * * *$ \\
\hline$d e b t_{t-1}$ & $0.044(0.191)$ & $0.001(0.002)$ & $0.006(0.025)$ \\
\hline cashflow $_{t}^{*} \boldsymbol{t}$ & $0.022(0.012)^{*}$ & $0.001(0.001)^{*}$ & $0.003(0.001)^{*}$ \\
\hline cashflow $_{t-1} * \boldsymbol{t}$ & $-0.088(0.014)^{* * *}$ & $-0.001(0.001)^{* * *}$ & $-0.011(0.002) * * *$ \\
\hline investment $_{t-1}$ & $-0.260(0.200)$ & $-0.004(0.003)$ & $-0.034(0.026)$ \\
\hline outputprice $t-1_{1}$ & $-3.154(2.993)$ & $-0.045(0.043)$ & $-0.415(0.392)$ \\
\hline outputprice $_{t-1} *$ land $_{t-1}$ & $1.030(0.167)^{* * *}$ & $0.015(0.003)^{* * *}$ & $0.135(0.022) * * *$ \\
\hline \multicolumn{4}{|l|}{ Wooldridge correction } \\
\hline investment (first period) & $-0.432(0.233)^{*}$ & & \\
\hline land price (mean) & $-2.920(3.010)$ & & \\
\hline debt (mean) & $-1.148(0.256)^{* * *}$ & & \\
\hline cashflow (mean) & $0.661(0.115)^{* * *}$ & & \\
\hline outputprice (mean) & $3.352(2.885)$ & & \\
\hline outputprice*land (mean) & $-1.113(0.206)^{* * *}$ & & \\
\hline cucumber & $1.886(2.639)$ & & \\
\hline bell pepper & $1.234(2.054)$ & & \\
\hline tomato & $0.057(2.193)$ & & \\
\hline$N$ & 1119 & & \\
\hline$n$ & 328 & & \\
\hline Wald $\chi^{2}$ & $-123.37 * * *$ & & \\
\hline Rho & -0.136 & & \\
\hline Log likelihood & -395.565 & & \\
\hline
\end{tabular}

Notes: $*$, $* *$ and $* * *$ represent statistical significance at respectively the $10 \%, 5 \%$ and $1 \%$ level. The Wald test has a $x^{2}$-distribution with 18 degrees of freedom. 
Chapter 7

\section{DEBT AND PRODUCTION EFFICIENCY IN CAPITAL INTENSIVE SECTORS: AN APPLICATION TO DUTCH HORTICULTURE}




\section{DEBT AND PRODUCTION EFFICIENCY IN CAPITAL INTENSIVE SECTORS: AN APPLICATION TO DUTCH HORTICULTURE ${ }^{16}$}

ABSTRACT: Agricultural producers often rely on debt capital in order to finance their operations and investments. Various theoretical and empirical studies investigated the relation between a firms debt structure and efficiency, with varying results. This chapter contributes to this literature by allowing for non-linearity and nonmonotonicity in the relation between debt and efficiency. The results point out that in the context of Dutch horticulture, highly indebted firms often obtain lower efficiency scores, whereas there is often no significant relation found for moderately indebted firms. These findings are robust to various estimation methods in the second stage of the analysis and also hold in various subsamples of specialized producers. Beyond, our obtained DEA efficiency score shows a high correlation with other measures of profitability and productivity, pointing at the consistency of our efficiency estimates for understanding firm performance.

${ }^{16}$ This chapter is based on the article: Los, E.J., (2020). Debt and production efficiency in capital intensive sectors: An application in Dutch horticulture. To be submitted. 


\subsection{Introduction}

Primary producers in modern agricultural sectors are often relying on external funding in order to finance their operations and investments (Henning and Jordaan, 2016). This is most notably the case in highly capital intensive sectors, where firms are largely dependent on debt capital. Various studies (e.g. Davidova and Latruffe, 2007; Latruffe et al., 2017; Mugera and Nyambane, 2015) examined the implications of differences in capital structure for actual farm performance, however with mixed evidence so far (Gadanakis et al., 2019). While several empirical studies point out that debt might increase efficiency, e.g. due to the potential to invest in more modern technologies, others suggest a negative relation as lenders might face high costs which potentially impacts the scope of their managerial decisions and input choices. Especially for policymakers and financial institutions, it is important to have insight in the relation between a firms debt position and its performance, as potential bankruptcies can lead to severe financial risks. This particularly holds for highly indebted firms, given the substantial financial risks involved.

While financial data is often used to assess farm performance and to predict company failures, various empirical studies (see e.g. Margaritis and Psillaki, 2007) emphasize the importance of non-financial data, such as efficiency scores, for benchmarking firm performance and predicting bankruptcies. These efficiency scores are often obtained by means of a non-parametric approach via Data Envelopment Analysis (DEA), or via Stochastic Frontier Models (SFM) (e.g. Latruffe et al., 2017; Alvarez and Del Corral, 2010; Hadley, 2006). Recent studies examined the variations in these efficiency across firms, by considering various geographical and farm characteristics, as well as the role of agricultural subsidies in explaining these differences (e.g. Martinez Cillero et al., 2018; Minviel and De Witte, 2017). In the current agricultural landscape, however, markets become more liberalized and primary producers often receive limited government support (e.g. El Benni et al., 2012). In combination with a growing capital intensity of agricultural firms, the financial management of these firms is becoming increasingly important, and potentially also impacting their level of efficiency.

The above particularly holds for Dutch horticulture, where firms are expanding in size rapidly, often relying on external credit in order to finance these investments (Van der Meulen et al., 2007). Given this high dependence on external capital, there is a considerable risk of bankruptcy in case payment requirements can no longer be met. Moreover, the relation between a firm's financial structure and its technical efficiency is highly relevant to assess given emerging developments in the financial world. In particular as banks are becoming more strict in lending out money, as a result of, a.o., the Basel-III agreements (Blundell-Wignall and Atkinson, 2010; Brester and Watts, 2019). Where traditional banks may be more reserved in lending out capital, it is however worth noting that external investment groups and private equity 
firms also choose to invest in Dutch glasshouse horticulture (see e.g. Onder Glas, 2019). This leads to additional capital flows into the sector, while not directly impacting the observed debt of primary producers.

The objective of this chapter is to study the relation between a firm's debt structure and its technical efficiency for a sample of Dutch horticultural firms. It does so by following a two-step approach. First, we apply DEA in order to estimate the technical efficiency scores of the firms included in our sample. These efficiency scores are also compared with other indicators of firm profitability and productivity. In a second-stage analysis, the obtained efficiency scores are regressed on indicators for the debt and capital structure of the firm. Hence, we are able to analyse how the debt structure of a firm is related to the variations in efficiency levels. Most empirical studies in agricultural sectors focus on potential differences between long and short term debt on efficiency (e.g. Zhu et al., 2012; Mugera and Nyambane, 2015), but seem to neglect any potential non-linearities and the fact that the relation between debt and efficiency might be non-monotonic, as it could also switch from e.g. positive to negative at higher levels of debt (Margaritis and Psillaki, 2007). In the context of Dutch horticulture, with the presence of highly indebted firms (see e.g. Statistics Netherlands, 2020b), it is therefore relevant to extend the approach by allowing for potential non-linearities.

The chapter proceeds with a brief overview of earlier studies on the relation between a firm's debt structure and its technical efficiency. Section 7.3 pays particular attention to the current debt situation in Dutch horticulture. The methodological approach and data are introduced in section 7.4 and 7.5. Section 7.6 presents the main empirical results, followed by conclusions and discussion.

\subsection{Finance, farm performance and efficiency}

Earlier theoretical and empirical work provides several explanations for the relation between capital structure and technical efficiency (Davidova and Latruffe, 2007). The so-called free cash flow, credit evaluation and agency cost-theory are the most widely used theories in the literature. The free cash flow theory, originally proposed by Jensen (1986), argues that debt motivates managers in order to run their business more efficiently due to the additional incentive of debt servicing. This theory assumes that companies have shareholders who, in the event of excessive debt, are able to take a firm into bankruptcy as long as they do not return the interest and principle payments (Jensen, 1986). Hence, one can question to what extent this theory fits with the practice of many agricultural sectors, with most often no separation between management and ownership. Nevertheless, a wide range of recent empirical studies on the relationship between efficiency and financial management in agriculture aims to test this theory empirically (e.g. Davidova and Latruffe, 2007; Giannakas et al., 2001; Mugera and Nyambane, 2015). In the context of agriculture, therefore, farmers are often seen as the agents who are forced by the lenders (principles) to repay their 
debts (Gadanakis et al., 2019). Giannakas et al. (2001) find support for this theory in a sample of Canadian wheat farms, as they find that farms with a greater reliance on debt operate their business more efficiently.

The agency-theory in contrast focuses on the additional costs of debt. According to Jensen and Meckling (1976), lenders (such as banks and other financial institutions) are confronted with costs of monitoring their borrowers. These costs are likely to be passed on to the borrowers. This potentially results in highly indebted farmers bearing high costs from receiving credit. Consequently, the scope of their managerial decisions might be restricted, causing a reduction in efficiency. In line with this agency-theory, several empirical studies in the agricultural sector (e.g. Latruffe et al., 2008) find an association between increased debt ratios and a lower level of technical efficiency.

The credit evaluation approach focuses on the potential inverse relationship between debt and technical efficiency. Since banks evaluate potential borrowers based on their repayment ability, they are likely to prefer (technically) efficient producers as borrowers, given their lower risk profile. Hence, this suggests a positive relation between debt and efficiency. O'Neill and Matthews (2001) found empirical evidence for this statement in a sample of Irish farmers.

In addition, various other explanations have been proposed on why a firm's debt position helps in explaining variations in technical efficiency. The embodied capital hypothesis (Chavas and Aliber, 1993) pays attention to the role of debt for financing capital acquisitions. If capital investments (which are typically financed by debt) lead to an upward shift of the production frontier, indebted firms might fuel technical change and as a result end up on or closer to the production frontier. This approach therefore points at the importance of credit for making sufficient investments in order to maintain and potentially improve efficiency over time (Cramon-Taubadel and Saldias, 2014).

Table 7.1 provides an overview of recent empirical research focusing on farm debt and technical efficiency ${ }^{17}$. The studies show different effects, with four out of the thirteen studies indicating a positive relation between farm debt and efficiency, and four pointing at a negative relation. Moreover, some studies find effects in both directions, while others find no structural relation between debt and efficiency. Hence, table 7.1 reflects the inconclusiveness in empirical studies. Arguably, the relation between debt and efficiency is subject to the idiosyncrasies of the studied sectors.

Furthermore, most studies focus on the potentially different effects between short and long-term debt, leading to additional ambiguity in the results. None of the studies below however allow for non-linearities in the relation between debt and efficiency. Yet, it is very relevant to study potential differences between moderately

17 Some of these studies directly estimate variations in farm-inefficiency, resulting in an opposite sign. Table 7.1 provides all results as a relation between debt and efficiency. 
indebted and extremely indebted firms (with the latter group of firms arguably experiencing a higher pressure to repay their loans). Margaritis and Psillaki (2007) therefore do include a quadratic specification for assessing the relation between leverage and efficiency in their study on small and medium enterprises in New Zealand. They find that both the linear (positively) as well as quadratic term (negatively) significantly impact efficiency, yet the positive effect dominates over the relevant range of debt values. Nevertheless, it shows that the relation between debt and efficiency is not necessarily monotonic. Although not extensively studied, this especially might play a role in the context of Dutch horticulture, given that the sector is characterized by capital intensive firms that largely rely on external capital for investments in new glasshouses as well as for modernizing their production technologies (Wageningen Economic Research, 2020d). The next section therefore provides a further background on debt in the context of Dutch horticulture. 
Table 7.1: Overview of recent empirical studies on debt and technical efficiency in agricultural sectors of developed countries.

\begin{tabular}{|c|c|c|c|c|}
\hline Authors & Context & Output variable & Debt measure & $\begin{array}{l}\text { Relation Debt \& } \\
\text { Efficiency }\end{array}$ \\
\hline Alarcon (2007) & $\begin{array}{l}\text { Spanish crop and } \\
\text { livestock farms }\end{array}$ & $\begin{array}{l}\text { Deflated sales from } \\
\text { continuing operations }\end{array}$ & $\begin{array}{l}\text { Long term debt-to- } \\
\text { asset ratio } \\
\text { Short term debt-to- } \\
\text { asset ratio }\end{array}$ & $\begin{array}{l}\text { No effect for long-run } \\
\text { debt. Short term and } \\
\text { total debt positive }\end{array}$ \\
\hline Barnes (2008) & $\begin{array}{l}\text { Cereals, dairy, sheep } \\
\text { and beef in Scotland }\end{array}$ & $\begin{array}{l}\text { Sum of revenues for } \\
\text { each agricultural } \\
\text { enterprise type, } \\
\text { including subsidies } \\
\text { and grants }\end{array}$ & $\begin{array}{l}\text { Ratio of short- and } \\
\text { long-term debt to net } \\
\text { worth }\end{array}$ & $\begin{array}{l}\text { Positive and } \\
\text { significant for dairy } \\
\text { and sheep sector }\end{array}$ \\
\hline $\begin{array}{l}\text { Gadanakis et al. } \\
\text { (2019) }\end{array}$ & Italian cereal farms & $\begin{array}{l}\text { Total crop output } \\
\text { (sales }+ \text { change in } \\
\text { stocks }+ \text { farmhouse } \\
\text { consumption) net of } \\
\text { subsidies }\end{array}$ & $\begin{array}{l}\text { Lagged debt-to-asset } \\
\text { ratio } \\
\text { Lagged long-term } \\
\text { debt-to-asset ratio } \\
\text { Short-term debt-to- } \\
\text { asset ratio }\end{array}$ & $\begin{array}{l}\text { Negative impact, in } \\
\text { the context of price } \\
\text { instability. }\end{array}$ \\
\hline $\begin{array}{l}\text { Giannakas et al. } \\
(2001)\end{array}$ & $\begin{array}{l}\text { Wheat farms in } \\
\text { Saskatchewan } \\
\text { (Canada) }\end{array}$ & $\begin{array}{l}\text { Annual wheat } \\
\text { production measured } \\
\text { in bushels }\end{array}$ & Debt to asset ratio & Positive \\
\hline $\begin{array}{l}\text { Karagiannis and } \\
\text { Sarris (2005) }\end{array}$ & $\begin{array}{l}\text { Greek tobacco } \\
\text { growers }\end{array}$ & $\begin{array}{l}\text { Gross revenue in } \\
\text { monetary terms }\end{array}$ & $\begin{array}{l}\text { Farm debt in } \\
\text { monetary terms }\end{array}$ & Negative \\
\hline $\begin{array}{l}\text { Kumbhakar and Lien } \\
\text { (2010) }\end{array}$ & $\begin{array}{l}\text { Norwegian grain } \\
\text { farms }\end{array}$ & $\begin{array}{l}\text { Grain output (feed } \\
\text { units) and subsidy } \\
\text { payments (index) }\end{array}$ & $\begin{array}{l}\text { Total debt / Total } \\
\text { assets }\end{array}$ & Negative \\
\hline $\begin{array}{l}\text { Lambert and Bayda } \\
\text { (2005) }\end{array}$ & $\begin{array}{l}\text { North Dakota (US) } \\
\text { crop farms }\end{array}$ & $\begin{array}{l}\text { Crop output in } \\
\text { monetary terms }\end{array}$ & $\begin{array}{l}\text { Current and } \\
\text { intermediate debt-to } \\
\text { asset ratio } \\
\text { Long term debt-to- } \\
\text { asset ratio }\end{array}$ & $\begin{array}{l}\text { Intermediate debt } \\
\text { positive. Short term } \\
\text { debt negative }\end{array}$ \\
\hline Latruffe et al. (2008) & $\begin{array}{l}\text { Livestock and crop } \\
\text { farms in Czech } \\
\text { republic (individual } \\
\text { owned firms and } \\
\text { corporate) }\end{array}$ & $\begin{array}{l}\text { Total output in } \\
\text { monetary terms }\end{array}$ & $\begin{array}{l}\text { Ratio of interest }+ \\
\text { rentals to total output }\end{array}$ & Negative \\
\hline Latruffe et al. (2017) & $\begin{array}{l}\text { Dairy farms in } \\
\text { Western Europe }\end{array}$ & $\begin{array}{l}\text { Total output in in } \\
\text { monetary terms }\end{array}$ & Total debt/total assets & $\begin{array}{l}\text { Inconclusive. Mostly } \\
\text { no effect, for } \\
\text { Denmark and Portugal } \\
\text { positive relation. } \\
\text { Spain negative effect. }\end{array}$ \\
\hline $\begin{array}{l}\text { Mugera and } \\
\text { Nyambane (2015) }\end{array}$ & $\begin{array}{l}\text { Broadacre farms in } \\
\text { Western Australia }\end{array}$ & $\begin{array}{l}\text { Output value from } \\
\text { crop and livestock in } \\
\text { monetary terms }\end{array}$ & $\begin{array}{l}\text { Long term debt-to- } \\
\text { asset ratio } \\
\text { Short term debt-to- } \\
\text { asset ratio }\end{array}$ & $\begin{array}{l}\text { Positive relation for } \\
\text { short-term debt, no } \\
\text { effect of long-term } \\
\text { debt. }\end{array}$ \\
\hline $\begin{array}{l}\text { O'Neill and Matthews } \\
\text { (2001) }\end{array}$ & $\begin{array}{l}\text { Irish crop, livestock } \\
\text { and mixed farms }\end{array}$ & $\begin{array}{l}\text { Gross output in } \\
\text { monetary terms }\end{array}$ & $\begin{array}{l}\text { Debt ratio of the total } \\
\text { farm borrowings to } \\
\text { the total value of } \\
\text { assets on the } \\
\text { farm }\end{array}$ & Positive \\
\hline Skevas et al. (2018a) & German dairy farms & $\begin{array}{l}\text { Deflated revenues } \\
\text { from milk sales + } \\
\text { deflated revenues } \\
\text { from meat }\end{array}$ & $\begin{array}{l}\text { Debt-to-asset ratio } \\
\text { Liabilities-to-asset } \\
\text { ratio }\end{array}$ & No effect. \\
\hline $\begin{array}{l}\text { Zhu, Demeter and } \\
\text { Oude Lansink (2012) }\end{array}$ & $\begin{array}{l}\text { Dairy farms in } \\
\text { Germany and Sweden }\end{array}$ & $\begin{array}{l}\text { Milk output value in } \\
\text { monetary terms }\end{array}$ & $\begin{array}{l}\text { Share of long and } \\
\text { intermediate run } \\
\text { loans in total assets } \\
(\%) \\
\text { Share of short run } \\
\text { loans to total assets } \\
(\%)\end{array}$ & $\begin{array}{l}\text { Predominantly } \\
\text { negative }\end{array}$ \\
\hline
\end{tabular}




\subsection{Farm debt in Dutch horticulture}

The recent increases in scale in Dutch horticulture are irrevocably accompanied by a high debt burden for individual firms. The average size of primary producers has almost doubled in the period 2008-2015, with also the emergence of a number of fastgrowing mega-firms (Los et al., 2019). Moreover, the dependence on external capital is high, given the capital intensity of the sector, with e.g. the use of high-quality climate systems in order to control the growth of crops (Van der Meulen et al., 2007).

The high indebtedness on the one hand is accompanied by a volatile income position on the other, mainly caused by high price volatility on both input and output markets (European Commission, 2017). This combination of high debts and uncertain earnings creates considerable risk for lenders and financial institutions. As a result, it is of utmost importance for these institutions to assess the performance of high-debt firms.

The development of the average annual debt per square meter and the earnings before interest taxes depreciation and amortization (EBITDA) per square meter in the period 2008-2015 are shown in figure 7.1 for all cucumber, bell pepper and tomato firms. The high volatility in earnings, as well as the relatively high level of debt stand out. Based on both the earnings and the level of debt, financial institutions often calculate the accompanying debt-to-EBITDA in order to assess how many years a firm would need in order to repay its loans (Denis and Wang, 2014). In financial markets, a debt-to-EBITDA below 4 is often considered as an indication of a sustainable debtlevel (Damijan, 2018). Hence if a firm is able to generate $15 €$ of earnings per square meter, a debt level of $€ 60$ per square meter is considered as financially sustainable. Figure 7.1 shows this is on average roughly the case for tomato firms in 2015. In particular in years with low earnings, this ratio however increases drastically, resulting in a higher risk for lenders.

When comparing the different crops, tomato firms on average clearly face the highest level of debt. This is not surprising as these firms also expanded most rapidly in recent decades. Beyond, figure 7.1 shows the somewhat lower average debt at the end of the observation period. This might be the result of either the disappearance of some highly indebted firms, or the stricter lending requirements applied by financial institutions in most recent years (e.g. Brester and Watts, 2019). Nevertheless, the high average debt levels per square meter in combination with increases in average firm size still result in high average debts at firm level. 


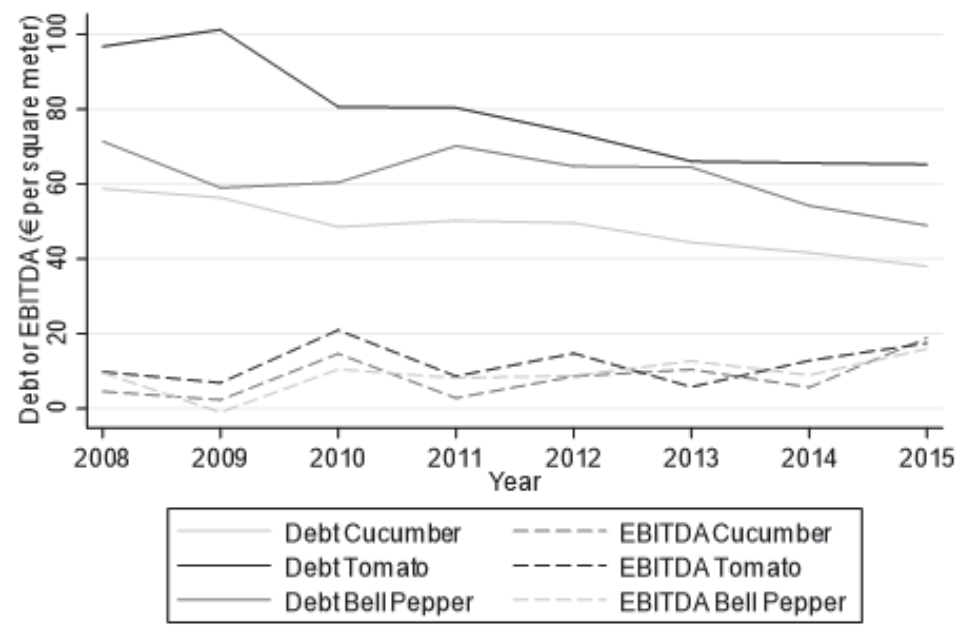

Figure 7.1: Average earnings and debt in $€$ per square meter for Dutch horticultural firms. Period 2008-2015.

The spread in these average levels of debt for the main products is given by the histograms in figure 7.2. For all main products, a considerable number of observations have debt levels of 0 (around 15 to $25 \%$ ). In particular cucumber firms are likely to operate without debt. This is not surprising as these firms are on average smaller and production of cucumbers often takes place in relatively older glasshouses as compared to bell pepper and tomato production. Furthermore, figure 7.2 clearly points at the visibility of highly indebted firms. Most notably some of the bell pepper and tomato firms face a debt at a value high above the average debt values shown in figure 7.1.
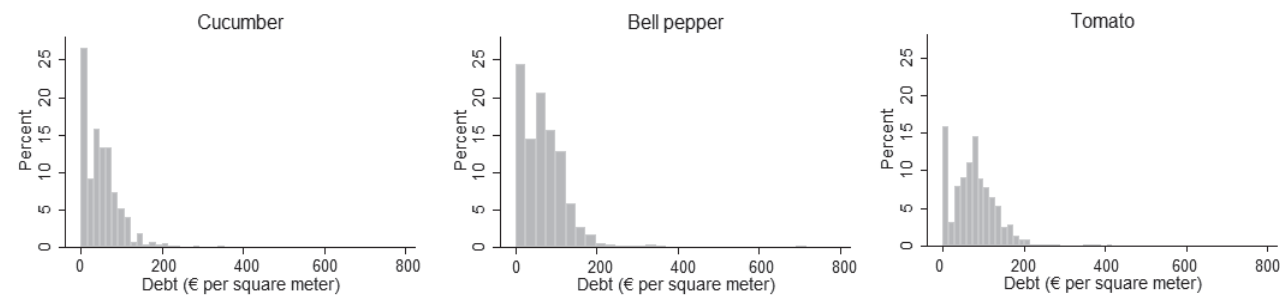

Figure 7.2: Spread in debt in $€$ per square meter for Dutch horticultural firms. Period 2008-2015.

\subsection{Methodology}

In order to assess the relation between a firm's capital structure and its technical efficiency, we apply a two stage method where the efficiency scores are estimated through the use of DEA. These efficiency scores are regressed on indicators for the debt and capital structure of the firm in the second stage of the analysis. As DEA is (in contrast to SFM) a non-parametric method, it does not depend on any specific functional form for the production function (Emrouzjenad and Yang, 2018). Moreover, we can use the obtained efficiency scores in a second stage regression as an outcome 
variable since DEA does not impose any assumptions on the distribution of efficiency scores (e.g. Hoff, 2007). The DEA procedure is based on defining the best virtual producer based on the linear combination of the inputs and output of one or several efficient firms (Odeck, 2007).

If one assumes a production process where output $(y)$ is produced through using a vector of inputs $x_{0}$, we can measure efficiency of firm $i$ relative to the boundary of the convex envelope of all inputs and outputs as follows:

$$
\begin{aligned}
& \text { Min } \theta \\
& \text { s.t. } \\
& \sum_{i=1}^{n} \lambda_{i} x_{i}-\theta x_{0}=-s_{i}^{-} ; \mathrm{i}=1, \ldots, \mathrm{n} \\
& \sum_{i=1}^{n} \lambda_{i} y_{i}-y_{0}=s_{i}^{+} \\
& \sum_{i=0}^{n} \lambda_{i}=1 \\
& \lambda_{i} \geq 0
\end{aligned}
$$

As described in more detail in section 7.5, we assume the usage of six inputs (land, labour, energy, capital, plant-material and other intermediate inputs). Note that for the output as well as for all inputs except land, we use monetary values. This has the advantage that we can account for potential quality differences in the final products or the usage of high-quality inputs, which are highly present in the context of Dutch horticulture (Aramyan et al., 2007).

In the above equations, $\theta$ refers to the input-decreasing efficiency measure of unit $o ; \lambda_{i}$ denotes the non-negative weight of the ith firms output and inputs in order to define a comparison point on the identified frontier. Restriction 2 ensures that the efficiency-corrected use of inputs equals at least the amounts of inputs used by the reference unit $o$ (Odeck, 2007). The third restriction ensures that the reference unit produces at least as much output as unit $i$. Restriction 4 allows for variable returns to scale (VRS). Firms that are technically efficient are those with input and output slack vectors equal to zero:

$$
-s_{i}^{-}=0 \& s_{i}^{+}=0
$$

Inefficient firms will obtain an $\theta$ of below 1 and hence have non-zero input and/or output slacks. In order to analyse the validity of the obtained efficiency scores, we will 
compare these values with other measures of firm profitability and productivity in section 7.6 (see e.g. Sellers and Alampi-Sottini, 2016).

In the second stage of the analysis, a FE model is estimated in order explain the variations in DEA-efficiency scores. A variety of estimation techniques are used in empirical research with respect to exploring the effect of external factors on efficiency scores in a second stage analysis (Hoff, 2007). Tobit models are often used as the efficiency scores are bounded between zero and unity (Lee et al., 2009). However, Hoff (2007) points out that in the case of modelling DEA scores, two-limit Tobit models are mis-specified as the probability of having a lower limit value of 0 is equal to zero (which is, as shown in figure 7.3, also the case in our sample). A one-limit Tobit model (only limiting the efficiency scores on the frontier of 1 ) however is also a misspecification as it assumes the DEA score is continuous on $[-\infty ; 1]$ (Hoff, 2007). In order to avoid these mis-specifications, we choose for a linear approximation in the second stage of the analysis ${ }^{18}$. If we use the obtained efficiency scores from the DEA and denote them with $T E$, we obtain:

$$
\begin{aligned}
T E_{i t}= & \alpha_{i}+\beta_{1} \text { Debt }+\beta_{2} L L C+\beta_{3} \text { Land / Labour } \\
& +\beta_{4} \text { Capital / Labour }+\beta_{5} t+\varepsilon_{i t}
\end{aligned}
$$

Where $\beta$ are the accompanying coefficients of the explanatory variables, $a$ is the firmspecific intercept and $\varepsilon$ the composite error term. In order to study the role of debt and other drivers in explaining variations in technical efficiency, we include the total firm debt (per square meter), a dummy variable on the organizational structure of the firm, the capital-labour ratio and land-labour ratio as well as a general time-trend as explanatory variables (see e.g. Davidova and Latruffe (2007) for a similar approach). The capital-labour and land-labour ratio in turn provide additional insights in the effects of differences in the underlying production structure on firm efficiency. To enable comparison of firms with different sizes, the total amount of debt is recalculated to a debt per square meter. Beyond, we allow for non-linearity by including a squared term for the debt-indicator in a second specification of the model. This allows us to capture any potential effects of a very high debt indebtedness on firm efficiency.

\subsection{Data and descriptive statistics}

The empirical analysis relies on firm-level data obtained from the Analysis Tool Rabobank (Rabobank, 2016). Hence, only horticultural firms with a loan from Rabobank are considered in our sample, implying we do not have specific information on firms obtaining credits from other banks or investment groups. However, Rabobank has a large market share in Dutch horticulture, ensuring that the firms included in the

${ }^{18}$ As an additional robustness check on the results, we also show the results of a Tobit and random effect (RE) model in the Appendix (see tables 7.A1 and 7.A2). 
sample cover more than half of the total horticultural production area in the Netherlands. The sample contains firm-level observations for the period 2008-2015 and includes annual accountancy data. It provides information on firm characteristics (as firm size and organizational structure) and detailed production information for specialized growers of cucumbers, tomato and bell pepper, as well as for firms growing other vegetables in glasshouses such as zucchini and eggplant. The annual costs associated with specific inputs (labour, energy, capital, plant-material and other intermediate inputs) as well as the revenues from production are available per firm.

Table 7.2 shows an overview of the variables used in both the DEA and the second-stage model. Regarding the inputs used in the DEA-model, it should be noted that labour consists of the total costs associated with external labour. Hence, own family labour is not taken into account. Due to the labour intensive production methods, horticultural firms are however largely dependent on external labour, with a share of almost $90 \%$ of external labour in the total labour requirement (Wageningen Economic Research, 2020a). Energy-inputs refer to all costs associated with gas and electricity, which are mainly used for heating the glasshouses and for providing artificial growing light to the plants. Capital costs involve all interest and depreciation costs. Plant-material is the sum of all fertilizer and crop protection costs and the expenses associated with buying plants and substrates. Other intermediate inputs are costs related to packing and transporting, as well as costs associated with the auction. Firm size is measured as the amount of hectares of glasshouses a firm produces on. The crop output is based on the total annual value (in euro's) of the outputs produced. Note that in almost all cases these are specialized firms, implying they only grow one type of product.

The debt indicator used in the second-stage analysis measures the total debt in euro's divided by the total square meters of glasshouses per firm per year. LLC is a dummy variable indicating whether a firm is a family-led firm (0) or a limited liability company (1). The capital/labour ratio denotes the total capital expenses over the total expenses on external labour. The land/labour ratio indicates the total surface of glasshouses in hectares over the total expenses on external labour.

For comparing the obtained efficiency scores from the DEA-model with other performance indicators in section 7.6.1, we use two measures of profitability and one productivity measure. The earnings in euros before interest, taxes, depreciation and amortization (EBITDA) are used as an indicator for firm profitability measure given the focus of this indicator on operational activities (e.g. Parachinni et al., 2015). Furthermore, we consider the margins per square meter, which is defined as the total net profit minus depreciation and interest costs over the total area of glasshouses in square meters. For measuring productivity, we use the total crop output over the total external labour expenses to obtain an indicator for labour productivity. 
The descriptive statistics in table 7.2 show considerable differences between firms. For cucumber firms, e.g., the average annual crop output per firm approximates a value of $€ 1.7$ million with an average firm size of 3.9 hectares. The spread within, but mainly between firms, however is clearly visible, noted by the relatively large between standard deviations. For cucumber firms, labour is on average the most costly input, followed by capital, plant-material and energy expenses. In line with figure 7.1, we see that the average debt is roughly six times the level of the annual earnings per firm. ${ }^{19}$ In particular for firm earnings, however, there is a high within standard deviation, reflecting the high volatility in earnings over time.

Moreover, we see the differences in average input usage between the crops. Compared to bell pepper, cucumber is a relatively labour-intensive crop, as the total labour expenses are on average relatively equal, yet the average firm size for bell pepper firms is much higher. Hence, the capital/labour ratio for cucumber firms is lower. Beyond, cucumbers are most often grown in relatively old glasshouses, which is also demonstrated in the lower debt per square meter.

${ }^{19}$ Note that debt is rescaled to debt in $€ 100$ per square meter in order to enable better comparison of the coefficients in the second-stage model. 
Table 7.2: Descriptive statistics of the main variables.

\begin{tabular}{|c|c|c|c|}
\hline & Cucumber & Bell Pepper & Tomato \\
\hline \multicolumn{4}{|l|}{ DEA-model: } \\
\hline \multirow[t]{2}{*}{ Crop output (in $10000 €$ ) } & $168.906(112.324)$ & $246.492(284.486)$ & $495.411(775.248)$ \\
\hline & $(105.695-\underline{46.791})$ & $(245.592-\underline{109.746})$ & $(797.445-\underline{191.941})$ \\
\hline \multirow[t]{2}{*}{ Firm size (ha) } & $3.964(2.244)$ & $6.970(7.451)$ & $10.350(11.469)$ \\
\hline & $(2.158-\underline{0.754})$ & $(6.309-\underline{2.442})$ & $(10.469-\underline{2.506})$ \\
\hline \multirow[t]{2}{*}{ Labour (in $10000 €$ ) } & $53.987(41.092)$ & $68.566(76.768)$ & $175.243(243.524)$ \\
\hline & $(40.679-\underline{13.131})$ & $(68.831-\underline{22.802})$ & $(229.325-\underline{53.797})$ \\
\hline \multirow[t]{2}{*}{ Energy (in $10000 €$ ) } & $34.786(22.571)$ & $44.996(46.401)$ & $94.956(195.289)$ \\
\hline & $(19.108-\underline{12.526})$ & $(36.117-\underline{24.742})$ & $(158.281-\underline{80.173})$ \\
\hline \multirow[t]{2}{*}{ Capital (in $10000 €$ ) } & $36.632(29.852)$ & $70.766(91.904)$ & $130.565(187.475)$ \\
\hline & $(31.802-\underline{9.586})$ & $(76.699-\underline{35.341})$ & $(183.493-\underline{38.123})$ \\
\hline \multirow[t]{2}{*}{ Plant-material (in $10000 €$ ) } & $35.750(24.277)$ & $41.297(45.234)$ & $89.018(286.802)$ \\
\hline & $(23.833-\underline{8.785})$ & $(38.048-\underline{15.993})$ & $(370.151-\underline{47.689})$ \\
\hline Other intermediate inputs (in 10 & $18.366(16.102)$ & $28.876(30.858)$ & $58.306(95.323)$ \\
\hline $000 €)$ & $(13.557-\underline{9.197})$ & $(29.586-\underline{14.231})$ & $(100.810-\underline{40.537})$ \\
\hline \multicolumn{4}{|l|}{ Second-stage model: } \\
\hline \multirow[t]{2}{*}{ Debt (in $€ 100$ per square meter) } & $0.502(0.462)$ & $0.672(0.578)$ & $0.770(0.564)$ \\
\hline & $(0.243-\underline{0.265})$ & $(0.492-\underline{0.357})$ & $(0.490-\underline{0.327})$ \\
\hline \multirow[t]{2}{*}{ LLC (1=yes) } & $0.339(0.473)$ & $0.255(0.436)$ & $0.378(0.485)$ \\
\hline & $(0.434-\underline{0.180})$ & $(0.382-\underline{0.218})$ & $(0.445-\underline{0.215})$ \\
\hline Land/Labour (Land (ha) per labour & $0.093(0.060)$ & $0.127(0.469)$ & $0.075(0.063)$ \\
\hline$(€))$ & $(0.049-\underline{0.036})$ & $(0.555-\underline{0.321})$ & $(0.038-\underline{0.052})$ \\
\hline Capital/Labour (Capital ( $€$ ) per & $0.859(0.244)$ & $0.950(0.207)$ & $0.901(0.159)$ \\
\hline labour $(€))$ & $(0.257-\underline{0.088})$ & $(0.235-\underline{0.088})$ & $(0.173-\underline{0.081})$ \\
\hline \multicolumn{4}{|l|}{ Other performance indicators: } \\
\hline \multirow{2}{*}{$\begin{array}{l}\text { Earnings (EBITDA in } € \text { per square } \\
\text { meter) }\end{array}$} & $7.490(8.152)$ & $8.909(7.007)$ & $12.068(9.607)$ \\
\hline & $(5.909-\underline{5.950)}$ & $(5.130-\underline{5.261)}$ & $(7.786-\underline{6.843)}$ \\
\hline \multirow{2}{*}{$\begin{array}{l}\text { Crop output (in } € 10000 \text { )/Labour } \\
\text { expenses }(€ \text { ) }\end{array}$} & $3.543(1.275)$ & $3.880(3.454)$ & $2.983(1.237)$ \\
\hline & $(1.123-\underline{0.682)}$ & $(4.039-2.337)$ & $(1.264-\underline{6.793})$ \\
\hline \multirow[t]{2}{*}{ Margin ( $€$ per square meter) } & $-2.252(7.918)$ & $-1.594(6.812)$ & $-0.160(8.688)$ \\
\hline & $(5.076-\underline{6.517)}$ & $(4.952-\underline{5.480})$ & $(6.547-\underline{6.836})$ \\
\hline$N(n)$ & $537(116)$ & $924(174)$ & $990(184)$ \\
\hline
\end{tabular}

Source: Authors, based on Rabobank (2016).

Note: The mean is followed by the standard deviations in parentheses. The row below provides a breakdown of the standard deviation in the between standard deviation (given in italic) and the within standard deviation (underlined).

\subsection{Empirical results}

\subsubsection{First stage results: DEA efficiency scores}

The firm-specific efficiency-scores are obtained from the DEA estimation in order to further analyse the relation between a firms capital structure and its efficiency. Figure 7.3 shows that the majority of the firms are scoring a technical efficiency between 0.7 and 0.9. A considerable share of cucumber firms also obtain efficiency scores below 0.7 , while tomato firms on average obtain the highest efficiency scores relative to the frontier. 


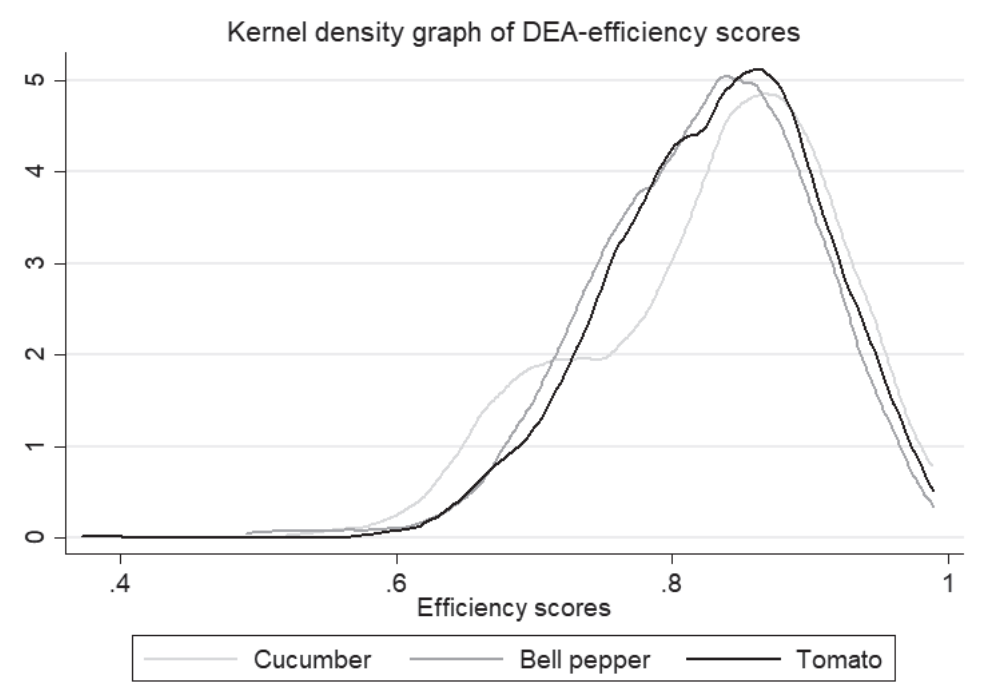

Figure 7.3: Kernel density estimates of DEA technical efficiency-scores for cucumber firms.

Over time, horticultural firms are increasing their efficiency. Table 7.3 shows the average efficiency scores for the total sample for all the studied years. The efficiency scores in 2008 and 2009 are considerably lower as compared to the later years. This might be due to firms increasing their efficiency over time, but can also be the result of bankruptcies of underperforming firms in the first years of the observational period. For the subsamples of the main crops, the same results hold.

Table 7.3: Technical efficiency scores over time, standard deviations between brackets (period 2008-2015).

\begin{tabular}{lllll}
\hline Year & Full sample & Cucumber & Bell pepper & Tomato \\
\hline $\mathbf{2 0 0 8}$ & $0.737(0.079)$ & $0.720(0.085)$ & $0.737(0.075)$ & $0.747(0.067)$ \\
$\mathbf{2 0 0 9}$ & $0.798(0.088)$ & $0.799(0.083)$ & $0.828(0.079)$ & $0.761(0.089)$ \\
$\mathbf{2 0 1 0}$ & $0.870(0.075)$ & $0.892(0.061)$ & $0.901(0.065)$ & $0.823(0.069)$ \\
$\mathbf{2 0 1 1}$ & $0.860(0.077)$ & $0.829(0.082)$ & $0.844(0.079)$ & $0.877(0.058)$ \\
$\mathbf{2 0 1 2}$ & $0.856(0.061)$ & $0.884(0.062)$ & $0.853(0.051)$ & $0.842(0.054)$ \\
$\mathbf{2 0 1 3}$ & $0.867(0.075)$ & $0.898(0.064)$ & $0.825(0.077)$ & $0.891(0.061)$ \\
$\mathbf{2 0 1 4}$ & $0.876(0.062)$ & $0.880(0.065)$ & $0.872(0.065)$ & $0.867(0.057)$ \\
$\mathbf{2 0 1 5}$ & $0.895(0.061)$ & $0.941(0.041)$ & $0.889(0.066)$ & $0.871(0.046)$ \\
\hline
\end{tabular}

To compare the efficiency scores with other measures of productivity (defined as the total product revenues/total labour expenses) and profitability (EBITDA and margin per square meter), we calculate Pearson correlation coefficients to examine the similarities between the measures. Table 7.4 shows relatively high and significant correlations between those measures for the total sample, which also holds for all the subsamples of the main crops. The efficiency estimates are in particular highly correlated with the earnings and margin per square meter. This shows that profitable firms are also likely to be among the most efficient firms. Moreover, it points at the consistency of our efficiency estimates for understanding firm performance. 
Table 7.4: Pearson correlation coefficients of measures of efficiency, productivity and profitability.

\begin{tabular}{lllll}
\hline & $\begin{array}{l}\text { Technical } \\
\text { Efficiency }\end{array}$ & $\begin{array}{l}\text { EBITDA per } \\
\text { square meter }\end{array}$ & $\begin{array}{l}\text { Margin per } \\
\text { square meter }\end{array}$ & $\begin{array}{l}\text { Crop output/ } \\
\text { Labour } \\
\text { expenses }\end{array}$ \\
\hline $\begin{array}{l}\text { Technical Efficiency } \\
\text { EBITDA per square meter }\end{array}$ & $\begin{array}{l}1.000 \\
0.523 * * *\end{array}$ & 1.000 & \\
$\begin{array}{l}\text { Margin per square meter } \\
\text { Crop output/labour }\end{array}$ & $0.446 * * *$ & $0.733^{* * *}$ & 1.000 & \\
expenses & $0.310 * * *$ & $0.346 * * *$ & $0.301 * * *$ & 1.000 \\
\hline Notes: $* * *$ represents statistical significance at the $1 \%$-level. & & \\
\hline
\end{tabular}

\subsubsection{Second stage results: Efficiency and debt}

In the second stage of the analysis, the obtained efficiency scores are modelled as a dependent variable. Table 7.5 shows the results of the model with the original debt term included as explanatory variable, whereas table 7.6 shows the results of adding the quadratic debt term. All intercepts are highly significant and relatively close to the mean sample values of the DEA analysis. Beyond, the results show a positive effect for the time trend, implying that the efficiency-score increases over time, with on average an increase in 0.0165 per year for the full sample in the linear model. Furthermore, we find a significant, negative association between debt and efficiency for the overall sample and for cucumber and tomato firms. Indebted firms are therefore likely to have a lower efficiency-score. For every additional $€ 100$ debt per square meter, the efficiency score drops with 0.0213 point in the full sample. This suggests evidence for the agency-theory, given the association between debt and lower efficiency. Table 7.5 however shows that after including the squared term of debt, the initial effect of debt on efficiency disappears. Moreover, the significance of the squared debt-term points that the relation between debt and efficiency is rather driven by the quadratic effect ${ }^{20}$. This implies that for observations with low to average debt levels, no effect between debt and efficiency is found. Yet, this effect is mainly driven by highly indebted firms who are found to have low efficiency levels. These findings are also consistent with the Tobit and RE models shown in tables 7.A1 and 7.A2 in the appendix.

In the quadratic RE model for bell pepper firms we even observe a positive and significant effect of debt on efficiency, followed by the negative quadratic effect. This suggests a low to average debt is actually positively associated with firm efficiency, yet this effect eases off for firms with larger debt. For values larger than 1.146 (calculated by using ( $\left.-\beta_{\text {debt }} / 2 \beta_{\text {debtsquared }}\right)$ ) the combined debt terms generate a negative value, implying non-monotonicity in the relation between debt and efficiency.

Overall, our results consistently point that having a too large debt is likely to have negative implications for a firms' technical efficiency. Several explanations are plausible for this finding. First, in line with the agency theory, high costs associated

${ }^{20}$ In line with this, the overall model fit as measured by the $\mathrm{R}^{2}$ for all subsamples is higher in the quadratic specification of the model. 
with indebtedness might restrict the scope of managerial decisions and hence reduces efficiency. Our findings suggest that this holds in particular for highly indebted firms. Second, high levels of debt generate a large external pressure on management which in turn might also negatively impact managerial decisions (Osma et al., 2018). It may however also be the case that highly indebted firms already had a lower efficiency score. This could force them to take out loans and invest in order to be able to keep up with further market developments. Yet, it is very unlikely that banks and financial institutions will specifically target these underperforming firms with loans, given the high risk this entails.

As an additional check, and in order to disentangle potential effects between high debts and recent investments, we also included a dummy variable capturing whether or not a firm invested in additional glasshouses during the observation period. These results can be found in table 7.A3 in the Appendix and show that including the investment variable does not change the relation between debt and efficiency. Moreover, and in line with the logic of the embodied capital hypothesis, it is found that investments are significantly and positively related to efficiency in the full sample as well as in the subsamples of bell pepper and tomato producing firms. This indicates that, holding other factors constant, firms which recently expanded are on average more efficient.

Regarding the remaining indicators, no consistent and significant effects are found. The results show no effect of organizational structure on firm efficiency. Only for cucumber and tomato firms, we observe a respectively positive and negative relation between a high capital/labour ratio and firm efficiency. This suggests that cucumber firms (where production mostly takes place in somewhat older glasshouses) can improve their efficiency by increasing the ratio of capital over labour, while the opposite effect is found for tomato firms.

Table 7.5: Results of the FE regression (linear model).

\begin{tabular}{lllll}
\hline & \multicolumn{1}{c}{ All } & \multicolumn{1}{c}{ Cucumber } & \multicolumn{1}{c}{ Bell Pepper } & \multicolumn{1}{c}{ Tomato } \\
\hline Debt & $-0.0213^{* * *}(0.004)$ & $-0.0464 * *(0.010)$ & $-0.0164 * *(0.005)$ & $-0.0251^{* * *}(0.006)$ \\
LLC & $-0.0027(0.006)$ & $-0.0128(0.014)$ & $-0.0054(0.008)$ & $0.0122(0.009)$ \\
Land/labour & $0.0034(0.006)$ & $0.1021(0.075)$ & $0.0025(0.006)$ & $0.0425(0.037)$ \\
Capital/labour & $-0.0012(0.004)$ & $0.0568^{*}(0.032)$ & $-0.0036(0.023)$ & $-0.0450^{*}(0.026)$ \\
Time trend & $0.0165^{* * *}(0.001)$ & $0.0245^{* * *}(0.002)$ & $0.0187 * *(0.001)$ & $0.0098^{* * *}(0.001)$ \\
Intercept & $0.7874 * * *(0.006)$ & $0.7166^{* * *}(0.029)$ & $0.7682 * * *(0.023)$ & $0.8514 * * *(0.025)$ \\
& & & & \\
$\mathbf{N}$ & 2815 & 522 & 886 & 899 \\
$\mathbf{n}$ & 572 & 115 & 174 & 175 \\
& & & & $28.82 * * *$ \\
F-test & $160.24 * * *$ & $60.86 * * *$ & $76.01 * * *$ & 0.044 \\
$\mathbf{R}^{2}$ & 0.175 & 0.284 & 0.261 & \\
\hline
\end{tabular}

Source: Authors, based on Rabobank (2016). Standard errors between brackets. Notes: *,** and *** represent statistical significance at respectively the $10 \%, 5 \%$ and $1 \%$ level. 
Table 7.6: Results of the FE regression (including quadratic debt-term).

\begin{tabular}{|c|c|c|c|c|}
\hline & All & Cucumber & Bell Pepper & Tomato \\
\hline Debt & $-0.0078(0.006)$ & $-0.0183(0.018)$ & $0.0045(0.009)$ & $0.0022(0.012)$ \\
\hline Debt*Debt & $-0.0043 * * *(0.001)$ & $-0.0135 *(0.007)$ & $-0.0050 * * *(0.001)$ & $-0.0095 * *(0.003)$ \\
\hline LLC & $-0.0032(0.005)$ & $-0.0155(0.011)$ & $-0.0068(0.009)$ & $0.0125(0.010)$ \\
\hline Land/labour & $0.0035(0.005)$ & $0.1022(0.075)$ & $0.0022(0.006)$ & $0.0440(0.037)$ \\
\hline Capital/labour & $-0.0017(0.004)$ & $0.0492(0.032)$ & $-0.0074(0.023)$ & $-0.0574 * *(0.027)$ \\
\hline Time trend & $0.0165 * * *(0.001)$ & $0.0244 * * *(0.002)$ & $0.0187 * * *(0.001)$ & $0.0099 * * *(0.001)$ \\
\hline Intercept & $0.7821 * * *(0.006)$ & $0.7166 * * *(0.029)$ & $0.7616 * * *(0.023)$ & $0.8493 * * *(0.025)$ \\
\hline $\mathbf{N}$ & 2815 & 522 & 886 & 899 \\
\hline $\mathbf{n}$ & 572 & 115 & 174 & 175 \\
\hline F-test & $135.15^{* * *}$ & $51.12 * * *$ & $66.34 * * *$ & $25.30 * * *$ \\
\hline $\mathbf{R}^{2}$ & 0.183 & 0.291 & 0.278 & 0.054 \\
\hline
\end{tabular}

Source: Authors, based on Rabobank (2016). Standard errors between brackets. Notes: *, ** and $* * *$ represent statistical significance at respectively the $10 \%, 5 \%$ and $1 \%$ level.

\subsection{Conclusion}

The findings of this chapter contribute to a growing literature assessing the relation between a firms capital structure and their production efficiency. An overview of recent empirical studies in various agricultural sectors provided in this chapter shows that the results of these studies are largely inconclusive. This is most likely due to the high dependence of this relationship on the specific production context. Dutch horticulture is therefore a very interesting context to further study this relationship, given the high capital intensity and the large dependence on external capital to modernize firms and finance new investments. Due to this high capital intensity, a relatively large share of firms are forced to operate with a high debt in relation to their earnings. In such a context, it is therefore very relevant to allow non-linearity and non-monotonicity in the relationship between debt and efficiency. In this chapter this is done in the form of a quadratic specification in a second-stage analysis, in which the association between debt position and the obtained DEA efficiency score is examined.

Initially, our results point at a negative relation between debt and efficiency, in line with the agency theory (Jensen and Meckling, 1986). However, after allowing for non-linearity, our findings suggest that this effect is mainly driven by highly indebted firms, as the initial linear term is no longer significant. Hence, this implies that the costs associated with debt are particularly impacting and restricting the scope of managerial decisions at highly indebted firms. Note that in a specific subsample of bell pepper firms it is found that having a low-to-moderate level of debt actually has a positive correlation with firm efficiency, yet for highly indebted firms the net effect of debt becomes negative. This implies the relation between debt and efficiency is not necessarily monotonic. Furthermore, it is important to note that our overall findings are robust to various estimation methods in the second stage of the analysis (see e.g. Hoff, 2007) and also hold in various subsamples of specialized producers. Beyond, our obtained DEA efficiency score shows high correlation with other measures of 
profitability and productivity, pointing at the consistency of our efficiency estimates for understanding firm performance.

Our results have further implications for both policymakers as well as financial institutions. In particular given the high financial risks involved, assessing the relation between debt and measures of firm performance is highly relevant. This is especially the case as high levels of debt are not associated with higher efficiency. Note however that we do find a positive association between investments in glasshouses and efficiency, suggesting that modernized firms are on average more efficient. This might complicate the decision of financial institutions on giving out credits.

A limitation of our approach is that we are unable to address new forms of financial streams flowing into the agricultural sector, such as financing through private equity. The literature in this field regarding agriculture is still somewhat limited and mainly focuses on land investments in developing countries and acquisitions by commodity trading firms (Clapp et al., 2017). Given that investment groups and private equity firms also choose to invest in Dutch glasshouse horticulture (e.g. Onder Glas, 2019) these new financial streams point at the complexity of capital structures in modern agriculture and hence form an interesting topic for further studies in this field.

Beyond, as shown by the inconclusiveness of previous empirical research, our results may be highly context-specific and subject to the idiosyncrasies of the studied sectors, as well as the price dynamics at output markets and the varying costs of debt and in the studied period. This limits the further generalizability of our results. Nevertheless, our results do emphasize the importance of allowing for non-linearity and non-monotonicity in the relation between debt and efficiency. Despite that most empirical studies on agricultural sectors seem to neglect this issue, our findings point at the special position of highly indebted firms, particularly given the high financial risks involved. 


\section{A Appendix}

Table 7.A1: Results of the Tobit regression (including quadratic debt-term).

\begin{tabular}{|c|c|c|c|c|}
\hline & All & Cucumber & Bell Pepper & Tomato \\
\hline Debt & $0.0033(0.005)$ & $-0.0017(0.017)$ & $0.0141 *(0.008)$ & $0.0182(0.011)$ \\
\hline Debt*Debt & $-0.0050 * * *(0.002)$ & $-0.0127 *(0.007)$ & $-0.0059 * * *(0.001)$ & $-0.0109 * * *(0.003)$ \\
\hline LLC & $-0.0011(0.004)$ & $-0.0122(0.012)$ & $0.0023(0.007)$ & $0.0052(0.008)$ \\
\hline Land/labour & $0.0671 * * *(0.023)$ & $0.2252 * * *(0.077)$ & $0.0113(0.009)$ & $0.0764 *(0.043)$ \\
\hline Capital/labour & $-0.0078(0.007)$ & $-0.0182(0.023)$ & $-0.0429 * * *(0.016)$ & $-0.0377(0.024)$ \\
\hline Time trend & $0.0176 * * *(0.001)$ & $0.0260 * * *(0.002)$ & $0.0193 * * *(0.001)$ & $0.0111 * * *(0.001)$ \\
\hline Intercept & $0.7692 * * *(0.008)$ & $0.7460 * * *(0.022)$ & $0.7837 * * *(0.016)$ & $0.8156 * * *(0.022)$ \\
\hline $\mathbf{N}$ & 2815 & 522 & 886 & 899 \\
\hline $\mathbf{n}$ & 572 & 115 & 174 & 175 \\
\hline Wald $x^{2}$ & $859.30 * * *$ & $314.60 * * *$ & $436.31 * * *$ & $141.90 * * *$ \\
\hline Log likelihood & 2888.085 & 518.655 & 1061.543 & 934.205 \\
\hline
\end{tabular}
statistical significance at respectively the $10 \%, 5 \%$ and $1 \%$ level. The Wald test has a $x^{2}$-distribution with 6 degrees of freedom.

Table 7.A2: Results of the RE regression (including quadratic debt-term).

\begin{tabular}{|c|c|c|c|c|}
\hline & All & Cucumber & Bell Pepper & Tomato \\
\hline Debt & $0.0036(0.005)$ & $0.0003(0.016)$ & $0.0133 *(0.008)$ & $0.0162(0.011)$ \\
\hline Debt*Debt & $-0.0051 * * *(0.001)$ & $-0.0135 *(0.006)$ & $-0.0058 * * *(0.001)$ & $-0.0103 * * *(0.003)$ \\
\hline LLC & $0.0003(0.004)$ & $-0.0111(0.011)$ & $0.0021(0.007)$ & $0.0053(0.007)$ \\
\hline Land/labour & $0.0111 * * *(0.004)$ & $0.1626 * *(0.066)$ & $0.0046(0.005)$ & $0.0553(0.036)$ \\
\hline Capital/labour & $-0.0053(0.003)$ & $-0.0023(0.021)$ & $-0.0354 * *(0.016)$ & $-0.0269(0.022)$ \\
\hline Time trend & $0.0172 * * *(0.001)$ & $0.0249 * * *(0.002)$ & $0.0192 * * *(0.001)$ & $0.0111 * * *(0.001)$ \\
\hline Intercept & $0.7716 * * *(0.005)$ & $0.7378 * * *(0.019)$ & $0.7772 * * *(0.016)$ & $0.8065 * * *(0.021)$ \\
\hline $\mathbf{N}$ & 2815 & 522 & 886 & 899 \\
\hline $\mathbf{n}$ & 572 & 115 & 174 & 175 \\
\hline Wald $x^{2}$ & $924.08 * * *$ & $323.41 * * *$ & $453.89 * * *$ & $150.71 * * *$ \\
\hline $\mathbf{R}^{\mathbf{2}}$ & 0.199 & 0.322 & 0.291 & 0.086 \\
\hline
\end{tabular}

Source: Authors, based on Rabobank (2016). Standard errors between brackets. Notes: *, ** and *** represent statistical significance at respectively the $10 \%, 5 \%$ and $1 \%$ level. The Wald test has a X2-distribution with 6 degrees of freedom.

Table 7.A3: Results of the RE regression (including quadratic debt-term and investment-variable).

\begin{tabular}{|c|c|c|c|c|}
\hline & All & Cucumber & Bell Pepper & Tomato \\
\hline Debt & $0.0025(0.005)$ & $-0.0002(0.016)$ & $0.0121(0.008)$ & $0.0146(0.011)$ \\
\hline Debt*Debt & $-0.0051 * * *(0.001)$ & $-0.0134 *(0.006)$ & $-0.0057 * * *(0.001)$ & $-0.0103 * * *(0.003)$ \\
\hline LLC & $-0.0001(0.004)$ & $-0.0113(0.011)$ & $0.0020(0.007)$ & $0.0051(0.007)$ \\
\hline Land/labour & $0.0114 * * *(0.004)$ & $0.1623 * *(0.066)$ & $0.0047(0.005)$ & $0.0549(0.036)$ \\
\hline Capital/labour & $-0.0055 *(0.003)$ & $-0.0029(0.021)$ & $-0.0380 * *(0.016)$ & $-0.0284(0.022)$ \\
\hline Investment & $0.0130 * *(0.005)$ & $0.0045(0.014)$ & $0.0162 *(0.008)$ & $0.0246 * *(0.010)$ \\
\hline Time trend & $0.0172 * * *(0.001)$ & $0.0249 * * *(0.002)$ & $0.0191 * * *(0.001)$ & $0.0111 * * *(0.001)$ \\
\hline Intercept & $0.7716 * * *(0.005)$ & $0.7375 * * *(0.019)$ & $0.7750 * * *(0.016)$ & $0.8024 * * *(0.021)$ \\
\hline $\mathbf{N}$ & 2815 & 522 & 886 & 899 \\
\hline $\mathbf{n}$ & 572 & 115 & 174 & 175 \\
\hline Wald $x^{2}$ & $930.72 * * *$ & $323.34 * * *$ & $458.46 * * *$ & $156.66^{* * *}$ \\
\hline $\mathbf{R}^{2}$ & 0.205 & 0.322 & 0.303 & 0.103 \\
\hline
\end{tabular}




\section{Chapter 8}

\section{GENERAL CONCLUSION AND DISCUSSIONS}




\subsection{Introduction}

The Dutch horticultural sector is internationally leading with both a high product quality and a high productivity per hectare. Agricultural products as well as knowledge and input materials, such as seeds and seedlings, are therefore to a large extent exported to other Member States within the European Union and third countries (Jukema, 2019). Nevertheless, the position of the primary producer within the food supply chain is fragile, particularly due to strong market volatility (Vink and Boezeman, 2018). The high degree of specialization in production, where most producers only grow one type of product (Jukema, 2019), ensures that in case of low prices for a specific product, the income of these producers decreases considerably. Consequently, this has led to quite a number of bankruptcies in the sector in the past decade (Statistics Netherlands, 2019b).

In addition, the sector is under pressure due to the current high usage of energy (Verreth et al., 2015) and the great dependence on external capital (Skevas, 2018a). In order to maintain economically viable operations, and to remain competitive internationally, it is important that primary producers are able to deal with these changing external environments. However, what is characteristic of Dutch greenhouse horticulture is the large degree of heterogeneity and the underlying differences between primary producers. This is reflected, amongst others, in the coexistence of classical family-led operations as well as primary producers with a complex organizational structure (e.g. Goncharova et al., 2008; Poppe and Vrolijk, 2019). Moreover, this heterogeneity is also evident from the differences in production orientation of individual firms, with a growing share of the producers aiming to produce for niche markets and other primary producers focusing on producing large quantities.

As pointed out in chapter 1 , the main objective of this thesis is to contribute to the literature on agricultural production by analysing firm-specific and heterogeneous responses to changes in the economic, institutional and financial environment in Dutch horticulture. Specific attention is paid to heterogeneity in firm structure (in particular regarding investment behaviour and scale increases), firm specific outcomes (with respect to both obtained output prices and technical efficiency), as well as to individual firm responses to changing policies.

These aspects are particularly relevant given recent literature on agricultural production which increasingly questions the homogeneity of (output) prices in agricultural markets (Falkowski, 2017; Sauer, 2012), as well as the unlimited and therefore homogenous access to capital (Henning and Jordaan, 2016), the identical reactions of firms to policy changes or changing production conditions (Koutchade, 2018; Reidsma, 2010; Finger and El Benni, 2020) and the use of homogenous technologies (Renner et al., 2020).

The synthesis of the findings of the five core chapters of this thesis is summarized in the next section (8.2). The remainder of this chapter provides general 
conclusions that go beyond the level of the individual chapters (section 8.3), the wider policy implications derived from the results (section 8.4 ) as well as a critical reflection in combination with potential avenues for future research (section 8.5).

\subsection{Synthesis of the main results}

With an increased focus on product quality, the widespread usage of vertical coordination mechanisms and a growing heterogeneity among firms, agricultural markets increasingly move away from the notion of perfectly competitive markets (Secton, 2013; Bonanno et al., 2018b). Empirical research on agricultural production should therefore address these developments, and put larger emphasis on e.g. product differentiation, differences in production methods, and strategic choices between firms.

Consequently - and in line with the first research objective identified in section 1.3 - chapter 3 of this thesis explicitly studied differences in firm structure, with a specific focus on firm size. Classically, the explanation for firm growth is that firms want to benefit from economies of scale, where the increased scale of production would ensure lower average (fixed) production costs (Kimura and Le Thi, 2013). The results in chapter 3 however show that cost reduction due to economies of scale is not the main driver behind the growth in horticultural firm size. In fact, the empirical analysis shows that larger horticultural firms face higher average production costs compared to smaller firms, in particular due to their higher expenses on labour and capital. Yet, these higher production costs are compensated by the on average higher and more stable output prices obtained by larger firms. This positive effect of firm size on firm revenues therefore provides a different rationale for the recent growth in average size of Dutch horticultural firms. Consequently, the results in chapter 3 show that revenuerelated aspects are becoming more important in understanding firm growth of primary producers in the horticultural sector. Hence, the findings suggest that, rather than solely internal firm processes, the relation between the primary producer and the market environment is important in shaping the structure of a modern agricultural firm.

In line with the second research objective, chapter 4 studied the differences in output prices between firms in more detail in order to assess heterogeneity in market positioning. While a large share of literature (Liu et al., 2019; Bonanno et al., 2018b; Assefa et al., 2017) pays attention to farmer-retail power relations in agricultural supply chains, little is known about potential differences between primary producers and the output prices they receive for their products. The results of the Markov transition analysis in chapter 4 show that the same firms are constantly found in the higher and lower quartiles of the price distribution, implying prices are not distributed randomly. In the context of Dutch horticulture, strategic investment decisions - such as the choice to invest in artificial growing light in order to prolong the growing season 
of plants, as well as the increased focus on quality aspects - are argued to play a considerable role in the formation of output prices (Verhaegh, 1998). Hence, a price/cost ratio is calculated to correct for any price differences occurring due to quality aspects. In order to allow for the inclusion of time-invariant variables such as most firm characteristics - e.g. organizational structure and firm size - a hybrid panel model is estimated (Schunk, 2013) which points out that larger firms are able to obtain higher output prices. It is argued that retail partners, as a result of dealing with larger partners, face lower transaction costs and are able to pass on some of the saved costs in the form of higher output prices (Sauer et al., 2012). In combination with the main findings of chapter 3 , these results point at the importance of the market environment for shaping the internal structure of the firm. It however should be noted that all firms are subject to strong output price volatilities in these markets, complicating the further market orientation of primary producers. Nevertheless, the results do point at considerable and structural differences in market positioning between firms.

Corresponding with the third research objective, chapter 5 paid particular attention to firm-specific responses as a result of changes in the institutional environment. Given the energy-intensive character of horticultural production, producers face increased pressure to take the environmental effects of production into account (Falkner, 2016; Chuchiella, 2018). Hence, chapter 5 focuses on assessing the effects of a proposed taxation on the usage of natural gas (Climate Agreement, 2019). Most studies that focus on the impact of climate policies on agricultural production and incomes (e.g. Baker et al., 2010; Babcock, 2015) do so at an aggregate level, using e.g. Partial Equilibrium or Computable General Equilibrium models (e.g. Beckman et al., 2012; Robertson et al., 2013). Earlier studies analysing the heterogeneous impact of these policies at disaggregated level or on different types of firms are limited (e.g. Berger and Troost, 2014). Moreover, panel data models on agricultural production often overlook potential (unobserved) heterogeneous responses to policy and price changes. Most of these models implicitly assume that primary producers respond homogeneously to economic incentives given that the effect of e.g. netput prices is most often specified as a fixed slope coefficient equal across all firms (Koutchadé et al., 2018). Hence, they are unable to assess the underlying heterogeneity in firm structure, differences in production processes - such as the usage of a CHP-engine or artificial growing light - and differences in e.g. energy contracts between firms.

The assumption of a fixed slope parameter, which would assume that every firm responds the same to changes in relative input prices, is relaxed by applying a Bayesian Random Coefficient Model. In combination with prior information on expected price elasticities, the estimated model shows how individual firms respond to changes in the price of the main energy sources (natural gas and electricity). The results point out that larger firms on average use less energy in their production, and hence are expected to face lower negative income effects based on the proposed taxation. 
Allowing for firm-specific responses furthermore reduces the underestimation of variability in responses. The model selection criteria show a better model fit as compared to traditional fixed slope parameters. This points at considerable heterogeneity in individual responses due to changes in relative input prices. Consequently, this shows that (unobserved) factors, such as differences in energy contracts or energy-systems and production choices at firm-level, are important for understanding how individual firms respond to changes in the institutional environment.

Chapters 6 and 7 on the other hand focused explicitly on the relation between the primary producer and the financial environment. In accordance with the fourth research objective, chapter 6 examined the impact of firm-specific credit constraints on investment behaviour. Traditionally, most empirical analyses on investment neglect the role of credit constraints, assuming perfect capital markets with unlimited availability of capital (Ardalan, 2017). The decision of a firm to invest is often made after an ex ante evaluation of the effects on the firm's expected results, also known as capital budgeting (Oude Lansink et al., 2001). Yet, after the 2007-2008 financial crisis banks apply stricter conditions in lending out capital, making it harder for horticultural firms to invest (Blundell-Wignall and Atkinson, 2010; Brester and Watts, 2019). Expanding a theoretical dynamic model of investment by including credit constraints allows for banks charging higher interest rates for lending to firms with a weak financial position (Demerjian and Owens, 2016). Hence, this allows for a more accurate image of firm-specific elements in the relation between the primary producer and the credit supplier. The results of the panel Tobit model in chapter 6 are not entirely unambiguous, but do point that over time the impact of the cashflow variable (measuring the firm-specific component) increases. This shows that it becomes less self-evident that firms have access to external capital. Consequently, heterogeneity in the relation between the primary producer and credit suppliers (the financial environment) is of growing importance. Moreover, the results show that firms with a high operating value are more likely to invest. This in turn suggest a growing divergence between smaller and larger growing firms within the horticultural sectors.

In line with the fifth research objective, the last chapter of the main body of this thesis studied to what extent the capital structure of a firm is associated with their actual performance. While a stream of literature (the so-called cash flow theories) finds evidence for a positive relation between debt and the efficiency of a firm (e.g. Mugera and Nyambane, 2015), other studies - in line with the agency cost theory focus on the additional costs of debt and hence point at the potential negative relation between debt and firm efficiency (Gadanakis et al., 2019; Latruffe et al., 2017). In the context of Dutch horticulture, it however should be noted that a considerable number of firms are very capital intensive and highly dependent on external capital (Statistics Netherlands, 2020b), implying large differences in the debt position between firms. 
Only assessing a linear relationship, as most other empirical research and traditional theories on the relation between debt and efficiency suggest, is therefore insufficient and inadequate in this context. Including a quadratic debt term allows for assessing potential non-linearity and non-monotonicity in the relation between debt and efficiency. The results in chapter 7 show a significant negative relation between the quadratic debt term and the obtained DEA efficiency scores of individual firms, whereas no or only small effects are found for the original debt term. This suggests that particularly firms with very high levels of debt are found to have a low efficiency score. These findings are robust to various estimation methods in the second stage of the analysis (see e.g. Hoff, 2007) and also hold in various subsamples of specialized producers. Beyond, the obtained DEA efficiency score shows high correlation with other measures of profitability and productivity, pointing at the consistency of our efficiency estimates for understanding firm performance.

From the individual chapters it can therefore be concluded that modern agricultural producers are rather different from the traditional view in which the farm is outlined as a homogeneous entity producing a standard product that is sold at a given price on an anonymous market. On the contrary, primary producers run complex and often heterogeneous firms who face dependency relationships with various partners in both the institutional, market and financial environment. This thesis also pointed at the increasing importance of these relationships, which is - amongst others - visible in the finding that investment behaviour of primary producers is over time increasingly constrained by their financial position, and hence their relation with the financial environment as highlighted in chapter 6.

Furthermore, as particularly shown in chapters 3 and 4, these relationships with the external environment are also important in shaping the internal structure of the firm. As shown in chapter 3, larger firms are barely able to exploit economies of scale in order to achieve lower costs. As a result, only considering internal processes (such as cost minimization at firm-level) is inadequate for explaining recent scale enlargements within the sector. Increases in firm size however do have a positive effect on the obtained output prices at firm-level, which suggests the relationships with external partners are important drivers of changes in firm structure. However, as particularly shown in chapter 5 , not all firms respond in the same manner to changes in their (institutional) environment. Moreover, the results of chapter 4 point at the ability of individual firms to structurally deviate from average market prices. These findings therefore show that the primary producer does not operate in a force field in which the external environment only exerts its pressure on the primary producer, but rather in an arena in which heterogeneous responses are central. 


\subsection{Policy implications}

The results discussed in the previous subsection give rise to wider implications for both policy makers and other actors in the identified environments of figure 1.1. Perhaps the most clear policy recommendations can be drawn from the results of chapter 5 which point out that firms do not respond homogeneously to changes in energy prices.

Given the increased pressure on agricultural producers to produce in an environmentally friendly manner, policy makers aim to incentivize producers to do so and to alter their production methods (Cuchiella et al., 2018; Falkner, 2016). Next to stricter regulations, implicit or explicit taxation are one of the few ways in which a government can incentivize producers (Haites, 2018). Hence, forthcoming changes in relative input prices as a result of additional taxation and the firm-specific responses to these changes are relevant to monitor, also in other (agricultural) sectors. The comparison of various model specifications in chapter 5 also points out that conventional panel models are likely to underestimate the variability in responses to changes in the institutional environment. Consequently, policy makers should closely monitor these firm-specific responses. In order to reach specific policy objectives, it is of particular interest to monitor how the largest users of natural gas are responding to certain price changes. Specifically incentivizing the producers with the largest demand for natural gas is likely to lead to the largest reductions in gas usage at aggregated level.

Moreover, it should be noted that expenses at firm-level are likely to become even higher when considering the large-scale investments that are needed to make the full transition towards the usage of other energy sources. This may put further pressure on the future structure of the sector, where currently both classical family firms, as well as more larger-sized corporations co-exist. As many policies, e.g. the subsidy-schemes as part of the EU's Common Agricultural Policy, aim to reduce inequalities between farms (Piet and Desjeux, 2020), it is therefore highly relevant to properly monitor potentially unwanted effects of climate policies on future income inequalities in different sectors. For example, firm-specific compensation schemes could be considered, given the highly diverse effect the policy will have on companies. In particular firms that are unable to join existing cluster to make use of geothermal energy are likely to end up in a disadvantageous situation.

Furthermore, important implications arise for credit suppliers. As shown by the results in chapter 7, firms with high levels of debt obtain on average lower efficiency scores. As argued in chapter 7, the scope of the managerial decisions of these highly indebted firms might be restricted, leading to a reduction in their efficiency. This in turn causes considerable risks for credit suppliers, in particular given the high levels of debt involved. Moreover, the results of chapter 3 show that larger firms are barely able to exploit economies of scale in order to achieve lower production costs. This finding is also in line with earlier empirical studies which show that the largest average 
cost reductions are often found between small and medium-sized firms rather than between medium- and large-sized firms (Van der Meulen et al., 2011). Hence, the trend towards further scale increases of horticultural producers comes with a concentration of liquidity risks for credit suppliers. These risks are particularly accentuated given the high level of market volatility in combination with the high degree of specialization of firms (Jukema, 2019).

In addition, the results of chapter 7 point at the high correlation between the technical efficiency measure and other performance indicators, such as various profitability measures. A critique on these profitability measures, often used by credit suppliers to monitor the performance of their borrowers, is that they are based on numbers from financial statements (Welc, 2017). Hence, they might be prone to aggressive accounting methods and tax-reducing motives and therefore not always reflect changes in actual firm performance. Consequently, credit suppliers might benefit from using efficiency scores obtained via either parametric or non-parametric methods as they serve as a useful additional indicator for measuring the performance of high-risk borrowers.

Lastly, implications arise for primary producers themselves. Since the results of chapter 3 show that the rationalization behind recent scale increases is not solely based on internal processes as cost minimization, it is argued that relations with partners in the market environment, such as retailers, play a significant role in shaping the current firm structure. Hence, this causes a path dependency in the development of firm size, where the current organization of the firm is strongly influenced by previous (external) conditions (see e.g. Sutherland et al., 2012). This leads to large investments at firm-level (Zimmerman and Heckelei, 2012) with - in the context of Dutch horticulture - high labour and capital expenses as a result. As also shown by Sexton (2013) this is furthermore likely to generate lock-in situations between farmers and retail partners, where specialized investments at firm-level (in e.g. capital and specific crops) make it more difficult to attract other buyers.

\subsection{Modern agricultural markets and modern data: new insights from Dutch horticulture}

As discussed in section 2.1, the empirical analysis of this thesis builds on secondary accountancy data obtained from Rabobank, the largest credit supplier in Dutch horticulture (Groeneveld, 2016). This contrasts with most other studies on agricultural production, which often rely on classical surveyed data such as FADN-data (Ge et al., 2018). As discussed in section 2.1, this has the benefit of a more cost-efficient way of obtaining data and hence the potential to include a larger number of firms in the sample. This is particularly advantageous given the increased heterogeneity in modern agricultural markets. Amongst others, this is also visible in recent data on horticultural incomes, which show an increasing spread between firms (Wageningen Economic 
Research, 2019b). In order to capture these variations in outcomes, but also variations in responses and firm structure, it is inevitable to rely on a large number of firm-level observations.

A larger number of firm-level observations also allows for using methods which specifically focus on studying these differences between firms. A large share of economic research uses classical assumptions on fixed output prices or homogeneous responses in order to study firm behaviour (Koutchade et al., 2018; Norwood and Lusk, 2018). Yet, the growing importance of firm-specific elements in production calls for a relaxation of these assumptions. As an example, the results of chapter 5 showed that classical usage of a fixed slope parameter underestimates the variability in responses to changes in the institutional environment. Furthermore, as shown in chapter 4 , the high variation in output prices between firms points at large deviations from a single fixed output price. Hence, this demands the usage of data and methods in empirical research that are able to deal with this heterogeneity, particularly in agricultural subsectors where primary producers grow an end-product with large differences in product quality. ${ }^{21}$

A few specific methods applied in this thesis which require the availability of sufficient firm-level data, are the Markov transition analysis on the distribution of output prices in chapter 4 and the firm-level responses estimated via a Random Coefficient Model in chapter 5. If, e.g., the empirical analysis in these chapters would only rely on firm-level data from the FADN dataset, with often only about 25 firm-level observations available per year for the main vegetable crops (Ge et al., 2018), this would be problematic. Subdividing these data in four quartiles, as done in chapter 4, would make the analysis very sensitive to small changes in case the data is based on only a small number of firms. However, due to the larger amount of firm-level data available, it is now possible to specifically show that many firms on a longer term deviate from the average output price in markets, which points at structural differences between primary producers in their market positioning.

Furthermore, estimating firm-specific responses is particularly advantageous if sufficient firm-level data is available. As shown by the results in chapter 5 , allowing for these firm-specific responses also improves the overall model fit compared to conventional fixed slope models. In order to properly visualize the heterogeneity in modern agricultural markets, the availability of panel data with not only a sufficient time dimension, but also with a sufficient number of firms available is therefore of great importance.

Moreover, this is also evident from the approach applied in chapter 6, where the relation between firm-specific financial variables and investment behaviour is assessed. Traditionally, one of the most frequently used procedures to evaluate the

\footnotetext{
${ }^{21}$ Note: In the production of other agricultural products, such as starch potatoes or sugar beets, which are usually further processed in factories, this might be less urgent given the lower heterogeneity in products and the lesser degree of contact with other partners in the market environment.
} 
profitability of an investment is the Net Present Value method (NPV), where investments are considered as economically feasible if the annual net cash flow exceeds both the principal and interest payments (Robison et al., 2015; Maart-Noelck and Musshoff, 2013). However, the additional costs of financing these investments become increasingly firm-specific due to developments in the financial environment. The latest Basel-agreements, but also forthcoming developments in the Basel IVagreements e.g. put additional emphasis on the cashflow of a firm in assessing their creditworthiness (Bodelinni, 2019). This in turn generates further heterogeneity in the conditions and requirements for obtaining credits. Hence, this also requests a more firm-specific approach in analysing investment behaviour.

\subsection{Critical reflection and suggestions for further research}

Before turning to suggestions for further research, it is important to first note the limitations of the analyses in this thesis. As earlier pointed out in the concluding sections of every individual chapter of this thesis, several limitations should be kept in mind when considering the implications of the results discussed above.

First, since the data used in the empirical analyses is not stratified or weighed such as e.g. FADN data (see e.g. Ge et al., 2018) some caution should be taken in generalizing the results from this thesis. However, as also discussed in sections 2.1 and 8.3, the large number of firms and the high percentage covered per crop do allow for a better examination of firm-specific responses and outcomes and moreover ensure that overall sectoral trends are captured by the data.

This brings to the front the second limitation, which concerns the contextspecific character of some of the results. This e.g. goes for the results obtained in chapter 7, which show that highly indebted firms often have lower efficiency scores. The wider literature on debt and efficiency shows a great variation in outcomes, depending on a specific production context (see e.g. Gadanakis et al., 2019; Latruffe et al., 2017). Hence, these results should not be interpreted as any laws of nature, but rather as empirical findings valid in a certain context.

Furthermore, data unavailability is likely to lead to potential bias due to omitted variables in some of the research chapters. This is for example an issue in the formulation of the heterogeneous price equation in chapter 4, where one could argue that various other aspects, such as investments in R\&D, the export position of a firm as well as specific contracts might play a role in the formation of output prices (Hallak and Sivadasan, 2013). It however should be noted that such external effects in the estimation procedure are captured by a firm-specific component, yet they are not explicitly estimated.

Moreover, the focus in the investment analysis (chapter 6) is specifically on investments in scale. Due to data unavailability, investments in other capital goods or investments in energy saving production goods are not considered. Taking into account 
such investments would provide a more comprehensive picture of investments at firmlevel. Furthermore, for analysing the debt structure of a firm in chapter 7, only bank credits are considered. For modern agricultural firms, however, the financial environment is often complex and characterized by various partners and options. For example, it is increasingly common for agricultural producers to lease certain production assets instead of owning them. In addition, the entry of private equity investors also plays a role, whereas the conceptualization of the financial environment in this thesis is limited to traditional credit suppliers, such as banks. In particular as banks might apply stricter regulations in lending out money (Brester and Watts, 2019), new forms of capital in agricultural finance are likely to become more relevant. Consequently, analysing the relation between firm performance and these new capital structures forms an interesting avenue for further research.

Another source of concern that may result from the approach applied in this thesis is the focus on short-term effects. For example in the simulations of increased energy prices in chapter 5, one of the underlying assumptions is that firms might switch between using natural gas and electricity in order to meet their energy demands. However, it would also be very relevant to study the potential switch towards new alternative energy sources, such as geothermal heat (Willems and Nick, 2019). Yet, due to the potentially large transition and changes in production methods needed for horticultural firms to switch to these alternative energy sources, it is difficult to predict these changes based on existing data. Further research and more complex simulation models would be needed in order to estimate the potential (heterogeneous) effects of such more drastic production changes.

In line with what is sketched above, also other drastic and more radical system changes, such as the introduction of robotics and increased automation in horticultural production systems, would shed new lights on some of the obtained results in this thesis. The increased usage of robotics in e.g. harvesting vegetables could substitute labour for capital and hence change the current (labour intensive) character of horticultural production (Bac et al., 2014). Such more systematic changes would e.g. also bring in new potential arguments for scale increases at firm-level (Shamshiri et al., 2018). As pointed out, simulation studies would be needed in order to capture such developments, as it is hard to assess the impact of such systematic changes based on current and recent production data as applied in this thesis.

Aside from simulation studies, a different stream of literature promotes the application of novel machine learning approaches (Storm et al., 2020). Particularly in combination with the increased availability of data this might also prove an important route in order to assess future changes in modern agricultural markets (Wolfert et al., 2017; Weersink et al., 2018). It however should be noted that, despite the growing availability of data, theoretical disciplinary knowledge will still play a central role (Karpatne et al., 2017). This is the case as information contained within the data is 
not always suitable for predicting certain outcomes, particularly in complex and dynamically changing processes. Hence, uniting theoretical models with new data sources is important in order to avoid spurious correlations (Storm et al., 2020). Combining this with novel estimation methods, which are specifically suited for heterogeneous sectors, is therefore of utmost importance in order to study changes in modern agricultural markets with a high degree of product differentiation and firm heterogeneity.

Hence, also more empirical based research - such as applied in this thesis - is needed in order to study and highlight the broad palette in which heterogeneity in agricultural production plays a role. In this thesis, this is specifically done by studying heterogeneity in firm structure and product choice, as well as by considering heterogeneity in responses and relationships with partners in the external environment of the firm. Additional research in other agricultural subsectors would be needed in order to further reduce the underestimation of variability and to get better insight into the complex and firm-specific behaviour of primary producers in modern agricultural markets. 


\section{REFERENCES}

Abel, A.B. and Eberly, J.C. (2011). How Q and cash flow affect investment without frictions: An analytical explanation. The Review of Economic Studies, 78 (4): 11791200.

Ait Sidhoum, A. and Serra, T. (2016). Volatility spillovers in the Spanish food marketing chain: The case of tomato. Agribusiness, 32 (1): 45-63.

Akay, A. (2012). Finite-sample comparison of alternative methods for estimating dynamic panel data models. Journal of Applied Econometrics, 27 (7): 1189-1204.

Alarcon, S. (2007). Debt financing and efficiency in agricultural firms. Paper presented at the Mediterranean Conference of Agro-Food Social Scientists. 103rd EAAE Seminar "Adding Value to the Agro-Food Supply Chain in the Future of Euromediterranean Space", Barcelona, Spain, April 23-25 2007.

Allison, P. D. (2009). Fixed effects regression models. SAGE publications.

Alvarez, A. and Arias, C. (2004). Technical efficiency and farm size: a conditional analysis. Agricultural Economics, 30 (3): 241-250.

Alvarez, A. and del Corral, J. (2010). Identifying different technologies using a latent class model: extensive versus intensive dairy farms. European Review of Agricultural Economics, 37 (2): 231-250.

Amorello, L. (2016). Beyond the Horizon of Banking Regulation: What to Expect from Basel IV? Harvard International Law Journal, 58: 21-38.

Aramyan, L.H., Oude Lansink, A.G.J.M. and Verstegen, J.A.A.M. (2007). Factors underlying the investment decision in energy-saving systems in Dutch horticulture. Agricultural Systems, 94: 520-527.

Ardalan, K. (2017). Capital structure theory: reconsidered. Research in International Business and Finance, 39: 696-710.

Arnade, C.and Pick, D. (2000). Seasonal oligopoly power: The case of the US fresh fruit market. Applied Economics, 32 (8): 969 - 977.

Assefa, T. T., Meuwissen, M.P.M., Gardebroek, C. and Oude Lansink, A.G.J.M. (2017). Price and volatility transmission and market power in the German fresh pork supply chain. Journal of Agricultural Economics, 68: 861-880.

Asquith, P., Beatty, A. and Weber, J. (2005). Performance pricing in bank debt contracts. Journal of Accounting and Economics, 40: 101-128.

Babcock, B.A. (2015). Costs and Benefits to Agriculture from Climate Change Policy. Iowa Ag Review, 15(3).

Bac, C.W., Van Henten, E.J., Hemming, J. and Edan, Y. (2014). Harvesting robots for high-value crops: state-of-the-art review and challenges ahead. Journal of Field Robotics, 31 (6): 888-911.

Baffes, J. and Vasavada, U. (1989). On the choice of functional forms in agricultural production analysis. Applied Economics, 21(8): 1053-1061.

Baker, J.S., McCarl, B.A., Murray, B.C., Rose, S.K., Alig, R.J., Adams, D., Latta, G., Beach, R. and Daiqneault, A. (2010). Net Farm Income and Land Use under a US Greenhouse Gas Cap and Trade. Agricultural and Applied Economics Association. Policy Issues 7: April 2010. 5 p.

Bakucs, Z., Falkowksi, J. and Ferto, I. (2014). Does market structure influence price transmission in the agro-food sector? A meta-analysis perspective. Journal of Agricultural Economics, 65 (1): 1-25.

Balmford, A., Amano, T., Bartlett, H., Chadwick, D., Collins, A., Edwards, D. and Waters, H. (2018). The environmental costs and benefits of high-yield farming. Nature Sustainability, 1(9): 477.

Baltagi, B. (2013). Econometric analysis of panel data. John Wiley and Sons Inc.

Banerjee, A., Mookherjee, D., Munshi, K. and Ray, D. (2001). Inequality, control rights and rent seeking: Sugar cooperatives in Maharasthra. Journal of Political Economy, 109 (1): $138-190$. 
Bareille, F. and Letort, E. (2018). How do farmers manage crop biodiversity? A dynamic acreage model with productive feedback. European Review of Agricultural Economics, 45 (4): 617-639.

Barkley, A. (2019). The economics of food and agricultural markets. New Prairie Press.

Barnes, A. (2008). Technical efficiency estimates of Scottish Agriculture: A note. Journal of Agricultural Economics, 59 (2): 370-376.

Basset, W.F., Chosak, M.B, Driscol., J.C. and Zakrajsek, E. (2014). Changes in bank lending standards and the macroeconomy. Journal of Monetary Economic, 62: 2340.

Beausang, C., Hall, C. and Toma, L. (2017). Food waste and losses in primary production: Qualitative insights from horticulture. Resources, Conservation and Recycling, 126: 177-185.

Beck, N. and Katz, J. N. (2001). Throwing out the baby with the bath water: A comment on Green, Kim, and Yoon. International Organization, 55 (2): 487-495.

Beckman, J., Hertel, T., Taheripour, F. and Tyner, W. (2012). Structural change in the biofuels era. European Review of Agricultural Economics, 39: 137-156.

Berger, T. and Troost, C. (2014). Agent-based modelling of climate adaptation and mitigation: options in Agriculture. Journal of Agricultural Economics, 65 (2): 323248.

Berkers, E., Geels, F.W. (2011). System innovation through stepwise reconfiguration : the case of technological transitions in Dutch greenhouse horticulture. Technology Analysis and Strategic management, 23(3): 227-247.

Blundell-Wignall, A., Atkinson, P. (2010). Thinking beyond Basel III: Necessary Solutions for Capital and Liquidity, OECD Journal: Financial Market Trends, Vol. 2010/1.

Biørn, E. (2016). Econometrics of Panel Data: Methods and Applications. Oxford University Press.

Bodellini, M. (2019). The long 'journey' of banks from Basel I to Basel IV: has the banking system become more sound and resilient than it used to be? Era Forum, 20(1): 81-97.

Bonanno, A., Russo, C. and Menapace, L. (2018a). Market power and bargaining in agrifood markets: A review of emerging topics and tools. Agribusiness, 34(1): 623.

Bonanno, A., Bimbo, F., Castanigro, M., Oude Lansink, A. and Viscecchia, R. (2018b). Credence attributes and the quest for a higher price - a stochastic frontier approach. European Review of Agricultural Economics, 46 (2): 163-192.

Brester, G.W. and Watts, M.J. (2019). The Basel accords, capital reserves, and agricultural lending. Agricultural Finance Review, 79 (1): 27-47.

Brinkmeier, E. (2011). Illegality in everyday life: Polish workers in Dutch agriculture. Foggy social structures, 45-66. In: Foggy Social Structures: Irregular migration, European Labour, Markets and the Welfare State, edited by Bommes, M., Sciortino, G. (2011). Imiscoe Research: Amsterdam University Press.

Camanzi, L., Malorgio, G. and Garzia Azcarate, T. (2011). The Role of Producer Organizations in Supply Concentration and Marketing: A Comparison between European Countries in the Fruit and Vegetable Sector. Journal of Food Products Marketing, 17 (2): 327-354.

Chavas, J-P., Aliber, M. (1993). An analysis of economic efficiency in agriculture: a nonparametric approach, Journal of Agricultural and Resource economics, 18: 116.

Chib, S. (1995). Marginal likelihood from the Gibbs output. Journal of the American Statistical Association, 90(432): 1313-1321.

Clapp, J. (2019). The rise of financial investments and common ownership in global agrifood firms. Review of International Political Economy, 26 (4): 604-629. 
Clapp, J., Isakson, S. R., and Visser, O. (2017). The complex dynamics of agriculture as a financial asset: introduction to symposium. Agriculture and Human Values, 34(1): 179-183.

Climate Agreement (2019). Obtained on August 2020, available at https://www.klimaatakkoord.nl/documenten/publicaties/2019/03/07/achtergron dnotitie-glastuinbouw-ontwerp-klimaatakkoord

CLO (2019). Glastuinbouw 1980-2015. Obtained on July 2020 from https://www.clo.nl/indicatoren/nl212307-glastuinbouw

Compernolle, T., Witters, N., Van Passel, S., and Thewys, T. (2011). Analyzing a selfmanaged CHP system for greenhouse cultivation as a profitable way to reduce CO2-emissions. Energy, 36(4): 1940-1947.

Costanigro, M., McCluskey, J.J. and Geomans, C. (2010). The economics of nested names: Name specificity, reputations, and price premia. American Journal of Agricultural Economics, 92 (5): 1339-1350.

Cooper, R. W. and Haltiwanger, J. C. (2006). On the nature of capital adjustment costs. The Review of Economic Studies, 73 (3): 611-633.

Cramon-Taubadel, S. V., Saldias, R. (2014). Access to credit and determinants of technical inefficiency of specialized smallholder farmers in Chile. Chilean Journal of Agricultural Research, 74 (4): 413-420.

Crespi, J.M., Satione, T.L., Sexton, R.J. (2012). Competition in U.S. farm product markets: Do long-run incentives trump short-run market power? Applied Economic Perspectives and Policy, 34 (4): 669-695.

Cuchiella, F., Gastaldi, M. and Miliacca, M. (2018). The management of greenhouse gas emissions and its effect on firm performance. Journal of Cleaner Production, 167: 1387 - 1400 .

Cummins, J.G., Hassett, K.A. and Oliner, S.D. (2006). Investment behaviour, observable expectations and internal funds. The American Economic Review, 96 (3): 796-810.

Curtiss, J. (2012). Determinants of financial capital use: Review of theories and implications for rural businesses. Factor Markets: Working Paper, No. 19: February 2012.

Damijan, J. P. (2018). Corporate financial soundness and its impact on firm performance: Implications for corporate debt restructuring in Slovenia. PostCommunist Economies, 30(2): 156-192.

Davidova, S., Latruffe, L. (2007). Relationships between Technical Efficiency and Financial management for Czech Republic Farms. Journal of Agricultural Economics, 58 (2): 269-288.

De Lauwere, C.D., Van der Burg, S. and Splinter, G. (2019). Greenhouse horticulture entrepreneurship in times of transition: Images, expectations and uncertainties. Wageningen Economic Research, Report 2019-093.

De Roest, K., Ferrari, P. and Knickel, K. (2018). Specialisation and economies of scale or diversification and economies of scope? Assessing different agricultural development pathways. Journal of Rural Studies, 59: 222-231.

Demerjian, P.R. and Owens, E.L. (2016). Measuring the probability of financial covenant violation on private debt contracts. Journal of Accounting and Economics, 61: 433-447.

Den Ouden, M., Dijkhuizen, A.A., Huirne, R. and Zuurbier, P.J. (1996). Vertical cooperation in agricultural production-marketing chains, with special reference to product differentiation in pork. Agribusiness, 12: 277-290.

Denis, D. J., and Wang, J. (2014). Debt covenant renegotiations and creditor control rights. Journal of Financial Economics, 113(3): 348-367.

Dehnen-Schmutz, K., Holdenrieder, O., Jeger, M.J., Pautasso, M. (2010). Structural change in the international horticulture industry: Some implications for plant health. Scientia Horticulturae 125: 1-15. 
Dixit, A. and Stiglitz, J. (1977). Monopolistic competition and optimal product diversity. American Economic Review, 67 (3): 297-308.

Dorais, M., Papadopoulos, A.P. and Gosselin, A. (2001). Greenhouse tomato fruit quality. Horticultural Reviews, 26: 239-262.

Elzen, B., Van Mierlo, B. and Leeuwis, C. (2012). Anchoring of innovations: Assessing Dutch efforts to harvest energy from glasshouses. Environmental Innovation and Societal Transitions, 5: 1-18.

Emrouznejad, A., and Yang, G. L. (2018). A survey and analysis of the first 40 years of scholarly literature in DEA: 1978-2016. Socio-Economic Planning Sciences, 61: 4-8.

Erjavec, C. and Lovec, M. (2017). Research of European Union's Common Agricultural Policy: disciplinary boundaries and beyond. European Review of Agricultural Economics, 44 (3): 732-754.

European Commission (2017). Dashboard on tomato prices and production by DGAGRI. Obtained on March 2018 from https://ec.europa.eu/agriculture/sites/agriculture/files/dashboards/tomatodashboard en.pdf

European Commission (2019). Dashboard on Tomato Prices and Production by DGAGRI. Obtained on August 2020 from https://ec.europa.eu/agriculture/sites/agriculture/files/dashboards/tomatodashboard en.pdf

Eurostat (2017). Standard Output Coefficients. Obtained on March 2018 from http://ec.europa.eu/eurostat/web/agriculture/so-coefficients

Falkowski, J., Malak-Rawlikowska, A., and Milczarek-Andrzejwska, D. (2017). Farmers' self-reported bargaining power and price heterogeneity: Evidence from the dairy supply chain. British Food Journal, 119 (8): 1672-1686.

Falkner, R. (2016). The Paris Agreement and the new logic of international climate politics. International Affairs, 92(5): 1107-1125.

Finger, R. and El Benni, N. (2020). Farm income in European agriculture: new perspectives on measurement, development and policies. European Review of Agricultural Economics, forthcoming.

Gadanakis, Y., Stefani, G., Lombardi, G.V., Tiberti, M. (2019). The impact of financial leverage on farm technical efficiency during periods of price instability. Agricultural Finance Review, 80: 1-21.

Gailhard, İ. U. and Bojnec, Š. (2015). Farm size and participation in agrienvironmental measures: Farm-level evidence from Slovenia. Land Use Policy, 46:273-282.

Gardebroek, C. (2004). Capital adjustment patterns on Dutch pig farms. European Review of Agricultural Economics, 31(1): 39-59.

Gardebroek, C. (2006). Comparing risk attitudes of organic and non-organic farmers with a Bayesian random coefficient model. European Review of Agricultural Economics, 33(4): 485-510.

Gardebroek, C. and Oude Lansink, A.J.G.M. (2004). Farm-specific adjustment costs in Dutch pig farming. Journal of Agricultural Economics, 55 (1): 3-24.

Ge, L., Van der Meer, R.W., Van der Veen, H.B. and Vrolijk, H.C.J. (2018). Sample of Dutch FADN 2015; Design principles and quality of the sample of agricultural and horticultural holdings. Wageningen Economic Research, Report 2018-011.

Giannakis, K., Schoney, R., Tzouvelekas, V. (2001). Technical efficiency, technological change and output growth of wheat farms in Saskatchewan. Canadian Journal of Agricultural Economics, 49: 135-152.

Goncharova, N., Oskam, A., Oude Lansink, A., Van Der Vlist, A., and Verstegen, J. (2008). Investment spikes in Dutch greenhouse horticulture. Journal of Agricultural Economics, 59(3): 516-536. 
Grashuis, J. and Magnier, A. (2018). Product differentiation by marketing and processing cooperatives: A choice experiment with cheese and cereal products. Agribusiness, 34(4): 813-830.

Groeneveld, H. (2016). Rabobank Before, During and After the Credit Crisis: From Modesty via Complacency to Fundamental Steps, 169-180. In Credit Cooperative Institutions in European Countries, edited by Karafolas, S. Springer, Cham.

Guariglia, A., Xiaoxuan, L. and Song, L. (2011). Internal finance and growth: Microeconometric evidence on Chinese firms. Journal of Development Economics, 96: 79-94.

Hadley, D. (2006). Patterns in technical efficiency and technical change at the farmlevel in England and Wales, 1982-2002. Journal of Agricultural Economics, 57: 81100.

Hallak, J.C. and Sivadasan, J. (2013). Product and process productivity: Implications for quality choice and conditional exporter premia. Journal of International Economics, 91: 53-67.

Hanf, C.H. and Kuhl, R. (1986). Possibilities and limits of individual marketing on family farm firms. European Review of Agricultural Economics, 13 (2): 149 - 167.

Haites, E. (2018). Carbon taxes and greenhouse gas emissions trading systems: what have we learned? Climate policy, 18(8): 955-966.

Hausman, J. A. (1978). Specification tests in econometrics. Econometrica, 46: 1251 1271.

Henning, J. I. and Jordaan, H. (2016). Determinants of financial sustainability for farm credit applications-A Delphi study. Sustainability, 8(1): 77.

Hernando, I. and Martinez-Carrascal, C. (2008). The impact of financial variables on firms' real decisions: Evidence from Spanish firm-level data. Journal of Macroeconomics. 30: 543-561.

Hertel, T.W. (2011). The global supply and demand for agricultural land in 2050: A perfect storm in the making? American Journal of Agricultural Economics, 93 (2): 259-275.

Herzfeld, T. and Jongeneel, R. (2012). Why do farmers behave as they do? Understanding compliance with rural, agricultural, and food attribute standards. Land Use Policy, 29(1): 250-260.

Hoff, A. (2007). Second stage DEA: Comparison of approaches for modelling the DEA score. European Journal of Operational Research, 181: 425-435.

Holloway, G., Nicholson, C., Delgado, C., Staal, S. and Ehui, S. (2000). Agroindustrialization through institutional innovation: Transaction costs, cooperatives and milk-market development in the east-African highlands. Agricultural Economics, 23 (3): 279-288.

Hovhannisyan, V., Cho, C. and Bozic, M. (2018). The relationship between price and retail concentration: evidence from the US food industry. European Review of Agricultural Economics, 46 (2), 319-345.

Hsiao, C. (2015). Random Coefficients Models In Panels. In Baltagi, B. (ed), The Oxford Handbook of Panel Data. Oxford: Oxford University Press, 402-417.

Huettel, S. and Jongeneel, R. (2011). How has the EU milk quota affected patterns of herd-size change? European Review of Agricultural Economics, 38 (4): 497-527.

Incrocci, L., Malorgio, F., Della Bartola, A. and Pardossi A. (2006). The influence of drip irrigation or subirrigation on tomato grown in closed-loop substrate culture with saline water. Scientia Horticulturae, 107 (4): 365 - 372.

Jensen, M. (1986). Agency costs of free cash flow, corporate finance and takeovers. American Economic Review, 76: 323-329.

Jensen, M. and Meckling, W. (1976). Theory of the firm: Managerial behaviour, agency costs and ownership structure. Journal of Financial Economics, 3: 305-360.

Jukema, G. (2013). Investeringen glastuinbouwbedrijven gedaald. Agri-monitor 2013: 1-3. 
Jukema, G. (2019). Horticulture in numbers. Obtained on September 2020 from https://library.wur.nl/WebQuery/wurpubs/fulltext/504578

Karagiannis, G., Sarris, A. (2005). Measuring and explaining scale efficiency with the parametric approach: The case of Greek tobacco growers. Agricultural Economics, 33: 441-451.

Karagiannis, G., Kellerman, M., Proll, S. and Salhofer, K. (2018). Markups and product differentiation in the German brewing sector. Agribusiness, 34: 61-76.

Karali, B. and Power, G.J., (2013). Short-and long-run determinants of commodity price volatility. American Journal of Agricultural Economics, 95(3): 724-738.

Karpatne, A., Atluri, G., Faghmous, J. H., Steinbach, M., Banerjee, A., Ganguly, A., Shekhar, S., Samatova, N. and Kumar, V. (2017). Theory-guided data science: a new paradigm for scientific discovery from data. IEEE Transactions on Knowledge and Data Engineering 29: 2318-2331.

Kas Magazine (2017). Veredelaars over komkommer. Obtained on August 2020 from http://www.kasmagazine.nl/fileadmin/user upload/ archief/kasmagazine-2017rassenkeuze/kasmagazine-2017-rassenkeuze/assets/common/downloads/2017Rassenkeuze.pdf

Knowledge Centre InfoMil (2019). Obtained on April 2020 from https://www.infomil.nl/onderwerpen/duurzaamheidenergie/energiebesparing/vragen-antwoorden/overige-vragen/omrekeningverbruik/

Knudson, W., Wysocki, A., Champagne, J. and Peterson, H.C. (2004). Entrepreneurship and Innovation in the Agri-Food System. American Journal of Agricultural Economics, 86 (5): 1330-1336.

Kimura, S. and Le Thi, C. (2013), Cross Country Analysis of Farm Economic Performance. OECD Food, Agriculture and Fisheries Papers, 60: OECD Publishing.

Kirova, M., Montanari, F., Ferreira, I., Pesce, M., Albuquerque, J.D., Monfort, C., Neirynck, R. and Mornoi, J. (2019). Research for AGRI Committee - Megatrends in the agri-food sector, European Parliament, Policy Department for Structural and Cohesion Policies.

Kohler, U. and Kreuter, F. (2005). Data analysis using Stata. Stata press.

Koning, N.B.J., Van Ittersum, M.K., Becx, G.A., Van Boekel, M.A.J.S., Brandenburg, W.A., Van Den Broek, J.A., Goudriaan, J., Van Hofwegen, G., Jongeneel, R.A., Schiere, J.B. and Smies, M. (2008). Long-term global availability of food: continued abundance or new scarcity? NJAS-Wageningen Journal of Life Sciences, 55 (3): 229-292.

Koop, G. (2003). Bayesian Econometrics. John Wiley and Sons.

Koutchadé, O.P., Carpenter, A. and Femenia, F. (2018). Modelling heterogeneous farm responses to European Union biofuel support with a random parameter multicrop model. American Journal of Agricultural Economics, 100(2): 434-455.

Kugler, M. and Verhoogen, E. (2011). Prices, plant size, and product quality. The Review of Economic Studies, 79 (1): 307 - 339.

Kumbhakar, S.C., Lien G. (2010). Impact of Subsidies on Farm Productivity and Efficiency. In: Ball V., Fanfani R., Gutierrez L. (eds) The Economic Impact of Public Support to Agriculture. Studies in Productivity and Efficiency, Springer, New York, NY

Lambert, D.K., Bayda, V. (2005). The impacts of farm financial structure on production efficiency. Journal of Agricultural and Applied Economics, 37 (1): 277-289.

Latruffe, L., Bravo-Ureta, B. E., Carpentier, A., Desjeux, Y., and Moreira, V. H. (2017). Subsidies and technical efficiency in agriculture: Evidence from European dairy farms. American Journal of Agricultural Economics, 99(3): 783-799.

Latruffe, L., Davidova, S., and Balcombe, K. (2008). Application of a double bootstrap to investigation of determinants of technical efficiency of farms in Central Europe. Journal of Productivity Analysis, 29(2): 183-191. 
Lee, C., Lee, J. and Kim, T. (2009). Defense Acquisition Innovation Policy and Dynamics of Productive Efficiency: A DEA Application to the Korean Defense Industry. Asian Journal of Technology Innovation, 17(2): 151-171.

Levi, R., Singhvi, S. and Zheng, Y. (2020). Economically motivated adulteration in farming supply chains. Management Science, 66 (1): 209-226.

Li, L., Sexton, R.J. and Xia, T. (2006). Food retailers pricing and marketing strategies, with implications for producers. Agricultural and Resource Economics Review, 35(2): 221-238.

Lindley, D. V. and Smith, A. F. (1972). Bayes estimates for the linear model. Journal of the Royal Statistical Society: Series B (Methodological), 34(1): 1-18.

Liu, Y., Chen, X. and Rabinowitz, A.N. (2019). The role of market power and state regulations in the heterogeneity of farm-retail price transmission of private label and branded products. Agricultural Economics, 50 (1): 91-99.

Los, E.J., Gardebroek, C., Huirne, R.B.M. (2019). Explaining recent scale increases in Dutch Horticulture. Eurochoices, 18 (3): 38-43.

Lund, P., and Price, R. (1998). The measurement of average farm size. Journal of Agricultural Economics, 49(1): 100-110.

Maart-Noelck, S.C. and Musshoff, O. (2013). Investing today or tomorrow? An experimental approach to farmers' decision behaviour. Journal of Agricultural Economics, 64(2): 295-318.

Magni, C. A. (2009). Investment decisions, net present value and bounded rationality. Quantitative Finance, 9 (8): 967-979.

Malak-Rawlikowksa, A., Milczarek-Andrzejewska, D. and Falkowski, J. (2019). Farmer's bargaining power and input prices: what can we learn from self-reported assessments? Social Sciences, 8: 63-76.

Margaritis, D., Psillaki, M. (2007). Capital structure and firm efficiency. Journal of Business Finance and Accounting, 34 (9): 1447-1469.

Martinez-Budría, E., Jara-Díaz, S. and Ramos-Real, F. J. (2003). Adapting productivity theory to the quadratic cost function: an application to the Spanish electric sector. Journal of Productivity Analysis, 20(2): 213-229.

Martinez-Cillero, M., Thorne, F., Wallace, M., Breen, J. and Hennessy, T. (2018). The effects of direct payments on technical efficiency of Irish beef farms: A stochastic frontier analysis. Journal of Agricultural Economics, 69: 669-687.

Martinez-Cillero, M., Thorne, F., Wallace, M., and Breen, J. (2019). Technology heterogeneity and policy change in farm-level efficiency analysis: an application to the Irish beef sector. European Review of Agricultural Economics, 46(2): 193214.

McCorriston, S. (2002). Why should imperfect competition matter to agricultural economists? European Review of Agricultural Economics, 29: 349-371.

Minviel, J.J, and De Witte, K. (2017). The influence of public subsidies on farm technical efficiency: A robust conditional nonparametric approach. European Journal of Operational Research, 259 (3): 1112-1120.

Modigliani, F. and Miller, M. (1958). The cost of capital, corporation finance and the theory of investment. The American Economic Review, 48 (3): 261-297.

Mouter, N., De Geest, A. and Doorn, N. (2018). A values-based approach to energy controversies: Value-sensitive design applied to the Groningen gas controversy in the Netherlands. Energy Policy, 122: 639-648.

Mugera, A.W. and Naymbane, G.G. (2015). Impact of debt structure on production efficiency and financial performance of Broadacre farms in Western Australia. The Australian Journal of Agricultural and Resource Economics, 59: 208-224.

Myers, R.J., Sexton, R.J. and Tomek, W.G. (2010). A century of research on agricultural markets. American Journal of Agricultural Economics, 92 (2): 376402. 
Neuhaus, J. M. and Kalbfleisch, J. D. (1998). Between-and within-cluster covariate effects in the analysis of clustered data. Biometrics, 638-645.

Nichols, M. (2017). Horticultural production in the future. International Symposium on Horticulture: Priorities and Emerging Trends, 1255: 7-12.

Nijdam, D.S., Rood, T.G.A and Van Oorschot, M.P (2019). Land use related to Dutch consumption, 1990-2013. Land Use Policy, 82: 401-413

Nishitana, K., Kaneko, S., Komatsu, S. and Fujii, H. (2014). How does a firm's management of greenhouse gas emissions influence its economic performance? Analyzing effects through demand and productivity in Japanese manufacturing firms. Journal of Productivity Analysis, 42: 355 - 366.

Norwood, F.B. and Lusk, J.L. (2018). Agricultural marketing and price analysis. Waveland Press Inc.

NVM (2020). Agricultural landprices 2002-2019. Obtained on 18/06/2020 from https://www.nvm.nl/agrarisch-landelijk/agrarische-grondprijzen/

Odeck, J. (2007). Measuring technical efficiency and productivity growth: a comparison of SFA and DEA on Norwegian grain production data. Applied Economics, 39(20): 2617-2630.

Onder Glas (2019). Investeringsmaatschappij stapt in Nederlandse tomatenteelt (in Dutch). Obtained on July 2020 from

https://www.onderglas.nl/investeringsmaatschappij-stapt-in-nederlandsetomatenteelt/

O'Neill, S. and Matthews, A. (2001). Technical efficiency in Irish Agriculture. The Economic and Social Review, 32: 263-284.

Osma, B.G., Gomez-Conde, J., De Las Heras, E. (2018). Debt pressure and interactive use of control systems: Effects on cost of debt. Management Accounting Research, 40: 27-46.

O'Toole, C.M., Newman, C. and Hennessy, T. (2014). Financing constraints and agricultural investment: effects of the Irish financial crisis. Journal of Agricultural Economics, 65 (1): 152-176.

Oude Lansink, A.J.G.M., Verstegen, J. and Van den Hengel, J.J. (2001). Investment decision making in Dutch greenhouse horticulture. Netherlands Journal of Agricultural Sciences, 49: 357 - 368.

Parachini, M.L., Bulgheroni, C., Borreani, G., Tabbacco, E., Banterle, A., Betroni, D., Rossi, G., Parolo, G., Origgi, R. and De Paola, C. (2015). A diagnostic system to assess sustainability at a farm level: The SOSTARE model. Agricultural Systems, 133: 35-53.

Perez-Mesa, J.C, Serrano-Arcos, M.D.M. and Sanchez-Fernandez, R. (2019). Measuring the impact of crises in the horticultural sector: the case of Spain. British Food Journal, 121 (5): 1050-1063.

Piet, L. and Desjeux, Y. (2020). Beyond Gini: New perspective on the distribution of farm income and the redistributive impact of CAP payments. European Review of Agricultural Economics, forthcoming.

Pietola, K. and Oude Lansink, A.G.J.M. (2006). Energy-saving technology choices by Dutch glasshouse firms. Journal of Agricultural Economics, 57: 129-144.

Pons, M., Bikfalvi, A., Llach, J. and Palcic, I. (2013). Exploring the impact of energy efficiency technologies on manufacturing firm performance. Journal of Cleaner Production, 52: 134-144.

Poppe, K.J. and Vrolijk, H.C.J. (2019). How to measure farm income in the era of complex farms. Paper prepared for presentation at the 171th EAAE Seminar 'Measuring and evaluating farm income and wellbeing of farm families in EuropeTowards a shared and broader approach for analysis and policy design?, 5th - 6th September 2019 Taenikon, Switzerland. Obtained on August 2020 from https://library.wur.nl/WebQuery/wurpubs/fulltext/500005

Rabobank (2016a). Analysis Tool Rabobank: Financial Data Horticulture. 
Rabobank (2016b). Numbers and trends: Horticulture.

Rajan, R.G. (2012). The corporation in finance. The Journal of Finance, 67 (4): 11731217.

Reidsma, P., Ewert, F., Lansink, A. O., and Leemans, R. (2010). Adaptation to climate change and climate variability in European agriculture: the importance of farm level responses. European Journal of Agronomy, 32 (1): 91-102.

Renner, S., Sauer, J. and El Benni, N. (2020). Why considering technological heterogeneity is important for evaluating farm performance. European Review of Agricultural Economics, forthcoming.

Ren, C., Liu, S., Van Grinsven, H., Reis, S., Jin, S., Lui, H. and Gu, B. (2019). The impact of farm size on agricultural sustainability. Journal of Cleaner Production, 220: 357-367.

Roberts, M.J. and Supina, D. (1996). Output price, markups and producer size. European Economic Review, 40: 909-921.

Roberts, M.R. (2015). The role of dynamic renegotiation and asymmetric information in financial contracting. Journal of Financial Economics, 116: 61-81.

Robertson, R., Nelson, G., Thomas, T. and Rosegrant, M. (2013). Incorporating process-based crop simulation models into global economic analyses. American Journal of Agricultural Economics, 95: 228-235.

Robison, L.J., Barry, P.J. and Myers, R.J. (2015). Consistent IRR and NPV rankings. Agricultural Finance Review, 75 (4): 499-513.

Roesch, A., and Lips, M. (2013). Sampling design for two combined samples of the Farm Accountancy Data Network (FADN). Journal of Agricultural, Biological, and Environmental Statistics, 18(2): 178-203.

Royal Netherlands Meteorological Institute (2019). Measurements and Observations. Obtained on August 2020 from https://www.knmi.nl/nederland-nu/klimatologie

Russo, C. and Goodhue, R. (2018). Farmgate prices, retail prices and supermarkets pricing decisions: An integrated approach. Agribusiness, 34 (1): 24-43.

Saitone, T. L., and Sexton, R. J. (2017). Agri-food supply chain: evolution and performance with conflicting consumer and societal demands. European Review of Agricultural Economics, 44(4): 634-657.

Samson, G.S., Gardebroek, C. and Jongeneel, R.A. (2016), Explaining production expansion decisions by Dutch dairy farmers. NJAS - Wageningen Journal of Life Sciences, 76: 87-98.

Sauer, J., Gorton, M. and White, J. (2012). Marketing, cooperatives and price heterogeneity: evidence from the CIS dairy sector. Agricultural Economics, 43(2): 165-177.

Schmidt, F.L., Oh, I.S. and Hayes, T.L. (2009). Fixed- versus random-effects models in meta-analysis: Model properties and an empirical comparison of differences in results. British Journal of Mathematical and Statistical Psychology, 62: 97-128.

Schneider, M. K., Lüscher, G., Jeanneret, P., Arndorfer, M., Ammari, Y., Bailey, D., and Eiter, S. (2014). Gains to species diversity in organically farmed fields are not propagated at the farm level. Nature communications, 5(1): 1-9.

Schunck, R. (2013). Within and between estimates in random-effects models: Advantages and drawbacks of correlated random effects and hybrid models. The Stata Journal, 13(1): 65-76.

Sellers, R. and Alampi-Sottini, V. (2016). The influence of size on winery performance: Evidence from Italy. Wine Economics and Policy, 5: 33-41.

Serra, T. and Gil, J.M. (2013). Price volatility in food markets: can stock building mitigate price fluctuations? European Review of Agricultural Economics, 40 (3): 507-528.

Sexton, R.J. (2013). Market power, misconceptions and modern agricultural markets. American Journal of Agricultural Economics, 95 (2): 209-219. 
Shamshiri, R.R., Weltzien, C., Hameed, I.A., Yule, I.J., Grift, T.E., Balasundram, S.K, Pitonakova, L., Ahmad, D. and Chowdhary, G. (2018). Research and development in agricultural robotics: a perspective of digital farming. Int J Agric and Biol Eng, 11(4): 1-14.

Sheldon, I. Industrial Organization of the food industry: the role of buyer power. 5069. In: The Routledge Handbook of Agricultural Economics, edited by Cramer, G.L., Paudel, K.P., Schmitz, A. Routledge: New York.

Sheng, Y., Zhao, S., Nossal,K. and Zhang, D. (2015). Productivity and farm size in Australian agriculture: reinvestigating the returns to scale. Australian Journal of Agricultural and Resource Economics, 59: 16-38.

Silva, E., Oude Lansink, A. and Stefanou, S.E. (2015). The adjustment-cost model of the firm: Duality and productive efficiency. International Journal of Production Economics, 168: 245-256.

Skevas, I., Emvalomatis, G., Brummer, B. (2018a). The effect of farm characteristics on the persistence of technical inefficiency: a case study in German dairy farming. European Review of Agricultural Economics, 45 (1): 3-25.

Skevas, T., Feng, W. and Guan, Z. (2018b). Farm capital investment and deviations from the optimal path. Journal of Agricultural Economics, 69 (2): 561-577.

Spence, M. (1976). Product selection, fixed costs and monopolistic competition. Review of Economic Studies, 43(2): 217-235.

Statistics Netherlands (2011). Numbers on Agriculture and Horticulture: 2011.

Statistics Netherlands (2019a). Average prices for natural gas and electricity. Obtained on July 2020 from https://opendata.cbs.nl/statline/\#/CBS/nl/dataset/81309NED/table?fromstatweb

Statistics Netherlands (2019b). Aantal faillissementen in de Nederlandse landbouw: 2009-2018. Obtained on October 2020 from https://www.cbs.nl/nlnl/maatwerk/2019/03/aantal-faillissementen-in-de-landbouw-2009-2018-

Statistics Netherlands (2020a). Landbouw: Gewassen en grondgebruik naar regio. Obtained on September 2020 from https://opendata.cbs.nl/statline/\#/CBS/nl/dataset/80780NED/table?dl=15258

Statistics Netherlands (2020b). Landbouw: Financiële gegevens landbouwbedrijven (in Dutch). Obtained on July 2020 from https://opendata.cbs.nl/statline/\#/CBS/nl/dataset/83275NED/table?fromstatweb

Storm, H., Baylis, K. and Heckelei, T. (2020). Machine learning in agricultural and applied economices. European Review of Agricultural Economics, 47 (3): 849-892.

Sutherland, L., Burton, R., Ingram, J., Blackstock, K., Slee, B. and Gotts, N. (2012). Triggering change: Towards a conceptualisation of major change processes in farm decision-making. Journal of Environmental Management, 104: 142-151.

Swamy, P. (1970). Efficient inference in a random coefficient regression model. Econometrica, 38: 311 - 323.

Syverson, C. (2007). Prices, spatial competition and heterogenous producers: An empirical test. The Journal of Industrial Economics, 60: 197 - 222.

Tonini, A. and Jongeneel, R. (2007). Modelling the dairy farm size distribution in Poland using an instrumental variable generalized cross entropy Markov approach. In 104th Seminar of the European Association of Agricultural Economists.

Van der Meer, R. W., Ge, L. and Van der Veen, H. B. (2019). Sample for the Dutch FADN 2016 (No. 2019-020). Wageningen Economic Research.

Van der Meulen, H.A.B. and Venema, G.S. (2005). Ontwikkeling Rond de Financiering van Agrarische Bedrijven. Report 2.05.01. The Hague, LEI (in Dutch).

Van der Meulen, H. A. B., Van Bommel, K. H. M., Vermeulen, P. C. M., and Zijlstra, J. (2007). Bedrijfsovername grote glastuinbedrijven. (Rapport / LEI : Domein 6, Beleid). Den Haag: LEI.

Van der Meulen, H.A.B., De Bont, K., Agricola, H., Van Horne, P., Hoste, R., Van der Knijff, A., Leenstra, Fl., Van der Meer, R. and De Smet, A. (2011). 
Schaalvergroting in de land- en tuinbouw. Effecten bij veehouderij en glastuinbouw. Landbouw Economisch Instituut, February 2011.

Van der Noll, R., Baarsma, B. and Roosenboom, N. (2010). Van Teelt tot Schap: Waardecreatie door de groothandel in groenten en fruit. SEO: Economic Research.

Van der Velden, N., Smit, P. and Van der Meer, R.W. (2014). Energiebelasting en de glastuinbouw.

Wageningen, LEI Wageningen UR (University and Research Centre), LEI Report.

Van der Velden, N. and Smit, P. (2018). Energiemonitor van de Nederlandse glastuinbouw 2017. Wageningen Economic Research: 2018-109.

Van Ees, H., Garretsen, J.H., De Haan L. and Sterken, E. (1997). Investeringen en kredietbeperking. Maandblad voor Accountancy en Bedrijfseconomie, 69: 557567.

Verbeke, G. and Molenberghs, G. (2000). Linear Mixed Models for Longitudinal Data. New York: Springer.

Verdouw, C.N., Bondt, N., Schmeitz, H. and Zwinkels, H. (2014). Towards a smarter greenport: Public-private partnership to boost digital standardisation and innovation in the Dutch horticulture. International Journal on Food System Dynamics, 5: 44-52.

Verhaegh, A.P. (1998). Costprices tomato, cucumber and pepper in the Netherlands and Spain. Agricultural Economics Institute, The Hague.

Vermeer, F. (2009). Quantitative research into the experience and use of cucumbers in German households. Productschap Tuinbouw.

Verreth, D. M. I., Emvalomatis, G., Bunte, F., and Lansink, A. O. (2015). Dynamic and static behaviour with respect to energy use and investment of Dutch greenhouse firms. Environmental and Resource Economics, 61(4), 595-614.

Vrolijk, H. and Poppe, K.J. (2016). Structural change in Dutch agriculture: impact on farm level statistics. Paper prepared for presentation at the $7^{\text {th }}$ International Conference on Agricultural Statistics, 26 th $-28^{\text {th }}$ October 2016 Rome, Italy. Obtained on $\quad$ October $2020 \quad$ from https://library.wur.nl/WebQuery/wurpubs/fulltext/404114

Vink, M. and Boezeman, D. (2018). Naar een wenkend perspectief voor de Nederlandse landbouw: voorwaarden voor veranderingen. Planbureau voor de Leefomgeving, report 2717. The Hague. Obtained on October 2020 from https://www.pbl.nl/sites/default/files/downloads/pbl-2018-naar-een-wenkendperspectief-voor-de-landbouw-2717.pdf

Wageningen Economic Research (2019a). Glastuinbouwcomplex drijft op export. Obtained on July 2020 from

https://www.agrimatie. $\mathrm{nl} /$ ThemaResultaat.aspx?subpubID $=2232$ andthemaID $=22$ 80andindicatorID $=2919$ andsectorID $=2240$

Wageningen Economic Research (2019b). Inkomens glastuinbouwbedrijven beperkt gestegen. Obtained on October 2020 from

https://agrimatie. $\mathrm{nl} /$ SectorResultaat.aspx?themaID $=2272$ andindicatorID $=2046 \mathrm{a}$ ndsubpubID $=2232$ andsectorID $=2240$

Wageningen Economic Research (2020a). Arbeidsinzet en productiviteit glastuinbouw. Obtained on March 2020 from

https://www.agrimatie.nl/SectorResultaat.aspx?subpubID $=2290$ andsectorID $=22$ 40andthemaID $=2264$

Wageningen Economic Research (2020b). Glastuinbouw: Bedrijven, areaal en omvang. Obtained on April 2020 from

https://www.agrimatie. $n \mathrm{l} /$ SectorResultaat.aspx?subpubID $=2290$ andsectorID $=22$ 40andthemaID $=2286$

Wageningen Economic Research (2020c). Areaal tuinbouw onder glas en aantal bedrijven. Obtained on October 2020 from 
https://www.agrimatie.nl/SectorResultaat.aspx?subpubID $=2232$ andsectorID $=22$ 40

Wageningen Economic Research (2020d). Investeringen glastuinbouw licht gestegen (in Dutch). Obtained on July 2020 from

https://agrimatie. $\mathrm{nl} /$ SectorResultaat.aspx?subpubID=2232andsectorID =2240and themaID $=2265$ andindicatorID $=2050$

Weersink, A., Fraser, E., Pannel, D., Duncan, E., Rotz, S. (2018). Opportunities and challenges for big data in agricultural and environmental analysis. Annual Review of Resource Economics, 10: 19-37.0

Welc, J. (2017). EBITDA vs. Cash Flows in Bankruptcy Prediction on the Polish Capital Market. European Financial and Accounting Journal, 12 (2): 91-103.

Willems, C.J.L. and Nick, H.M. (2019). Towards optimisation of geothermal heat recovery: An example from the West Netherlands Basin. Applied energy, 247: 582593.

Wohlgenant, M.K. (2001). Marketing margins: Empirical analysis, in B. Gardner, and S. Rausser, eds., Handbook of Agricultural Economics. Elsevier Science.

Wolfert, S., Ge, L., Verdouw, C. Boogaardt, M.J. (2017). Big data in smart farming: A review. Agricultural Systems, 153: 69-80.

Wooldridge, J. M. (2005). Simple solutions to the initial conditions problem in dynamic, nonlinear panel data models with unobserved heterogeneity. Journal of Applied Econometrics, 20 (1): 39-54.

Wooldridge, J.M. (2010). Econometric analysis of cross section and panel data. Massachusetts Institute of Technology.

Zhu, X., Demeter, R.M., Oude Lansink, A. (2012). Technical efficiency and productivity differentials of dairy farms in three EU countries: the role of CAP subsidies. Agricultural Economics Review, 13 (1): 66-92.

Zhu, X., and Lansink, A. O. (2010). Impact of CAP subsidies on technical efficiency of crop farms in Germany, the Netherlands and Sweden. Journal of Agricultural Economics, 61(3): 545-564.

Zimmermann, A. and Heckelei, T. (2012). Structural change of European dairy farms: a cross-regional analysis. Journal of Agricultural Economics, 63 (3): 576-603.

Zussman, P., and Rausser, G.C. (1994). Intraorganizational influence relations and the optimality of collective action. Journal of Economic Behaviour and Organization, 24(1): 1-17. 


\section{SUMMARY}

With a large degree of heterogeneity in firm structures, a strong emphasis on product differentiation and a growing importance of vertical integration, the Dutch horticultural sector can be seen as a modern agricultural market par excellence. This thesis examines how primary producers in Dutch glasshouse horticulture respond heterogeneously to changes in their market, institutional and financial environment.

This is executed by modelling heterogeneity in firm-specific outcomes, responses and conditions using various micro-econometric techniques. The empirical analysis builds, as explained in chapter 2, on firm-specific production data obtained from the ATR database provided by Rabobank. This database contains information of yearly financial statements of individual horticultural firms. The advantage of using such data compared to traditionally sampled data mainly resides in the greater availability of firm-level data. This is particularly beneficial in the case of heterogeneous sectors, in which individual producers are likely to deviate strongly from average trends.

In chapter 3, specific attention is paid to the heterogeneity in firm structure by assessing the drivers behind firm growth. Specifically in Dutch horticulture, primary producers have rapidly increased in scale in the last decade. The results show that cost reductions due to economies of scale are not the main driver behind the growth in horticultural firm size. However, larger firms do obtain on average higher and more stable output prices obtained. This positive effect of firm size on firm revenues therefore provides a different rationale for the recent growth in average size of Dutch horticultural firms.

In an attempt to assess the heterogeneity in market positioning between firms, chapter 4 investigated differences in output prices between firms. Research on agricultural production often implicitly assumes that producers are price-takers and hence obtain homogeneous prices. However, given recent developments in product differentiation and vertical integration, a growing dispersion in output prices is observed. The results in chapter 4 show that the same firms are able to obtain high output prices over time. Moreover, larger firms are structurally able to obtain higher output prices. This finding also holds after correcting for potential price differences due to differences in production costs.

Chapter 5 in contrast not focused on heterogeneity in outcomes, but rather on heterogeneous responses at firm-level. Given the high usage of natural gas in horticultural production, a recent policy proposal is to raise taxation on natural gas. We assess whether firms respond differently to these price incentives, by allowing for firm-specific responses. The findings in this chapter point out that assuming homogeneous responses (through applying classical fixed slope parameters) leads to an underestimation of variability. Furthermore, larger firms are found to use on average less gas per square meter in their production. 
In chapter 6 , the relation between the financial environment and the primary producer is studied. It specifically focuses on the heterogeneity in credit constraints for understanding investment behaviour at firm level. In light of recent developments on financial markets, these credit constraints become increasingly important and hence contradict with the idea of perfect capital markets with unlimited availability of capital. Consequently, liquidity indicators and the actual cashflow of a firm are expected to become more important for understanding investment behaviour. The panel Tobit model estimated in chapter 6 however shows no clear effect of the level of liquidity parameters such as cashflow on actual investments, yet it does provide evidence that over time these liquidity indicators become more important in determining the investments at firm-level. Moreover, the results show that firms with a high operating value are more likely to invest. This indicates a growing divergence between smaller and larger growing firms within these sectors.

Chapter 7 evaluated the impact of capital structures on firm performance. In order to achieve this objective, efficiency scores are obtained via a DEA-procedure. In the second stage of the analysis, these scores are regressed on indicators for the capital structure of a firm. The results suggest the importance of non-monotonicity and non-linearity in the relation between debt and performance. Highly indebted firms are often underperforming, whereas no or only modest effects are found for the original debt term. These findings are robust to various estimation methods in the second stage of the analysis and also hold in various subsamples of specialized producers. Beyond, the obtained DEA efficiency score shows high correlation with other measures of profitability and productivity, pointing at the consistency of our efficiency estimates for understanding firm performance.

Lastly, chapter 8 provides a synthesis of these results as well as a discussion of the usage of firm-level data in light of new advancements in the collection of data in agricultural production. Furthermore, policy implications are discussed and it provides a critical reflection on the work that was done in this thesis. The last section provides avenues for further research. It stresses the importance of future research to reduce the underestimation of variability in order to get better insight into the complex and firm-specific behaviour of primary producers in modern agricultural markets. 


\section{BIOGRAPHY}

Evert Jan Los was born on December 21, 1989 in Delft, the Netherlands. He obtained a bachelor degree in both Sociology and Economics and Policy at respectively Erasmus University and Wageningen University, before graduating from his master's degree in Agricultural Economics at Wageningen University in 2015. During his masters, he interned for the Dutch Agricultural and Horticultural Association (LTO Nederland) in Brussels, Belgium, where he was involved in projects focused on the European policy in fruits and vegetables.

In 2016, Evert started his Ph.D. studies at Wageningen University under supervision of Dr. Ir. C. Gardebroek and Prof. Dr. Ir. R.B.M. Huirne. His research interest focuses on econometric panel data models, with a particular interest in production and price analysis in the context of modern agricultural markets. Currently, he is employed as a lecturer in agricultural (business) economics and statistics at AERES University of Applied Sciences in Dronten, the Netherlands. 
"De geschiedenis verloochent de weduwen, terwijl zij het zijn die haar door de generaties heen op de schouders dragen."

-Wiesław Myśliwski, De laatste hand

\section{Acknowledgements}

Languages have the terrible characteristic of failing at essential moments. Writing some words on an empty page therefore feels like a shortcoming and omission in order to thank and express my gratitude towards the people who were crucial over the years of my dissertation, but let me give it a try anyway.

First and foremost, I would like to thank my supervisors, Koos Gardebroek and Ruud Huirne. Initially as thesis supervisor during my studies in Wageningen and the last few years as promotor during my PhD, Koos has been the driving force of my (academic) progress in Wageningen. Without exaggerating, I can safely say that my work has greatly benefitted from your knowledge, experience and scientific attitude. I admire the fast and comprehensive feedback I've always received at the countless draft versions of various chapters. Whenever I was stuck with analysing some form of regression, it was great to know that after a meeting I could always return with a new and broader sense of direction. Aside from the content-related feedback, I consider myself lucky with a supervisor who also set an example for me in a broader sense. In the first place as a professional with high (moral) standards in your role as scientist and lecturer. Moreover also as somebody who, despite the busy work and life-schedule of a modern-day scientist, has the ability to look after others and set the right priorities.

I would like to thank Ruud for his confidence in me to start this project, but more importantly also for his enthusiasm, guidance and ability to connect science and the outside world. This thesis has greatly benefitted from all those aspects. Without your efforts, and the opportunities which were created along the way, it would have been undoubtedly much more difficult to succeed in my work. Furthermore, I would like to send a special thanks to Marian Jonker for organizing the opportunity to start this PhD project, as well as to the rest of the administrative staff and Prof. Justus Wesseler for running the chair group of Agricultural Economics and Rural Policy.

The AEP-group has always felt like a warm home during my PhD. For that, I particularly need to thank my office-mates from day one, Hoyga and Thomas, for their hospitality, friendliness and combination of bad and good jokes. Talking about bad jokes, there is another colleague whom I'd like to thank: Dusan Drabik. Your warmbloodedness is well needed in our sometimes cold country. With your own way of doing you have formed a source of inspiration over the last few years. 
Although he is trying to hide it most of the times, I furthermore would like to thank one of the most friendly people of the whole Leeuwenborch-building: Jack Peerlings. Your genuine interest and collegiality at both personal and professional level over the years has been very much appreciated.

Moreover, I would like to thank all my other colleagues during this period, which means everyone from Min to Max and the whole range in between: despite the sometimes individual focus of our projects, most of us found the time and took the effort to become involved with each other's work and lives. I hope we will continue to do so in the future.

Beyond, I am highly indebted to former study friends in Wageningen, friends from the ice rink and my initial corridor mates for making Wageningen a nice and comfortable place for me to stay in the first place. You truly contributed to our university's slogan to help to improve the quality of life. A special word of thanks goes out to Jorn Haalboom for putting the time and effort into creating the cover of this thesis.

Aart en de rest van de familie, buren en andere naasten: ook jullie ben ik natuurlijk veel dank verschuldigd. Voor de oprechte interesse, maar vooral voor de broodnodige steun en hulp in donkere dagen. Het is fijn om elkaar te kunnen vinden en vast te houden wanneer nodig.

Pap en mam: als kleinzoon van een Groningse boer en een Hollandse tuinder stond het misschien wel in de sterren geschreven dat ik ooit in Wageningen zou gaan studeren. Misschien ook wel net zo goed niet. Welk pad ik ook koos, door jullie heb ik me altijd enorm gesteund en geliefd gevoeld. Om op een punt waarin het nemen van mijn kant misschien steeds meer zou kunnen veranderen in geven, voelt het dan ook wrang en leeg om jullie te moeten missen. In het licht van dat alles heb ik me regelmatig afgevraagd wat dit proefschrift nu betekent. Een antwoord daarop moet ik wellicht eeuwig schuldig blijven, maar toch zou ik het graag aan jullie willen opdragen. Aan de herinneringen, warmte en liefde die ik nog altijd voel.

Lieve Janneke, van begin tot einde van dit traject was je mijn steun en toeverlaat. Je vermogen om soms ook maar stug door te gaan hield ook mij vaak op de been. Ik prijs me gelukkig dat ik op ingewikkelde momenten altijd hoop kan vinden in jouw handen en ogen.

Evert Los, Wageningen - January 2021 


\section{Evert Jan Los}

Wageningen School of Social Science (WASS)

Completed Training and Supervision Plan

\section{A) Project Related competences}

Agricultural Economics and Policy

Agent Based Modelling for Complex Adaptive

Systems

Advanced Microeconomics

Risk Analysis and Risk Management in

Agriculture

\section{B) General Research ReLATEd COMPETENCES}

Writing research proposal

WASS Introductory Course

Introduction to $\mathrm{R}$ for statistical analysis

Reviewing scientific papers (European Review

of Agricultural Economics, Review of

Agricultural and Applied Economics)

'Heterogeneity in output prices: Evidence

from the Dutch horticultural sector'

'Explaining output price heterogeneity in

Dutch horticulture'

'Credit constraints and investments in Dutch

horticulture'

'Assessing the impact of alternative energy policies on the energy usage and income of horticultural firms: an application in the

Dutch climate agreement'

'Firm-specific responses to energy policies in

Dutch horticulture'

\section{C) Career related competences}

Start to Teach - Orientation on teaching

Teaching Assistant: Advanced Econometrics

Teaching Assistant: Introduction to

Econometrics

Teaching Assistant: Microeconomics and

Behaviour

Teaching Assistant: Economics of

Agribusiness

$\begin{array}{lll}\text { WASS } & 2016 & 2 \\ \text { WUR } & 2016 & 6 \\ & & \\ \text { WUR } & 2017 & 6 \\ \text { WASS } & 2017 & 2\end{array}$

WASS

$2016 \quad 6$

WASS

$2016 \quad 1$

PE\&RC

$2018 \quad 0.6$

$\mathrm{n} / \mathrm{a}$

2018

2

EAAE XV Congress,

$2017 \quad 1$

Parma - Italy

WASS PhD day

$2017 \quad 0.5$

AAEA annual meeting,

20181

Washington, DC - USA

171th EAAE Seminar,

20191

Tanikon - Switzerland

Seminar section

$2019 \quad 0.5$

Economics WUR

WGS

$2018 \quad 1$

WUR

$2016 \quad 1$

WUR

$2016 \quad 1$

WUR

20161

WUR

20191 


\section{Colophon}

The research described in this dissertation was financially supported by the former Institute of Risk Management in Agriculture.

Financial support from the Agricultural Economics and Rural Policy Group for printing this dissertation is gratefully acknowledged.

Printed by: Proefschriftmaken.nl || www.proefschriftmaken.nl 



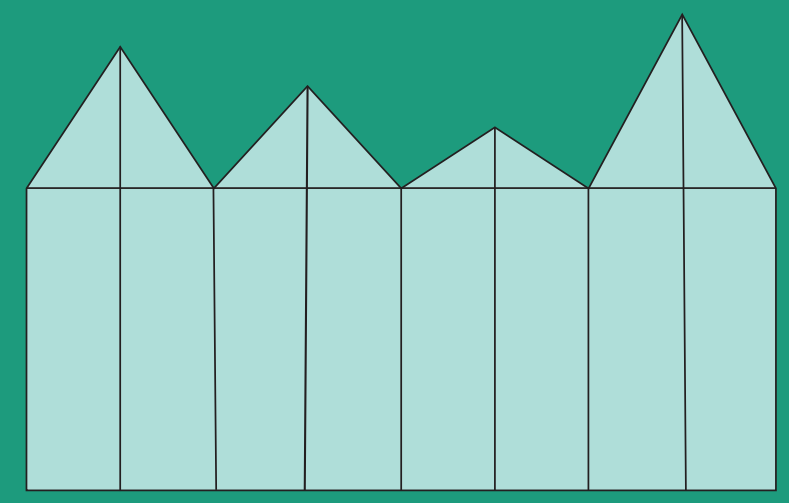

